\title{
ADVANCED CONTROL OF A ROTARY DRYER
}

\section{LEENA YLINIEMI}

Department of Process Engineering

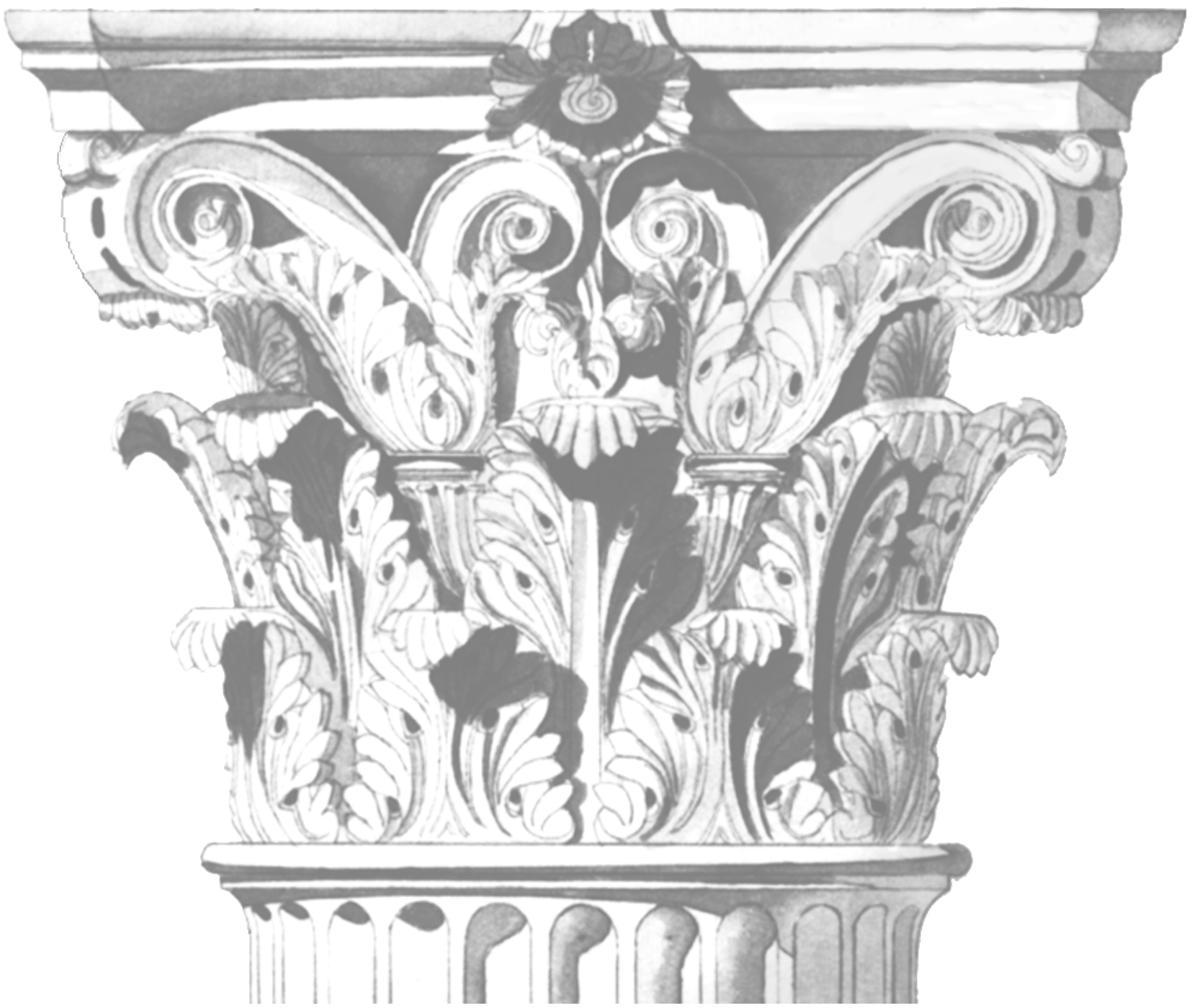



ADVANCED CONTROL OF A ROTARY DRYER

Academic Dissertation to be presented with the assent of the Faculty of Technology, University of Oulu, for public discussion in Raahensali (Auditorium L 10), Linnanmaa, on June 29th, 1999, at 12 noon. 
Copyright (c) 1999

Oulu University Library, 1999

Manuscript received 31.5.1999

Accepted I.6.1999

Communicated by

Associate Professor António Dourado Correia

Professor Sirkka-Liisa Jämsä-Jounela

ISBN 95I-42-528I-0

(URL: http://herkules.oulu.fi/isbn95 | 42528/0/)

ALSO AVAILABLE IN PRINTED FORMAT

ISBN 95|-42-5280-2

ISSN 0355-32I3 (URL: http://herkules.oulu.fi/issn035532 I3/)

OULU UNIVERSITY LIBRARY

OULU 1999 
Dedicated to

Ilkka, Mari and Anna 
Real knowledge is based on experience.

(Chinese saying) 
Yliniemi, Leena, Advanced control of a rotary dryer

Department of Process Engineering, University of Oulu, FIN-90570 Oulu

1999

Oulu, Finland

(Manuscript received 31 May, 1999)

\begin{abstract}
Drying, especially rotary drying, is without doubt one of the oldest and most common unit operations in the process industries. Rotary dryers are workhorses which are easy and reliable to operate, but neither energy-efficient nor environmentally friendly. In order to conform better to the requirements of modern society concerning working conditions, safety practices and environmental aspects, the development of control systems can provide opportunities for improving dryer operation and efficiency.

Our in depth understanding of rotary drying is poor, because it is a very complex process that includes the movement of solids in addition to thermal drying. Thus even today rotary dryers are controlled partly manually, based on the operator's "eye" and experience, and partly relying on conventional control methods. The control of a rotary dryer is difficult due to the long time delay, which means that accidental variations in the input variables can disturb the process for long periods of time before they are reflected in the output variables. To eliminate such disturbances at an early stage, increasing interest has been shown in more sophisticated control systems such as model-based constructs, fuzzy logic and neural nets in recent years. Although it has proved difficult and time-consuming to develop model-based control systems, due to the complexity of the process, intelligent control methods based on fuzzy logic and neural nets offer attractive solutions for improving dryer control. These methods make it possible to utilise experience, knowledge and historical data, large amounts of which are readily available.

The aim of this research was to improve dryer control by developing new hybrid control systems, one consisting of a fuzzy logic controller (FLC) and PI controller and the other of a three-layer neural network (NN) and PI controller. The FLC and NN act as supervisory controllers giving set points for the PI controllers. The performance of each was examined both with simulations and in pilot plant experiments. The pilot plant dryer at the University of Oulu closely resembles a real industrial situation, so that the results are relevant. Evaluation of these results showed that the intelligent hybrid controllers are well suited for the control of a rotary dryer, giving a performance in which disturbances can be eliminated rapidly and operation of the dryer can thereby be improved, with the aim of enhancing its efficiency and environmental friendliness.
\end{abstract}

Keywords: $\quad$ rotary drying, fuzzy logic, neural networks, hybrid control 



\section{Acknowledgements}

This thesis is based on work carried out in the Control Engineering Laboratory, Department of Process Engineering, University of Oulu. Research into the modelling and control of a rotary dryer was started in the early 1980's as a three-year industrial project supervised by Professor Paavo Uronen and financed by the Ministry of Trade and Industry and six Finnish mining and mineral companies: Karl Forsström, Kemira, Lohja, Outokumpu, Partek and Rautaruukki. I wish to thank Professor Paavo Uronen, now Rector of Helsinki University of Technology, for his support during the project. Also I wish to thank Asko Arola, Sauli Harju, Lasse Pesonen and Timo Puijola for the valuable work that they have carried out in the project. The ministry and companies are acknowledged for their financial support, which made it possible to construct the experimental research environment in the laboratory. Professor Kauko Leiviskä supervised the later stages of my work, and I particularly wish to express my gratitude to him for his guidance and support.

I would like to thank Professor Sirkka-Liisa Jämsä-Jounela of Helsinki University of Technology and Professor Antonio Dourado of the University of Coimbra, Portugal, for their thorough review of the thesis and for their useful recommendations.

I also wish to thank the staff of Department of Process Engineering and the staff of Control Engineering Laboratory, in particular Jukka Koskinen and Mika Mecklin, who assisted me in the experimental part of the work.

Financial support provided by the Foundation for the Advancement of Technology, the Tauno Tönning Foundation and Infotech Oulu is gratefully acknowledged.

Most of all, I wish to express my deepest gratitude to my husband Ilkka and to our daughters Mari and Anna for all the patience and kind understanding they have shown during the course of this work, especially in the final stages of producing this thesis. 



\section{Contents}

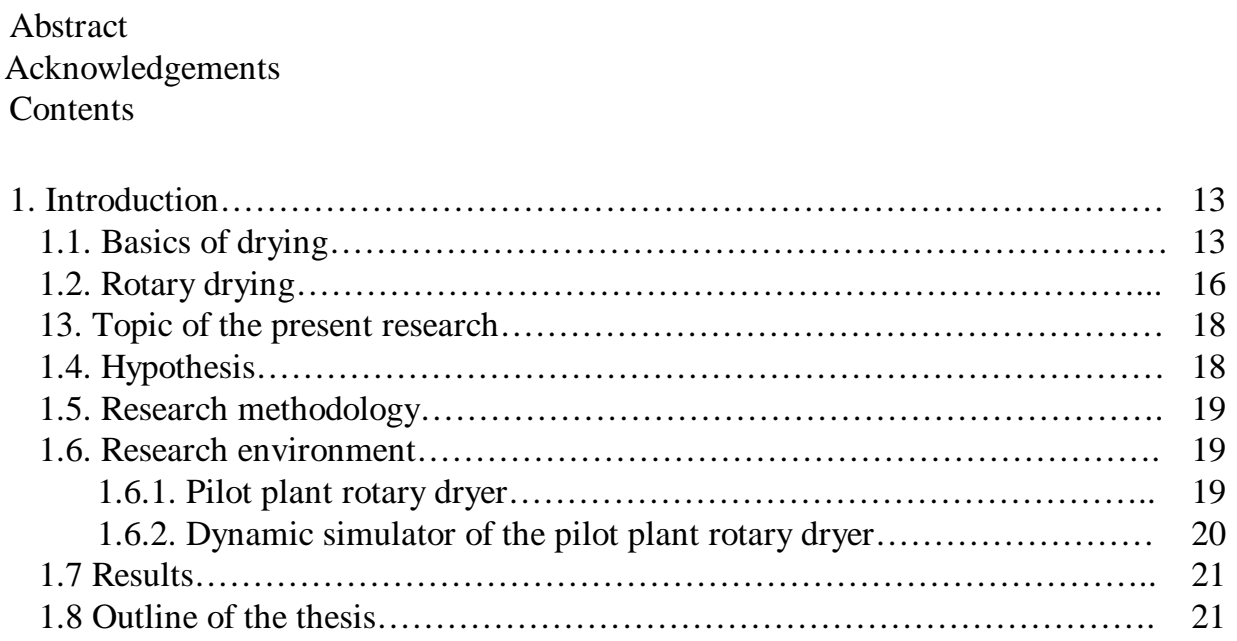

2. Mathematical modelling of a rotary dryer............................. 22

2.1. Models of residence time............................................ 23

2.2. Models for the heat transfer coefficient............................. 25

2.3. Overall models for a rotary dryer................................... 26

3. Development of a dynamic model for the pilot plant dryer................. 30

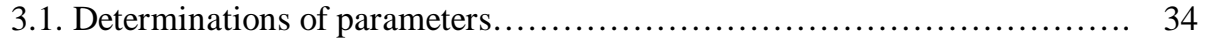

3.2. Simulations ..................................................... 41

3.2.1. Steady state simulator..................................... 41

3.2.2. Dynamic simulator......................................... 43

3.2.3. Model experiments....................................... 45

4. Control of a rotary dryer........................................... 50

4.1. Approaches to the control problem adopted in the literature.............. 51

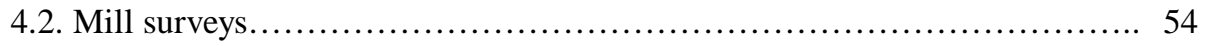

5. Conventional control of the pilot plant rotary dryer....................... 56

5.1. Feedback control.............................................. 56

5.2. Combined feedforward-feedback control........................... 58

6. Development of a fuzzy logic controller (FLC) for the pilot plant dryer......... 64

6.1. Design and implementation of a fuzzy logic controller................... 65

6.1.1. Tuning of the fuzzy logic controller.......................... 69 


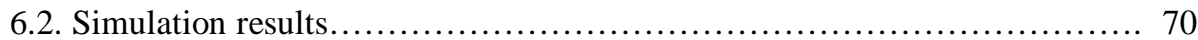

6.3. Experimental results............................................. 74

7. Development of a neural network controller for the pilot plant dryer........... 84

7.1. Design and implementation of a neural network controller................ 85

7.1.1. Structure of the neural network controller for simulation studies....... 85

7.1.2. Structure of the neural network controller for experimental studies.... 89

8. Discussions and conclusions............................................. 92

References............................................................. 96

Appendices 1...5. 


\section{Introduction}

\subsection{Basics of drying}

Drying is an operation of great commercial importance in all industrial applications ranging through the food, agricultural, mining and manufacturing sectors. Modern society requires better product quality, improved safety practices and more environmentally benign operations, as well as higher productivity, better energy efficiency and reduced material wastage. As drying is certainly one of the most energy-intensive operations in industry, and as most dryers operate at low thermal efficiency, the development of models and control systems offers an opportunity to improve dryer operation and efficiency.

Drying is a process in which an unbound and/or bound volatile liquid is removed from a solid by evaporation. Solids can be classified as (van Brakel 1980)

- nonhygroscopic capillary-porous material, such as sand, crushed minerals, nonhygroscopic crystals, polymer particles, and some ceramics

- $\quad$ hygroscopic-porous material, such as clay, molecular sieves, wood and textiles

- colloidal (nonporous material), such as soap, glue, nylons and various food products, the main features of which are that all liquid is physically bound and there is no pore space, i.e. evaporation can take place only at the surface.

It is the first of these categories that is considered here, i.e. solids is defined as nonhygroscopic capillary-porous material having the following features:

- There is a clearly recognisable pore space, which is filled with liquid if the solid is completely saturated and with air when the solid is completely dry.

- The amount of physically bound moisture is negligible; that is, the solid is nonhygroscopic. 
- $\quad$ The solid does not shrink during drying.

When a solid dries, two simultaneous fundamental processes occur:

- Heat is transferred to the solid from the surrounding medium, most commonly air.

- Moisture is transferred as a liquid or a vapour within the solid and as a vapour from its surface.

The conventional heat transfer methods are convection, conduction, infra-red radiation and dielectric heating, a modern drying technique in which internal heat is generated by radio or microwave frequencies. In most dryers heat is transferred by more than one method, but each industrial dryer has one predominant heat transfer method. In rotary dryers this is convection, the necessary heat usually being provided by direct contact of a hot gas with the wet solid.

Although moisture removal by evaporation from the surface of a solid into the surrounding medium is essential for the drying process, a knowledge of the drying phenomena that take place inside the solid (moisture migration) assists the understanding and design of the process. It also supports the determination of equipment parameters and optimum conditions in the dryer. Much work has been performed over several decades aimed at the theoretical modelling of drying phenomena, and many drying mechanisms (theories) have been developed for various materials and various sets of drying conditions. The basis for such drying mechanisms is that moisture inside solids can be transferred in either a liquid or a gaseous phase. In general, the moisture in porous solids can be transported according to diffusion theory, capillary theory and evaporation condensation theory, the drying mechanism being dependent on the structure of the solid, the type of moisture bonding, the moisture content and the temperature and pressure in the pores of the solid.

Diffusion theory assumes that the moisture moves through the solid in liquid form as a result of the moisture concentration difference inside the solid, while capillary theory assumes that only liquid is present in the capillaries of the solid and that the flow of this liquid moisture through the interstices and over the surface is caused by liquid-solid molecular attraction. Evaporation condensation theory assumes that the flow of moisture within a solid takes place entirely in gaseous phases. Many comprehensive surveys of drying theories exist in the literature, as reviewed by Yliniemi et al. (1981).

Even though a number of theories have been proposed for describing drying phenomena inside various solids and for various drying conditions, their applicability to real problems is poor due to the complexity of the phenomena and the lack of experimental investigations which could prove their relevance to industrial dryers. A big gap therefore still exists between theory and practice.

Due to the complexity of theoretical models of drying phenomena, the design of industrial dryers is more commonly based on the examination of external drying conditions. Drying phenomena are described by curves which present the moisture in the solids or the rate of drying as a function of time. A typical drying curve and drying rate curve for convective drying are shown in Figures 1 and 2. 


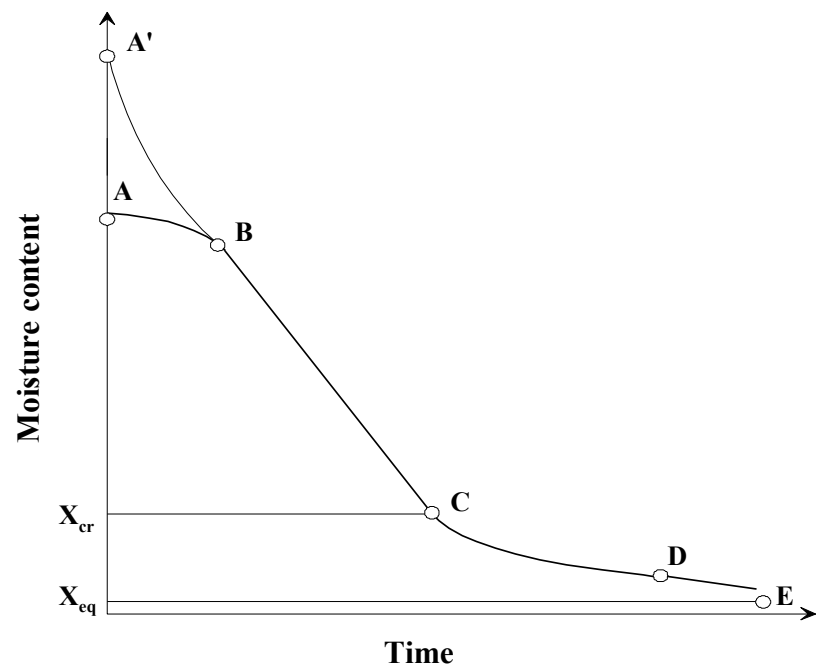

Fig. 1. A typical drying curve for convective drying (Strumillo \& Kudra 1986).

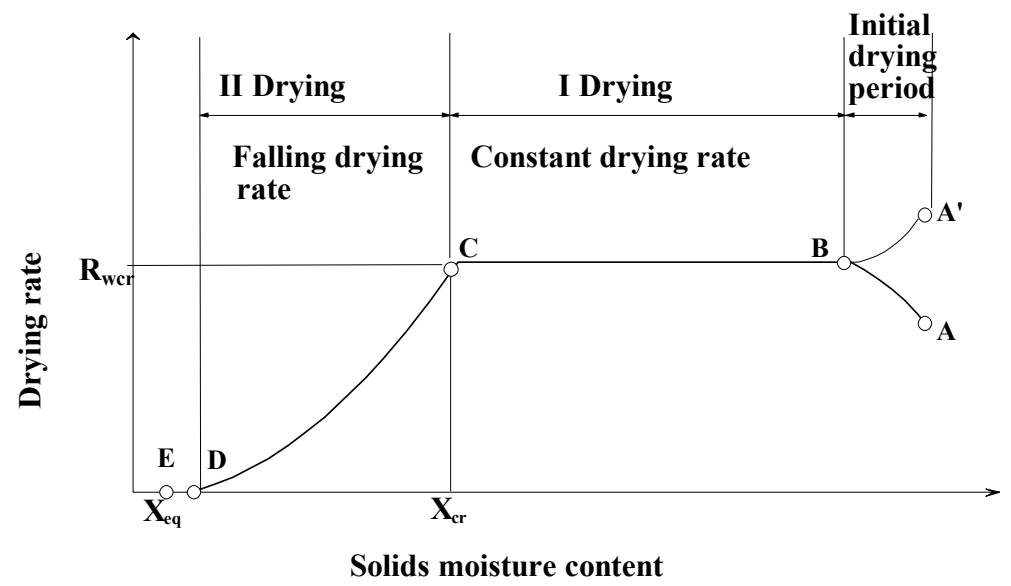

Fig. 2. A typical drying rate curve for convective drying (Strumillo \& Kudra 1986).

According to Figures 1 and 2 a drying profile can be divided into three parts: preheating (initial drying period), a constant rate period and a falling rate period or periods, depending on the characteristics of the solids. Curve A-B illustrates the change in moisture in the solid with time during the initial drying period. During this period the temperatures of the solid and its liquid-covered surface are lower than the equilibrium temperature, and as a result the drying rate in the range $\mathrm{A}-\mathrm{B}$ will increase until the surface temperature reaches the temperature corresponding to the line B - C. If the temperature of the wet solid is higher than the equilibrium temperature, the initial drying period will follow the line A'- B. The initial period is usually very short, and in practise it is neglected. The drying rate in the period $\mathrm{B}-\mathrm{C}$ is constant and equal to the slope of the 
line $\mathrm{B}-\mathrm{C}$. The moisture content at the transition stage between the constant rate and falling rate periods is called the critical moisture content $\mathrm{X}_{\mathrm{cr}}$. At this critical point a linear drop in moisture content takes place and the straight line becomes a curve which asymptotically approaches the equilibrium moisture content of the solid $\mathrm{X}_{\mathrm{eq}}$.

As mentioned earlier, the drying process is influenced both by external conditions, such as the temperature, velocity and humidity of drying air, and by the internal drying mechanism inside the solid. In the constant rate period the external conditions control the rate of drying, but in the falling rate period the internal moisture transport mechanism is dominant. The shape of a drying profile depends on the material to be dried. The course of drying is often determined experimentally using batch dryers or oven dryers, in which case drying conditions should be as close to the real conditions as possible.

Drying is without doubt one of the oldest and most common unit operations in the process industries. It is a very complex and poorly understood process despite the research that has been carried out over many decades. The field is vast, as more than two hundred variants of industrial dryers can be found depending on the materials to be dried and the drying conditions. This means that extensive experimental observations and operating experience exist. Drying research is limited in this thesis to direct air-heated convective rotary dryers for use with nonhygroscopic capillary-porous material.

\subsection{Rotary drying}

Large quantities of granular material with particles of $10 \mathrm{~mm}$ or larger that are not too fragile or heat sensitive or cause any other solids handling problems are dried in rotary dryers in the process industries. The rotary dryer is one of the most common types of industrial dryer. It is a cylindrical shell usually constructed from steel plates, slightly inclined, typically $0.3-5 \mathrm{~m}$ in diameter, 5-90 $\mathrm{m}$ in length and rotating at 1-5. It is usually operated with a negative internal pressure to prevent dust escape. Solids introduced at the upper end move towards the lower or discharge end. Depending on the arrangement for the contact between the drying gas and the solids, a dryer may be classified as direct or indirect, con-current or counter-current. An array of lifting flights of various shapes is constructed inside the shell to shower the solids in order to ensure contact with the gas. These flight configurations vary from spirals to straight flights. The effect of the flight design i.e. the number of flights, their dimensions and their shape, on the performance of the dryer is very complicated.

A rotary dryer has two distinct functions: as a conveyor and as a heating device. The movement of solids through the dryer is influenced by the following mechanisms: lifting, cascade action, sliding and bouncing, as depicted in Figure 3. 


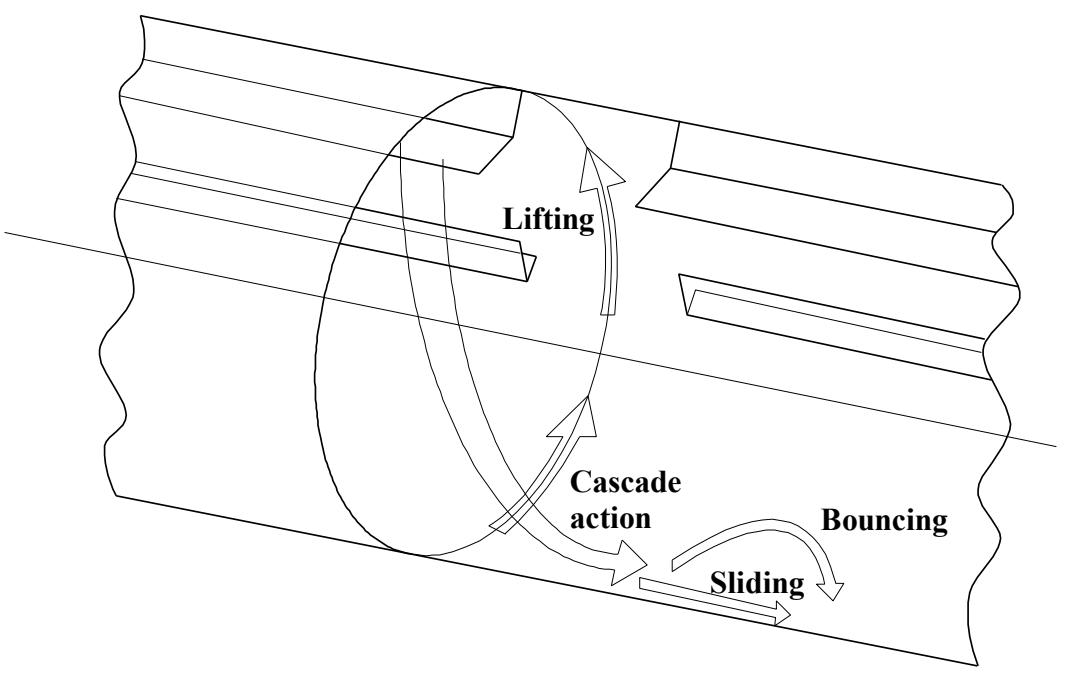

Fig. 3. A cascading rotary dryer (Baker 1983).

As the dryer rotates, solids are picked up by the flights, lifted for a certain distance around the drum and showered through the air in a cascading curtain. Most of the drying occurs at this time, as the solids are in close contact with the gas. Flight action is also partly responsible for the transport of solids through the drum.

The factors affecting the modelling of a rotary dryer can be classified as follows (Kelly 1995):

- $\quad$ physical properties of the solids, such as particle size and shape, density and moisture content,

- dryer variables, such as the diameter and length of the drum and the design and number of lifting flights and

- operating conditions, such as the feed flow and temperature, the flow and temperature of the drying air and the slope and rotation speed of the drum.

All the above factors affect the heat transfer in the drum, and all except the temperatures of the solids and drying air have an effect on the loading (hold up) and time of passage of the drum. The hold up of solids has a great effect on the operation of the dryer, as an excessively low hold up will reduce the production rate but too great a hold up will make material roll on the bottom of the dryer so that the desired moisture content will not be achieved and the power required to turn the dryer will be increased. A hold up of 3-15\% of the total drum volume, with values in the range 8-12\% most common, gives satisfactory operation (Keey 1995). The thermal efficiency of a rotary dryer depends on the manner of drying and varies over a wide range from $25 \%$ in an indirect-fired system to $85 \%$ in a steam tube (McKetta \& Cunningham 1983). 


\subsection{Topic of the present research}

Although rotary dryers have been used for many decades in numerous industrial sectors, research into their modelling and control has been limited and can be said to be still in its infancy. This is largely for the following reasons:

1 Current situation. Rotary drying is without doubt one of the oldest and most common operations in the process industries. Rotary dryers are workhorses, the operation of which is easy and reliable, but neither energy-efficient nor environmentally friendly. Most rotary dryers, especially older ones, are still controlled partly manually, relying on the "eye" and experience of the operator.

2 Complex process. Our deeper understanding of rotary drying is poor, because it is a very complex process that includes the movement of solids in addition to their thermal drying. As the process is highly non-linear and is dependent on time and position, mathematical modelling is very difficult and time-consuming. In general, models are rough approximations of real processes, and therefore often of questionable usefulness. This means that the development of modelbased control systems, although these are preferable to conventional ones because of the slow dynamic nature of rotary dryers, has not been very popular among designers of rotary dryers.

3 Lack of emphasis. The value of the good operation of rotary dryers for product quality and drying efficiency was not often recognised in the past.

4 Lack of control research into rotary dryers: Little interest has been shown up to now in developing measurement and control functions for rotary dryers. Now that intelligent control methods based on experience have achieved their breakthrough, research into the control of rotary dryers has been revived, especially with respect to increasing the interest shown in changing existing rotary dryers for "smart" dryers in an effort to improve dryer operation.

\subsection{Hypothesis}

The hypothesis to be investigated here may be stated as:

The design, maintenance, and operation of a complex process such as rotary drying are demanding tasks that could be assisted by making use of extensive experimental observations and operating experience in order to move towards "smart " dryers, the control of which is based on intelligent methods such as expert systems, fuzzy logic and neural nets. It is proposed in this thesis that intelligent control combined with conventional PID control can improve the operation of rotary dryers by increasing energy efficiency and product quality. Improved control performance means that it is possible to respond better to the requirements of modern society concerning working conditions, safety practices and environmental aspects. 


\subsection{Research methodology}

The research strategy includes the following phases:

1 Problem Analysis: The performance of a rotary dryer based on conventional feedback control and semi-empirical model-based feedforward-feedback control is analysed by means of experiments carried out with the pilot plant dryer located at the University of Oulu, with the aim of estimating the amount of design work involved and the quality of the control achieved.

2 Construction: Based on the results of the problem analysis and a review of the literature on the modelling and control of rotary dryers, two intelligent hybrid control systems are developed. These are based on the author's experience with the operation of the pilot plant rotary dryer over several years and on data collected from the dryer.

3 Demonstration: The applicability of intelligent hybrid control systems is tested with simulations and pilot plant experiments. The control results are compared with results achieved using conventional control systems.

\subsection{Research environment}

\subsubsection{Pilot plant rotary dryer}

For the experimental work reported in this thesis, a direct air-heated, con-current pilot plant rotary dryer was designed and constructed at the University of Oulu. A schematic drawing of the pilot plant dryer with its auxiliary equipment and instrumentation is presented in Appendix 1, see also the report by Yliniemi \& Koskinen (1995). The screw conveyor feeds the solid, calcite (more than $98 \% \mathrm{CaCO}_{3}$ ), from the silo into a drum of length $3 \mathrm{~m}$ and diameter $0.5 \mathrm{~m}$. The drum is slightly inclined horizontally and insulated to eliminate heat losses, and contains 20 spiral flights for solids transport. Two belt conveyors transfer the dried solid back into the silo for wetting. Propane gas is used as the fuel. The fan takes the flue gases to the cyclone, where dust is recovered. The dryer can operate in a con current or counter current manner. The experiments were carried out in a con-current manner, because this is usually more economical and therefore very often used for drying granular material in industry unless the solids are heat sensitive (McKetta \& Cunningham 1983).

The dryer is connected to a Damatic $\mathrm{XD}^{\circledR}$ instrumentation system for modelling and control research. In addition to measurements of temperature and flow of the solids and drying air, the input and output moisture of the solids is measured continuously. As online moisture measurement of the solids is very important for the control of a dryer, a special investigation into moisture measurement methods and analysers was carried out. Moisture measurement experiments using two solids, calcite and magnetite, were 
performed by means of two infrared analysers, a microwave analyser and a radioactive analyser. Indirect measurement of the moisture content of the solids was examined using a Humicap ${ }^{\circledR}$ analyser, which measures the humidity of the drying air above the solids, which correlates with the moisture contained in them. The results show that each of these analysers is valid for the measurement of moisture in the solids under particular sets of conditions, but there is no method or analyser which applies to all solids in all measurement situations. The results are reported in detail by Yliniemi et al. (1984). The situation is still same even though new equipment has come onto the market, e.g. infrared analysers with two or three reference wavelengths. The measurement and control equipment used in the pilot plant dryer is described in Appendix 2.

\subsubsection{Dynamic simulator of the pilot plant rotary dryer}

For this work a dynamic simulator was developed in order to understand better the behaviour of a rotary dryer and to examine how various input variables and model parameters influence the output variables of a dryer. The simulator is based on a semiempirical model of the pilot plant dryer consisting of heat and mass transfer equations and the experimental drying rate equation. The residence time of the solids was determined experimentally, and the volumetric heat transfer coefficient was calculated using the correlations obtained from the literature. The simulator runs in the Matlab ${ }^{\circledR}$ environment and the user interface has been implemented using Multimedia Toolbook ${ }^{\circledR}$ and Simulink ${ }^{\circledR}$. The contents and use of the dynamic simulator are described by Yliniemi \& Leiviskä (1995). The user interface is presented in Appendix 3.

\subsection{Results}

This work contributes to improving the performance of rotary dryers by developing new control systems in which experimental knowledge and historical data can be utilised. Rotary drying is a very complex non-linear process that includes other phenomena in addition to drying, notably the progress of the solids during drying. The most common control technique used in rotary dryers, feedback PI control, has proved inadequate due to the long delay time of the dryer. The development of a model-based feedforward controller combined with PI control, which gives better control performance, is cumbersome and time consuming due to the complexity of the rotary dryer model, and consequently control systems in which expert systems, fuzzy logic and neural nets are combined with conventional control techniques have become attractive. These add another dimension to the control of a rotary dryer, the human element.

Intelligent hybrid control systems based on fuzzy logic and neural networks are proposed here for the control of a rotary dryer in order to achieve better performance in terms of product quality and energy efficiency. The control results discussed in more detail in the following chapters have been verified with simulations and pilot plant experiments. 


\subsection{Outline of the thesis}

This first chapter has discussed the basics of drying phenomena, and in particular rotary drying, in order to provide an understanding of the course of drying in a rotary dryer. The topic of the research has been stated and some background to it is given. The research environment, the dynamic simulator and pilot plant dryer are described.

Chapter 2 focuses on the modelling of a rotary dryer. The review of the literature concerning the main design parameters, the residence time of solids and the volumetric heat transfer coefficient, are given, together with the overall modelling of a rotary dryer. A dynamic model for the pilot plant dryer based on heat and mass transfer is developed in Chapter 3. This model is used later to determine the main variables manipulated in a dryer and to study the behaviour of the control strategies developed in this work. The validity of the model is tested both by simulations and by experiments with the pilot plant.

Chapters 4 to 7 deal with the control of a rotary dryer. A review of different control approaches is made in Chapter 4, while Chapter 5 describes the behaviour of conventional control systems such as feedback PI control and model-based feedforwardfeedback control. Chapters 6 and 7 present various intelligent hybrid control systems based on fuzzy logic and neural nets and describe the testing of their control performance with simulations and pilot plant experiments. The suitability of the various control systems is estimated. Conclusions are drawn in Chapter 8 . The basics of fuzzy logic and backpropagation neural networks are presented in Appendices 4 and 5. 


\section{Mathematical modelling of a rotary dryer}

In general, the operation of a process can be described with a model, which can be intuitive, verbal, causal, qualitative or quantitative. A mathematical model, which is an example of a quantitative model, consists of algebraic, differential or integral equations. The main advantage of a mathematical model is that it can predict the behaviour of a process without experimentation. Mathematical models of chemical processes such as rotary drying are based on the fundamental laws of physics and chemistry, including continuity equations such as mass, energy and momentum balances, transport phenomena such as mass, energy and momentum transport, equilibrium descriptions such as phase and chemical equilibrium, kinetic descriptions and state equations. Depending on the purpose, the model can be a coarse model of the overall process or a very detailed model of parts of the process. The assumptions used in the development of a model determine its accuracy, validity and complexity.

Although much research has been done into the modelling of drying phenomena, relatively little of this activity has been directly concerned with rotary dryers. This may be due to the fact that rotary drying is a very complex process, including not only drying phenomena but also the progress of the solids during drying. Instead of the overall modelling of a rotary dryer, most investigations have concentrated on developing a residence time equation and establishing a volumetric heat transfer coefficient. These make it possible to determine the passage time of the solids and the overall heat load and their relation to the dimensions and operating conditions of the dryer. These relations are mostly empirical by nature. As both residence time and the heat transfer coefficient are very important factors in designing and modelling dryers, they are discussed in more detail in this thesis.

The overall model of a rotary dryer is composed of two subsidiary models, one describing the detailed behaviour of the solids and the other describing the drum. The first includes characteristics of the solids such as drying kinetics, and the second, the equipment model, predicts the residence time and heat transfer. By combining these two models a set of mathematical equations is obtained, the solution of which simulates the drying of solids in a rotary dryer. 


\subsection{Models of residence time}

Studies of the residence time distribution of solids in a rotary dryer (Miskell \& Marshall 1956, Hirosue \& Shinohara 1982, Hallström 1985) have indicated that the movement of solids can be treated as a plug flow with a small amount of axial dispersion. Modern dryers can be handled as ideal mixing reactors with a degree of backmixing. Hence it is reasonable to use the mean residence time alone to quantify the speed of particle movement. It is true that investigations have been concentrated more recently on the residence time distribution in order to identify the factors that cause some particles to move faster or slower through the drum than others.

The mean residence time of the solids is defined as to the ratio between the hold up of solids in a drum and the feed rate, according to the equation (Kelly 1995):

$$
\overline{\mathrm{t}}=\frac{\mathrm{H}}{\mathrm{F}}
$$

where $\bar{t}$ is the mean residence time of the solids (s), $\mathrm{H}$ is the hold up of the solids in the drum $(\mathrm{kg})$ and $\mathrm{F}$ is the axial flow rate of solids in the drum $(\mathrm{kg} / \mathrm{s})$. The hold up determines the quantity of particles in the drum under steady state conditions.

Residence time is dependent on the particle flow path in an air-particle stream and on the arrangement and shape of the lifting flights, and is also influenced by the air flow, particle feed and characteristics and physical parameters of the drum. The complexity of the movement of particles through a rotary dryer makes it very difficult to derive a residence time model which is valid for a large number of situations. Most studies have been made on small-scale dryers for specific materials and under specific operating conditions.

Prutton et al. (1942) published the first extensive study, showing that the data for a design-loaded drum could be correlated by means of the empirical equation

$$
\overline{\mathrm{t}}=\frac{\mathrm{kL}}{\text { D ntan } \mathrm{a}} \pm \frac{\mathrm{m} \mathrm{vg}}{60},
$$

where $\mathrm{L}$ is the length of the drum (m), D is the drum diameter $(\mathrm{m}), \mathrm{n}$ is the rotational speed of the drum ( $\mathrm{r} / \mathrm{min}), \alpha$ is the angle of inclination of the drum to the horizontal, $\mathrm{v}_{\mathrm{g}}$ is the gas velocity $(\mathrm{m} / \mathrm{s}), \mathrm{k}$ is a dimensionless constant depending on the number and design of the lifting flights and $\mathrm{m}$ is an empirical constant depending on the characteristics of the solids that must be determined experimentally for each material.

Based on the extensive study by Friedman \& Marshall (1949a) in which hold ups were measured for a large variety of solids in a rotary dryer, such as sand, wood chips, plastic, granules and flakes, and for different operating conditions, Perry \& Chilton (1973) published the equation

$$
\overline{\mathrm{t}}=\frac{0.23 \mathrm{~L}}{\mathrm{Dn}^{0.9} \tan \mathrm{a}} .
$$

This approximates to the data obtained with six to eight flights. The correlation developed by van Krevelen \& Hoftijzer (1949a) was of the same form as those presented in the equations (2) and (3). 
Later, Saeman \& Mitchell (1954) made more theoretical investigations which also took the effects of drum loading and flight profile on residence time into account. The residence time equation is of the form

$$
\overline{\mathrm{t}}=\frac{\mathrm{L}}{\mathrm{f}(\mathrm{H}) \operatorname{Dn}(\operatorname{tana} \pm \mathrm{mvg})},
$$

where $\mathrm{f}(\mathrm{H})$ is the cascade factor, the value of which is between 2 for lightly loaded dryers and $\pi$ for heavily loaded dryers having small flights. It was assumed in the derivation of this equation that the horizontal drift of a cascading particle is linearly dependent on the gas velocity and the length of the fall.

The basis of the residence time study by Schofield \& Glikin (1962) was that the principal mechanism of particle movement through the drum is a cascade motion. They made a theoretical analysis of this cascade motion and obtained a model which establishes a theoretically more accurate basis for the calculation of residence time. The general equation is then

$$
\overline{\mathrm{t}}=\frac{\mathrm{L}}{(\text { cascade length })_{\mathrm{av}}} *(\text { cascade time }) \mathrm{av},
$$

where (cascade length) $)_{\mathrm{av}}$ is the distance along the drum over which the average particle progresses by cascade and (cascade time) av $_{\text {iv }}$ is the time taken by the average particle for each cascade. Kelly \& O'Donnell (1968) applied the equation to a fully loaded drum.

Baker (1983) made a comprehensive survey of the above studies by comparing different residence time equations in a hypothetical con-current dryer with an outside diameter of $2 \mathrm{~m}$, length $12 \mathrm{~m}$, rotational speed $5 \mathrm{r} / \mathrm{min}$ and slope $1^{0}$. The air flow was typical of rotary dryers, being $3 \mathrm{~m} / \mathrm{s}$. The calculations showed that the range of residence time predictions presented in Table 1 is so wide as to be almost meaningless.

Table 1. Summary of residence time predictions (Baker 1983).

\begin{tabular}{ll}
\hline Author (s) & $\begin{array}{c}\text { Residence time } \\
(\mathrm{min})\end{array}$ \\
\hline Prutton et al. (1942) & $0-16.9$ \\
Friedman \& Marshall (1949a) & 0.8 \\
Saeman \& Mitchell (1954) & $5.8-9.2$ \\
Schofield \& Glikin (1962) & 4.5 \\
Kelly \& Donnell (1968) & 4.5 \\
\hline
\end{tabular}

Kamke \& Wilson (1986a) developed a computer model for predicting the mean residence time at any point along a drum with centrefill flights during the falling solid phase. The model was simulated by examining the effect of air velocity, drum speed and drum diameter on residence time.

Sherritt et al. (1993) developed a residence time model that considers the flow of particles through a drum consisting of two streams: the airborne phase produced by the 
internal flights which lift the solids and control their cascade through the air stream, and the dense phase at the bottom of the drum. The hold up and axial flow rate of particles in the two phases are determined separately. The model is more flexible than the previous ones, because the drum may be inclined or horizontal, with con-current or counter-current flow, may have lifting flights of any type and may be underloaded or overloaded.

The two residence time models presented by Duchesne et al. (1996) are based on the model of a series of interacting perfect tanks with dead volumes and on the modified Cholette-Cloutier model. The first model has two parameters: the number of perfect tanks and the conductance, characterising the flow of solids from one tank to the next. The modified Cholette-Cloutier model takes account of dead zones. The residence time model was calibrated on an industrial dryer, taking into account the effect of lifters and air drag.

Even though many studies were carried out to develop a mean residence time model or residence time distribution, the residence time is still determined experimentally in many cases. In pilot plant drums the material feed is stopped suddenly, the drum is unloaded and the material is weighed. Knowing the feed rate, the mean residence time can be calculated from equation (1). Tracer techniques are used in larger industrial drums. Kelly \& Donnell (1977) reported on the use of radioactive tracer techniques. They studied the behaviour of a radioactive particle, an ordinary particle of pumice dyed and soaked in aqueous radioactive cobalt 60 . The aim was to confirm the accuracy of theoretical models for the mean cycle time of a cascading particle in a rotary drum.

\subsection{Models for the heat transfer coefficient}

The other essential for the design and operation of a rotary dryer is to obtain a reliable prediction of the overall volumetric heat transfer coefficient, $U_{v}\left(W / m^{3} K\right)$, which is defined as the rate at which heat is transferred in a unit volume of the drum under a unit temperature difference driving force. The rate of heat transfer between the air and the solids is defined by the equation:

$$
\mathrm{Q}=\mathrm{U}_{\mathrm{v}} \mathrm{V}_{\mathrm{v}} \Delta \mathrm{T}_{\mathrm{lm}},
$$

where $\mathrm{Q}$ is the rate of heat transfer between the air and the solids $(\mathrm{W}), \mathrm{V}_{\mathrm{v}}$ is the drum volume $\left(\mathrm{m}^{3}\right)$ and $\Delta \mathrm{T}_{\mathrm{lm}}$ is the logarithmic mean temperature difference between the air and the solids at the inlet and outlet of the drum (K). The volumetric heat transfer coefficient contains a heat transfer coefficient based on the effective area of contact between the gas and the solids and the ratio of this area to the drum volume. This eliminates the need to specify where most of the heat transfer occurs, e.g. into the material in the air, on the flights, or in the rolling bed.

A lot of experimental research has been carried to develop correlations for the volumetric heat transfer coefficient, e.g. the work of Friedman \& Marshall (1949b), McCormick (1962), Schofield \& Glikin (1962) and Myklestad (1963a). The correlations based on these works are still in use.

According to McCormick (1962), most of the relationships can be reduced to the equation 


$$
\mathrm{Uv}=\frac{\mathrm{k}}{\mathrm{D}} \mathrm{G}^{\mathrm{n}},
$$

where $\mathrm{G}$ is the air mass velocity $\left(\mathrm{kg} / \mathrm{hr} \mathrm{m}^{2}\right), \mathrm{D}$ is the inside diameter of the drum $(\mathrm{m})$ and $\mathrm{k}$ and $\mathrm{n}$ are empirical constants. The value of $\mathrm{n}$ depends on the properties of the solids, the flight geometry, the rotational speed and the dryer hold up. Determination of the value was based on experiments with small-scale dryers, and it lies between $0.46-0.67$, a value of 0.67 being most reliable. The correlation gives satisfactory results for steady state considerations, but it does not reflect the dynamic behaviour of the heat transfer rate in a rotary dryer when the rotational speed of the dryer or the hold up changes.

Perry (1963) has recommended the following common correlation based on data from Friedmann \& Marshall (1949b):

$$
\mathrm{Uv}=\frac{44}{\mathrm{D}} \mathrm{G}^{0.16},
$$

However, Kuramae \& Tanaka (1977) maintain, however, that the inverse relation between the heat transfer coefficient and the dryer diameter in the equation (8) is not entirely correct. Myklestad (1963a) proposed the correlation

$$
\mathrm{Uv}=0.52 \mathrm{G}^{\mathrm{n}}
$$

for the counter-current drying of pumice, while Baker (1983) made an extensive review of heat transfer models in which he compared models based on experiments with a laboratory-scale dryer. Kamke \& Wilson (1986b) also provided a comprehensive report on the correlations used to relate volumetric heat transfer to operating conditions.

Even though many theoretical and experimental correlations between residence time and the heat transfer coefficient have been presented, no universally acceptable model which combines all the relevant design and operating parameters is yet available. It must therefore be concluded that the correlations presented to date can at best yield only an order-of-magnitude estimate. The determination of residence time and heat transfer coefficient is still based mainly on the experience of users over many years and on pilot plant experiments carried out with solids.

\subsection{Overall models for a rotary dryer}

The overall model comprising those for the solids and the drum is usually based on a set of differential equations for the transfer of mass and heat between the gaseous and solid phases, which are simplified in order to obtain practical, usually linear, differential expressions. Static models can be used to determine moisture and temperature profiles for the solids and drying air in an axial direction, but their reliability is difficult to prove, because the moisture contents and temperatures inside a drum are difficult to measure. Dynamic models for rotary dryers are partial differential equations with distributed 
parameters for both moisture and temperature in gases and solids. For practical purposes, they are usually approximated by corresponding lumped parameter models.

The first research into the overall mathematical modelling of a rotary dryer was conducted in the early 1960's, when Myklestad (1963b) developed a static model for counter-current rotary drying on the following assumptions:

- A volumetric heat transfer coefficient can be used.

- The temperature of the solids is constant throughout the dryer in the constant rate period and is linearly related to their moisture content in the falling rate period.

- A linear relationship between the temperature of the drying air and the moisture content of the solids can be used.

This model was used to determine moisture profiles for solids as a function of dryer length in the constant and falling rate periods. Later, Myklestad (1963b) tested its applicability to the control of product moisture in a pilot plant rotary dryer. Sharples et al. (1964) modelled a rotary dryer by means of four simultaneous differential equations describing the heat and mass transfer processes. The empirical expression for the drying rate of the solids was determined assuming that it was dependent on their temperature and moisture and independent of the velocity of the air. Residence time was based on the correlation of Schofield and Glikin (1962), and the volumetric heat transfer coefficient was assumed to be proportional to the cascade rate, which is a function of the rotational speed and flight loading. The validity of the model was tested in the counter-current drying of granular fertilisers.

Thorpe (1972) divided the drum into a large number of ideal stages and applied heat and mass transfer balances to each stage. Residence time was approximated according the correlation of Saeman and Mitchell (1954). No comparison between simulated and measured temperature and moisture profiles was made. Deich \& Stals'kii (1975) developed a dynamic model on the following assumptions:

- The parameters of the solids and drying air are distributed.

- The solids are of constant size and chemical composition.

- The specific heat of the solids is constant.

- The heat and mass transfer coefficients are constant.

- The velocities of the solids and drying air along the drum axis are constant.

- The conduction, diffusion and radiation are negligible.

The model is non-linear due to the non-linearity of the drying rate model.

The static and dynamic models for a phosphate rotary dryer developed by Najim et.al (1976) consisted of four partial differential heat and mass transfer equations, and the results were in good agreement with the experimental data. The assumptions were quite similar to those made in the previous studies, namely:

- The specific heats of the solids and drying medium are independent of temperature.

- The heat transfer coefficient is constant.

- The velocities of phosphate and drying air in the drum are constant.

- All non-conductive heat exchange is negligible. 
Thorne and Kelly (1980) developed a dynamic mathematical model that combined the particle transport model of Kelly \& O'Donnell (1977) with the drying kinetics model of Garside et al. (1970), in which drying was based on vapour diffusion. The overall model was tested for gypsum particles in a pilot dryer. Reay (1979) presented an overall model for a rotary dryer that included models for solids and equipment separately, the first describing the drying characteristics of the solids by predicting the drying rate as a function of moisture in the solids and the temperature and humidity of the drying air. The solids model is independent of the type of dryer. The equipment model described the dryer, and included information on air-solids heat transfer and particle motion. The gassolids contact pattern, and possibly also the degree of backmixing in both the gas and solids, would be part of this model. According to Reay (1979), the main difficulty in deriving a fundamental model for a rotary dryer is to obtain reliable predictions for the heat transfer coefficient and residence time.

Kisakurek (1982) compared results simulated by an overall model with experimental measurements. The drying of gypsum particles in a pilot-scale dryer was assumed to occur solely in the falling rate period. Residence time was modelled using the equation proposed by Schofield \& Glikin (1962). It is not clear from his paper how he estimated the heat transfer coefficient. Platin et al. (1982) developed a mathematical model for a con-current dryer and used a simulation to predict the effects of various system parameters on dryer performance.

Brasil \& Seckler (1988) presented a model for the drying of granular fertilisers that was based on the heat and mass transfer balances developed by Sharples \& Glikin (1964) but also took the influence of particle diameter on dryer operation into account by assuming that the rate of drying is a function of the particle diameter. Simulation showed that the proposed model was valid for the design of a dryer.

Douglas et al. (1992) developed a lumped parameter model by discretising the dryer into several sections on the assumption of equilibrium operational conditions, perfect mixing and constant drying. Wang et al. (1993) removed these limitations when developing a distributed parameter model for an industrial sugar dryer. The mathematical solution resulted in a differential-algebraic equation system. The assumption that no interaction exists between falling particles, which was used for determining the multiphase heat transfer coefficient was also removed. Steady state and dynamic simulations for examining the behaviour of both the distributed parameter model and the lumped parameter model with ten equilibrium discretised sections were carried out for the sugar dryer.

Duchesne et al. (1997a) presented a dynamic rotary dryer simulator which consists of four submodels: a combustion chamber model, a solids transport model, a gas model and a model for heat and mass transfer phenomena. The effect of different input process variables and parameters on the output temperature and moisture content of the air and solids were examined by means of simulations, and the results showed that the fuel flow has twice the effect on the output moisture of the solids that the secondary air flow has. It is therefore obvious that the fuel flow should be selected as the main variable to be manipulated in order to control of the output moisture of the solids. The secondary air flow rate should be kept as low as possible, which means that the drying air temperature should be as high as is technically possible. The results also showed that it is important for the design and implementation of control strategies to measure the input and output moisture content of the solids on-line. 
Development of a fuzzy model for a pilot plant dryer using a linguistic equation approach has been started at the Control Engineering Laboratory of the University of Oulu. Preliminary results have been published in the articles by Juuso et al. (1998) and Koskinen et al. (1998).

Although research into the overall mathematical modelling of a rotary dryer has led to an increased understanding of rotary dryers, no general purpose model has been developed to describe the dynamic behaviour of heat, mass and momentum transfer in rotary dryers. Many models are cumbersome and are either dryer-specific or product-specific. Fuzzy and neural network modelling could therefore be preferable to mathematical modelling, as in general a lot of experience and data regarding rotary dryers can be assumed to exist. 


\section{Development of a dynamic model for the pilot plant dryer}

A dynamic lumped parameter model linearised in the neighbourhood of the operating point can be used as a basis for simulating the drying of solids in a rotary dryer. The pilot con-current dryer located at the Control Engineering Laboratory was taken as an example. The following section describes the development of a dynamic model based on heat and mass transfer and the testing of its validity by means of simulations and pilot plant experiments using calcite as the material to be dried. The model is used later to define the main variables to be manipulated in control design and experiments.

A rotary dryer is a distributed parameter system in which both temperature and moisture are functions of time and distance, according to the general equation:

$$
\frac{\partial \mathrm{x}_{\mathrm{i}}(\mathrm{l}, \mathrm{t})}{\partial \mathrm{t}} \pm \mathrm{v}_{\mathrm{i}}(\mathrm{t}) \frac{\partial \mathrm{x}_{\mathrm{i}}(\mathrm{l}, \mathrm{t})}{\partial \mathrm{l}}=\mathrm{f}_{\mathrm{i}}\left(\mathrm{x}_{\mathrm{i}}, 1, \mathrm{t}\right)
$$

where $\mathrm{x}_{\mathrm{i}}$ is the moisture or temperature in the solids or gas phase

$\mathrm{v}_{\mathrm{i}}$ is the linear velocity in the solids or gas phase

1 is the axial co-ordinate, and

$\mathrm{t}$ is time.

A positive sign for $\mathrm{v}_{\mathrm{i}}$ applies to con-current drying and a negative sign to counter-current drying. The partial differential equations describing mass and heat transfer in the gas and solids phases for a con-current dryer are of the form (Deich \& Stalskii 1975): 


$$
\begin{aligned}
& \frac{\partial \mathrm{X}}{\partial \mathrm{t}}+\mathrm{v}_{\mathrm{s}} \frac{\partial \mathrm{X}}{\partial \mathrm{l}}=-\mathrm{R}_{\mathrm{w}} \\
& \frac{\partial \mathrm{Y}}{\partial \mathrm{t}}+\mathrm{v}_{\mathrm{g}} \frac{\partial \mathrm{Y}}{\partial \mathrm{l}}=\mathrm{R}_{\mathrm{w}} \frac{\mathrm{F}_{\mathrm{s}}}{\mathrm{F}_{\mathrm{g}}} \\
& \mathrm{Cs} \frac{\partial \mathrm{T}_{\mathrm{s}}}{\partial \mathrm{t}}+\mathrm{v}_{\mathrm{s}} \mathrm{C}_{\mathrm{s}} \frac{\partial \mathrm{T} \mathrm{s}}{\partial \mathrm{l}}=\frac{\mathrm{U}_{\mathrm{v}} \mathrm{V}_{\mathrm{v}}}{\mathrm{F}_{\mathrm{s}}}\left(\mathrm{T}_{\mathrm{g}}-\mathrm{T}_{\mathrm{s}}\right)-? \mathrm{R}_{\mathrm{w}} \\
& \mathrm{Cg}_{\mathrm{g}} \frac{\partial \mathrm{T}_{\mathrm{g}}}{\partial \mathrm{t}}+\mathrm{vg}_{\mathrm{g}} \mathrm{C}_{\mathrm{g}} \frac{\partial \mathrm{T}_{\mathrm{g}}}{\partial \mathrm{l}}=-\frac{\mathrm{U}_{\mathrm{v}} \mathrm{V}_{\mathrm{v}}}{\mathrm{F}_{\mathrm{g}}}\left(\mathrm{T}_{\mathrm{g}}-\mathrm{T}_{\mathrm{s}}\right)-? \frac{\mathrm{F}_{\mathrm{s}}}{\mathrm{F}_{\mathrm{g}}} \mathrm{R}_{\mathrm{w}}
\end{aligned}
$$

where $\mathrm{C}_{\mathrm{g}} \quad$ is the heat capacity of the drying air $(\mathrm{kJ} / \mathrm{kg} \mathrm{K})$,

$\mathrm{C}_{\mathrm{s}} \quad$ is the heat capacity of the solids $(\mathrm{kJ} / \mathrm{kg} \mathrm{K})$,

$\mathrm{F}_{\mathrm{g}} \quad$ is the linear density of the drying air $(\mathrm{kg} / \mathrm{m})$,

$\mathrm{F}_{\mathrm{s}} \quad$ is the linear density of the solids $(\mathrm{kg} / \mathrm{m})$,

$\mathrm{R}_{\mathrm{w}} \quad$ is the drying rate $(1 / \mathrm{s})$,

$\mathrm{T}_{\mathrm{g}} \quad$ is the temperature of the drying air $(\mathrm{K})$,

$\mathrm{T}_{\mathrm{s}} \quad$ is the temperature of the solids $(\mathrm{K})$,

$\mathrm{U}_{\mathrm{v}} \quad$ is the volumetric heat transfer coefficient $\left(\mathrm{kJ} / \mathrm{m}^{3} \mathrm{~K} \mathrm{~s}\right)$,

$\mathrm{V}_{\mathrm{v}}$ is the drum volume per unit length (free for air flow) $\left(\mathrm{m}^{3} / \mathrm{m}\right)$,

$\mathrm{X}$ is the solids moisture,

$\mathrm{Y} \quad$ is the gas humidity,

$v_{g} \quad$ is the linear velocity of the drying air in the axial direction $(\mathrm{m} / \mathrm{s})$,

$v_{\mathrm{s}} \quad$ is the linear velocity of the solids in the axial direction $(\mathrm{m} / \mathrm{s})$, and

$\lambda \quad$ is the heat vaporisation of water $(\mathrm{kJ} / \mathrm{kg})$.

The above equations are based on the following assumptions:

- The volumetric heat transfer coefficient is constant along the dryer.

- Heat transfer by conduction in the solids and drying air is negligible.

- Diffusion of water vapour in the axial direction is negligible.

- The heat required for the vaporisation of water is constant.

- The linear velocity of the drying air in the axial direction is constant.

- The granular size distribution is constant.

- No chemical reactions in take place the solids during drying.

- The temperatures of the solids and drying air and the moisture content of the solids are functions of time and the axial co-ordinate alone.

- Heat loss from the dryer into the surroundings is small.

The distributed parameter model is complex and cumbersome to handle, and the temperature and especially the moisture content of the solids and drying air inside the dryer are difficult to measure. It is therefore simplified to a lumped parameter model in 
which the partial derivative of the axial co-ordinate length is replaced by the total length of the drum. The equation for gas humidity is not included in the overall model for the dryer, because humidity is not measured in the pilot dryer. The model is now of the form:

$$
\begin{aligned}
& \frac{\mathrm{dX}_{\mathrm{s}, \text { out }}}{\mathrm{dt}}+\mathrm{vs}_{\mathrm{s}} \frac{\left(\mathrm{X}_{\mathrm{s}, \text { out }}-\mathrm{X}_{\mathrm{s}, \text { in }}\right)}{\mathrm{L}}=-\mathrm{R}_{\mathrm{w}} \\
& \mathrm{C}_{\mathrm{s}} \frac{\mathrm{dT}_{\mathrm{s}, \text { out }}}{\mathrm{dt}}+\mathrm{v}_{\mathrm{s}} \mathrm{C}_{\mathrm{s}} \frac{\left(\mathrm{T}_{\mathrm{s}, \text { out }}-\mathrm{T}_{\mathrm{s}, \text { in }}\right)}{\mathrm{L}}=\frac{\mathrm{Uv}_{\mathrm{v}} \mathrm{V}_{\mathrm{v}}}{\mathrm{F}_{\mathrm{s}}}\left(\mathrm{T}_{\mathrm{g}, \text { out }}-\mathrm{T}_{\mathrm{s}, \text { out }}\right)-? \mathrm{R}_{\mathrm{w}} \\
& \mathrm{C}_{\mathrm{g}} \frac{\mathrm{dT}_{\mathrm{g}, \text { out }}}{\mathrm{dt}}+\mathrm{VgC}_{\mathrm{g}} \frac{\left(\mathrm{T}_{\mathrm{g}, \text { out }}-\mathrm{T}_{\mathrm{g}, \text { in }}\right)}{\mathrm{L}}=-\frac{\mathrm{U}_{\mathrm{v}} \mathrm{V}_{\mathrm{v}}}{\mathrm{F}_{\mathrm{g}}}\left(\mathrm{T}_{\mathrm{g}, \text { out }}-\mathrm{T}_{\mathrm{s}, \text { out }}\right)-? \frac{\mathrm{F}_{\mathrm{s}}}{\mathrm{F}_{\mathrm{g}}} \mathrm{R}_{\mathrm{w}}
\end{aligned}
$$

where $\mathrm{X}_{\mathrm{s} \text {,out }}, \mathrm{T}_{\mathrm{s}, \text { out }}$ and $\mathrm{T}_{\mathrm{g} \text {,out }}$ describe the moisture and temperature values at the exit from the dryer.

The model is non-linear, because the drying rate $R_{w}$, which describes the course of drying inside the solids, is generally a non-linear function of solids characteristics and drying air temperature in the falling rate period, as many researchers have found in their experimental investigations (van Krevelen \& van Hoftijzer 1949b, Sharples et al. 1964, Kisakurek 1972, Brasil \& Seckler 1988). The rate of drying is assumed in this thesis to be a linear function of solids moisture, solids temperature and the temperature of the drying air in the neighbourhood of the operating point, according to the equation

$$
\mathrm{R}_{\mathrm{w}}=\mathrm{k}_{1} \mathrm{X}_{\mathrm{s}}+\mathrm{k}_{2} \mathrm{~T}_{\mathrm{s}}+\mathrm{k}_{3} \mathrm{~T}_{\mathrm{g}}
$$

where $\mathrm{k}_{1}(1 / \mathrm{s}), \mathrm{k}_{2}(1 / \mathrm{s} \mathrm{K})$ and $\mathrm{k}_{3}(1 / \mathrm{s} \mathrm{K})$ are constants determined experimentally. For linear approximation of the dynamic model, it is assumed that the variables deviate only slightly from the operating point. Using Taylor series expansion, the linearised model is in the general form

$$
\dot{\mathbf{x}}=\mathbf{A x}+\mathbf{B u}
$$

$$
\mathbf{y}=\mathbf{C x}
$$

where 
$\mathbf{x}=\left[\begin{array}{c}\mathrm{X}_{\mathrm{s}, \text { out }} \\ \mathrm{T}_{\mathrm{s}, \text { out }} \\ \mathrm{T}_{\mathrm{g}, \text { out }}\end{array}\right], \mathbf{u}=\left[\begin{array}{c}\mathrm{T}_{\mathrm{g}, \text { in }} \\ \mathrm{T}_{\mathrm{s}, \text { in }} \\ \mathrm{X}_{\mathrm{s}, \text { in }} \\ \mathrm{V}_{\mathrm{s}} \\ \mathrm{F}_{\mathrm{g}} \\ \mathrm{F}_{\mathrm{s}}\end{array}\right], \mathbf{A}=\left[\begin{array}{ccc}\mathrm{a}_{11} & \mathrm{a} 12 & \mathrm{a} 13 \\ \mathrm{a}_{21} & \mathrm{a} 22 & \mathrm{a} 23 \\ \mathrm{a} 31 & \mathrm{a} 32 & \mathrm{a} 33\end{array}\right]$

$\mathbf{B}=\left[\begin{array}{llllll}b_{11} & b_{12} & b_{13} & b_{14} & b_{15} & b_{16} \\ b_{21} & b_{22} & b_{23} & b_{24} & b_{25} & b_{26} \\ b_{31} & b_{32} & b_{33} & b_{34} & b_{35} & b_{36}\end{array}\right], \mathbf{C}=[111]$

and the elements of the matrix $\mathbf{A}$ and $\mathbf{B}$ are

$$
\begin{aligned}
& \mathrm{a}_{11}=-\left(1 / \mathrm{L}_{\mathrm{s}}+\mathrm{k}_{1}\right) \\
& \mathrm{a}_{12}=-\mathrm{k}_{2}, \quad \mathrm{a}_{13}=-\mathrm{k}_{3} \\
& \mathrm{a}_{21}=-\frac{? \mathrm{k}_{1}}{\mathrm{C}_{\mathrm{s}}} \\
& \mathrm{a}_{22}=-\left(1 / \overline{\mathrm{V}}_{\mathrm{s}}+\frac{\mathrm{U}_{\mathrm{v}} \mathrm{V}_{\mathrm{v}}}{\mathrm{C}_{\mathrm{s}} \overline{\mathrm{F}_{\mathrm{s}}}}+\frac{? \mathrm{k}_{2}}{\mathrm{C}_{\mathrm{s}}}\right) \\
& \mathrm{a}_{23}=\frac{\mathrm{U}_{\mathrm{v}} \mathrm{V}_{\mathrm{v}}}{\mathrm{C}_{\mathrm{s}} \overline{\mathrm{F}_{\mathrm{s}}}}-\frac{? \mathrm{k}_{3}}{\mathrm{C}_{\mathrm{s}}} \\
& \mathrm{a}_{31}=-\frac{? \overline{\mathrm{F}_{\mathrm{s}}}}{\mathrm{C}_{\mathrm{g}} \overline{\mathrm{F}}_{\mathrm{g}}} \mathrm{k}_{1} \\
& \mathrm{a}_{32}=\frac{\mathrm{U}_{\mathrm{v}} \mathrm{V}_{\mathrm{v}}}{\mathrm{C}_{\mathrm{g}} \overline{\mathrm{F}_{\mathrm{g}}}}-\frac{? \overline{\mathrm{F}_{\mathrm{s}}}}{\mathrm{C}_{\mathrm{g}} \overline{\mathrm{F}_{\mathrm{g}}}} \mathrm{k}_{2} \\
& \mathrm{a}_{33}=-\left(\frac{\overline{\mathrm{V}_{g}}}{\mathrm{~L}_{\mathrm{L}}}+\frac{\mathrm{U}_{\mathrm{v}} \mathrm{V}_{\mathrm{v}}}{\mathrm{C}_{\mathrm{g}} \overline{\mathrm{F}_{\mathrm{g}}}}+\frac{? \overline{\mathrm{F}_{\mathrm{s}}}}{\mathrm{C}_{\mathrm{g}} \overline{\mathrm{F}_{\mathrm{g}}}} \mathrm{k}_{3}\right)
\end{aligned}
$$


and

$$
\begin{aligned}
& b_{11}=b_{12}=b_{15}=b_{16}=b_{21}=b_{23}=b_{25}=b_{32}=b_{33}=b_{34}=0 \\
& \mathrm{~b}_{13}=1 / \mathrm{L} \overline{\mathrm{v}}_{\mathrm{s}} \\
& \mathrm{b}_{14}=-1 / \mathrm{L}\left(\overline{\mathrm{X}}_{\mathrm{s}, \text { out }}-\overline{\mathrm{X}}_{\mathrm{s}, \text { in }}\right) \\
& \mathrm{b}_{22}=1 / \mathrm{L} \overline{\mathrm{V}_{\mathrm{s}}} \\
& \mathrm{b}_{24}=-1 / \mathrm{L}\left(\overline{\mathrm{T}_{\mathrm{s}}, \text { out }}-\overline{\mathrm{T}_{\mathrm{s}}, \text { in }}\right) \\
& \mathrm{b}_{26}=-\frac{\mathrm{U}_{\mathrm{v}} \mathrm{V}_{\mathrm{v}}}{\mathrm{C}_{\mathrm{s}} \overline{\mathrm{F}}_{\mathrm{s}}^{2}}\left(\overline{\mathrm{T}_{\mathrm{g}}, \text { out }}-\overline{\mathrm{T}_{\mathrm{s}}} \text {, out }\right) \\
& \mathrm{b}_{31}=\frac{\overline{\mathrm{V}}_{\mathrm{s}}}{\mathrm{L}} \\
& \mathrm{b}_{35}=\left(\overline{\mathrm{T}_{\mathrm{g}} \text {, out }}-\overline{\mathrm{T}}_{\mathrm{s}, \text { out }}\right) \frac{\mathrm{U}_{\mathrm{v}} \mathrm{V}_{\mathrm{v}}}{\mathrm{C}_{\mathrm{g}}{\overline{\mathrm{F}_{\mathrm{g}}}}^{2}}+\frac{? \overline{\mathrm{F}_{\mathrm{s}}}}{\mathrm{C}_{\mathrm{g}}{\overline{\mathrm{Fg}_{\mathrm{g}}}}^{2}}\left(\mathrm{k}_{1} \overline{\mathrm{X}}_{\mathrm{s}, \text { out }}+\mathrm{k}_{2} \overline{\mathrm{T}}_{\mathrm{s}} \text {, out }+\mathrm{k}_{3} \overline{\mathrm{T}_{\mathrm{g}}} \text {, out }\right) \\
& \mathrm{b}_{36}=-\frac{?}{\mathrm{C}_{\mathrm{g}} \overline{\mathrm{F}_{\mathrm{g}}}}\left(\mathrm{k}_{1} \overline{\mathrm{X}}_{\mathrm{s}} \text {, out }+\mathrm{k}_{2} \overline{\mathrm{T}}_{\mathrm{s}} \text {, out }+\mathrm{k}_{3} \overline{\mathrm{T}}_{\mathrm{g}} \text {, out }\right)
\end{aligned}
$$

The steady state values for the variables are denoted by bars above the notations. The variables without bars represent small changes from the steady state values.

\subsection{Determination of parameters}

The model includes parameters for which values are calculated from correlations presented in the literature or determined experimentally. Of the physical parameters, heat capacity is evaluated for both solids and drying air at the arithmetic mean of their input and output temperatures. This can be done due to the low temperature dependence in the temperature range used for solids and drying air in this work (Luyben \& Wenzel 1988). The mean value for the heat capacity of drying air is $1.01 \mathrm{~kJ} / \mathrm{kg} \mathrm{K}$ and the for calcite (mainly $\mathrm{CaCO}_{3}$ ) is $0.84 \mathrm{~kJ} / \mathrm{kg} \mathrm{K}$.

The volumetric heat transfer coefficient is calculated from the correlation presented in equation (8), which gives a value of $0.27 \mathrm{~kJ} / \mathrm{m}^{3} \mathrm{~s} \mathrm{~K}$, which is based on experimentally determined values of $0.46 \mathrm{~kg} / \mathrm{s} \mathrm{m}^{2}$ for the flow of drying air and $0.7 \mathrm{~m} / \mathrm{s}$ for the velocity of the air. The inside diameter of the drum is $0.5 \mathrm{~m}$.

The free volume in the drum for air flow is estimated by subtracting the volume occupied by the solids from the total drum volume resulting in the value for $\mathrm{V}_{\mathrm{v}}$. 
The residence time is determined experimentally by stopping the feed flow and by unloading the drum. When solids is weighted after stopping, the average hold up is 26.3 $\mathrm{kg}$. According to the equation (1) the mean residence time of solids in the drum is about 10 minutes when the feed flow is $0.04 \mathrm{~kg} / \mathrm{s}$.

A study of how solids dries may be based on the internal mechanism of liquid flow or on the effect of external conditions, such as the temperature, humidity and velocity of drying air. As a voluminous literature on drying theories shows the former procedure generally requires a complicated theoretical analysis and therefore the latter procedure based on drying experiments is more generally used in industry.

In this thesis the drying experiments of calcite for determining the drying rate diagrams were carried out in a laboratory scale oven heated by electrically. A sample of calcite, which is to be dried, is put on the plate and the sample is weighted as a function of time. The drying experiments were made for various initial moisture levels in three different drying air temperatures. Drying rate data are presented in Tables $2 \ldots . .10$.

Table 2. Drying rate data for calcite with an initial moisture content of $1.0 \mathrm{~m}$-\% at a drying temperature of $453 \mathrm{~K}$

\begin{tabular}{|c|c|c|c|c|}
\hline $\begin{array}{l}\text { Drying } \\
\text { time } \\
\mathrm{s}\end{array}$ & $\begin{array}{l}\text { Sample } \\
\text { weight } \\
\text { g }\end{array}$ & $\begin{array}{l}\text { Moisture } \\
\text { evaporated } \\
\text { g }\end{array}$ & $\begin{array}{l}\text { Moisture } \\
\text { content } \\
\%\end{array}$ & $\begin{array}{l}\text { Drying rate } \\
10^{-5} 1 / \mathrm{s}\end{array}$ \\
\hline 0 & 42.17 & & 1.15 & \\
\hline 120 & 42.08 & 0.09 & 0.95 & 1.70 \\
\hline 240 & 42.00 & 0.17 & 0.76 & 1.64 \\
\hline 360 & 41.86 & 0.31 & 0.43 & 2.02 \\
\hline 480 & 41.76 & 0.41 & 0.19 & 2.01 \\
\hline 600 & 41.69 & 0.48 & 0.02 & 1.89 \\
\hline 720 & 41.68 & 0.49 & 0 & 1.61 \\
\hline
\end{tabular}

Table 3. Drying rate data for calcite with an initial moisture content of $1.0 \mathrm{~m}$-\% at a drying temperature of $478 \mathrm{~K}$.

\begin{tabular}{lllll}
\hline $\begin{array}{l}\text { Drying } \\
\text { time } \\
\mathrm{s}\end{array}$ & $\begin{array}{l}\text { Sample } \\
\text { weight } \\
\mathrm{g}\end{array}$ & $\begin{array}{l}\text { Moisture } \\
\text { evaporated } \\
\mathrm{g}\end{array}$ & $\begin{array}{l}\text { Moisture } \\
\text { content } \\
\%\end{array}$ & $\begin{array}{l}\text { Drying rate } \\
10^{-5} 1 / \mathrm{s}\end{array}$ \\
\hline 0 & 41.27 & & 1.08 & \\
120 & 41.17 & 0.10 & 0.82 & 2.10 \\
240 & 41.06 & 0.21 & 0.56 & 2.16 \\
360 & 40.93 & 0.34 & 0.24 & 2.32 \\
480 & 40.84 & 0.43 & 0.02 & 2.19 \\
600 & 40.83 & 0.44 & 0 & 1.79 \\
\hline
\end{tabular}


Table 4. Drying rate data for calcite with an initial moisture content of $1.0 \mathrm{~m}$-\% at a drying temperature of $493 \mathrm{~K}$.

\begin{tabular}{lllll}
\hline $\begin{array}{l}\text { Drying } \\
\text { time } \\
\mathrm{s}\end{array}$ & $\begin{array}{l}\text { Sample } \\
\text { weight } \\
\mathrm{g}\end{array}$ & $\begin{array}{l}\text { Moisture } \\
\text { evaporated } \\
\mathrm{g}\end{array}$ & $\begin{array}{l}\text { Moisture } \\
\text { content } \\
\%\end{array}$ & $\begin{array}{l}\text { Drying rate } \\
10^{-5} 1 / \mathrm{s}\end{array}$ \\
\hline 0 & 41.35 & & 1.14 & \\
120 & 41.24 & 0.11 & 0.871 & 2.25 \\
240 & 41.11 & 0.24 & 0.56 & 2.44 \\
360 & 40.95 & 0.40 & 0.17 & 2.70 \\
480 & 40.89 & 0.46 & 0.02 & 2.33 \\
600 & 40.88 & 0.47 & 0 & 1.90 \\
\hline
\end{tabular}

Table 5. Drying rate data for calcite with an initial moisture content of $2.5 \mathrm{~m}$-\% at a drying temperature of $453 \mathrm{~K}$.

\begin{tabular}{lllll}
\hline $\begin{array}{l}\text { Drying } \\
\text { time } \\
\mathrm{s}\end{array}$ & $\begin{array}{l}\text { Sample } \\
\text { weight }\end{array}$ & $\begin{array}{l}\text { Moisture } \\
\text { evaporated } \\
\mathrm{g}\end{array}$ & $\begin{array}{l}\text { Moisture } \\
\text { content } \\
\%\end{array}$ & $\begin{array}{l}\text { Drying rate } \\
10^{-5} 1 / \mathrm{s}\end{array}$ \\
\hline 0 & 42.81 & & 2.64 & \\
120 & 42.73 & 0.08 & 2.45 & 1.56 \\
240 & 42.59 & 0.22 & 2.13 & 2.14 \\
360 & 42.36 & 0.45 & 1.59 & 2.92 \\
480 & 42.12 & 0.69 & 1.03 & 3.36 \\
600 & 41.94 & 0.87 & 0.61 & 3.39 \\
720 & 41.80 & 1.01 & 0.28 & 3.28 \\
840 & 41.71 & 1.10 & 0.07 & 3.06 \\
960 & 41.68 & 1.13 & 0 & 2.75 \\
\hline
\end{tabular}

Table 6. Drying rate data for calcite with an initial moisture content of $2.5 \mathrm{~m}$-\% at a drying temperature of $478 \mathrm{~K}$.

\begin{tabular}{lllll}
\hline $\begin{array}{l}\text { Drying } \\
\text { time } \\
\mathrm{s}\end{array}$ & $\begin{array}{l}\text { Sample } \\
\text { weight }\end{array}$ & $\begin{array}{l}\text { Moisture } \\
\text { evaporated } \\
\mathrm{g}\end{array}$ & $\begin{array}{l}\text { Moisture } \\
\text { content } \\
\%\end{array}$ & $\begin{array}{l}\text { Drying rate } \\
10^{-5} 1 / \mathrm{s}\end{array}$ \\
\hline 0 & 40.17 & & 2.42 & \\
120 & 40.06 & 0.11 & 2.14 & 2.34 \\
240 & 39.85 & 0.32 & 1.62 & 3.35 \\
360 & 39.58 & 0.59 & 0.95 & 4.10 \\
480 & 39.38 & 0.79 & 0.45 & 4.11 \\
600 & 39.26 & 0.91 & 0.15 & 3.79 \\
720 & 39.20 & 0.97 & 0 & 3.36 \\
\hline
\end{tabular}


Table 7. Drying rate data for calcite with an initial moisture content of $2.5 \mathrm{~m}$-\% and a drying temperature of $493 \mathrm{~K}$.

\begin{tabular}{|c|c|c|c|c|}
\hline $\begin{array}{l}\text { Drying } \\
\text { time } \\
\mathrm{S}\end{array}$ & $\begin{array}{l}\text { Sample } \\
\text { weight } \\
\text { g }\end{array}$ & $\begin{array}{l}\text { Moisture } \\
\text { evaporated } \\
\mathrm{g}\end{array}$ & $\begin{array}{l}\text { Moisture } \\
\text { content } \\
\%\end{array}$ & $\begin{array}{l}\text { Drying rate } \\
10^{-5} 1 / \mathrm{s}\end{array}$ \\
\hline 0 & 42.11 & & 2.65 & \\
\hline 120 & 41.99 & 0.12 & 2.35 & 2.45 \\
\hline 240 & 41.70 & 0.41 & 1.66 & 4.10 \\
\hline 360 & 41.46 & 0.65 & 1.09 & 4.31 \\
\hline 480 & 41.23 & 0.88 & 0.55 & 4.37 \\
\hline 600 & 41.07 & 1.04 & 0.17 & 4.13 \\
\hline 720 & 41.01 & 1.10 & 0.02 & 3.64 \\
\hline 840 & 41.00 & 1.11 & 0 & 3.15 \\
\hline
\end{tabular}

Table 8. Drying rate data for calcite with an initial moisture content of $5.0 \mathrm{~m}$-\% at a drying temperature of $453 \mathrm{~K}$.

\begin{tabular}{lllll}
\hline $\begin{array}{l}\text { Drying } \\
\text { time s }\end{array}$ & $\begin{array}{l}\text { Sample } \\
\text { weight } \\
\mathrm{g}\end{array}$ & $\begin{array}{l}\text { Moisture } \\
\text { evaporated } \\
\mathrm{g}\end{array}$ & $\begin{array}{l}\text { Moisture } \\
\text { content } \\
\%\end{array}$ & $\begin{array}{l}\text { Drying rate } \\
10^{-5} 1 / \mathrm{s}\end{array}$ \\
\hline 0 & 43.03 & & 5.18 & \\
120 & 42.94 & 0.09 & 4.97 & 1.69 \\
240 & 42.79 & 0.24 & 4.63 & 2.30 \\
360 & 42.51 & 0.52 & 3.97 & 3.34 \\
480 & 42.16 & 0.87 & 3.16 & 4.20 \\
600 & 41.84 & 1.19 & 2.42 & 4.60 \\
720 & 41.59 & 1.44 & 1.84 & 4.64 \\
840 & 41.34 & 1.69 & 1.26 & 4.67 \\
960 & 41.19 & 1.84 & 0.91 & 4.45 \\
1080 & 41.05 & 1.98 & 0.58 & 4.26 \\
1200 & 40.95 & 2.07 & 0.35 & 4.02 \\
1320 & 40.87 & 2.16 & 0.16 & 3.80 \\
1440 & 40.82 & 2.21 & 0.05 & 3.56 \\
\hline
\end{tabular}


Table 9. Drying rate data for calcite with an initial moisture content of $5.0 \mathrm{~m}$-\% at a drying temperature of $478 \mathrm{~K}$.

\begin{tabular}{lllll}
\hline $\begin{array}{l}\text { Drying } \\
\text { time } \\
\mathrm{s}\end{array}$ & $\begin{array}{l}\text { Sample } \\
\text { weight }\end{array}$ & $\begin{array}{l}\text { Moisture } \\
\text { evaporated } \\
\mathrm{g}\end{array}$ & $\begin{array}{l}\text { Moisture } \\
\text { content } \\
\%\end{array}$ & $\begin{array}{l}\text { Drying rate } \\
10^{-5} 1 / \mathrm{s}\end{array}$ \\
\hline 0 & 40.19 & & 5.08 & \\
120 & 40.08 & 0.11 & 4.80 & 2.28 \\
240 & 39.81 & 0.38 & 4.13 & 3.94 \\
360 & 39.39 & 0.80 & 3.09 & 5.53 \\
480 & 38.98 & 1.21 & 2.07 & 6.27 \\
600 & 38.64 & 1.55 & 1.22 & 6.43 \\
720 & 38.41 & 1.78 & 0.65 & 6.15 \\
840 & 38.26 & 1.93 & 0.27 & 5.72 \\
960 & 38.38 & 2.01 & 0.08 & 5.21 \\
1080 & 38.15 & 2.04 & 0 & 4.70 \\
\hline
\end{tabular}

Table 10. Drying rate data for calcite with an initial moisture content of $5.0 \mathrm{~m}-\%$ at a drying temperature of $49 \mathrm{~K}$.

\begin{tabular}{lllll}
\hline $\begin{array}{l}\text { Drying } \\
\text { time } \\
\mathrm{s}\end{array}$ & $\begin{array}{l}\text { Sample } \\
\text { weight } \\
\mathrm{g}\end{array}$ & $\begin{array}{l}\text { Moisture } \\
\text { evaporated } \\
\mathrm{g}\end{array}$ & $\begin{array}{l}\text { Moisture } \\
\text { content } \\
\%\end{array}$ & $\begin{array}{l}\text { Drying rate } \\
10^{-5} 1 / \mathrm{s}\end{array}$ \\
\hline 0 & 42.46 & & 5.105 .08 & \\
120 & 42.34 & 0.12 & 4.80 & 2.43 \\
240 & 41.96 & 0.50 & 3.91 & 4.95 \\
360 & 41.41 & 1.05 & 2.61 & 6.90 \\
480 & 41.00 & 1.46 & 1.65 & 7.18 \\
600 & 40.69 & 1.77 & 0.92 & 6.96 \\
720 & 40.48 & 1.98 & 0.42 & 6.49 \\
840 & 40.35 & 2.11 & 0.12 & 5.93 \\
960 & 40.30 & 2.16 & 0 & 5.31 \\
\hline
\end{tabular}

The corresponding drying curves and drying rate profiles are plotted in Figures $4 . . .9$. 


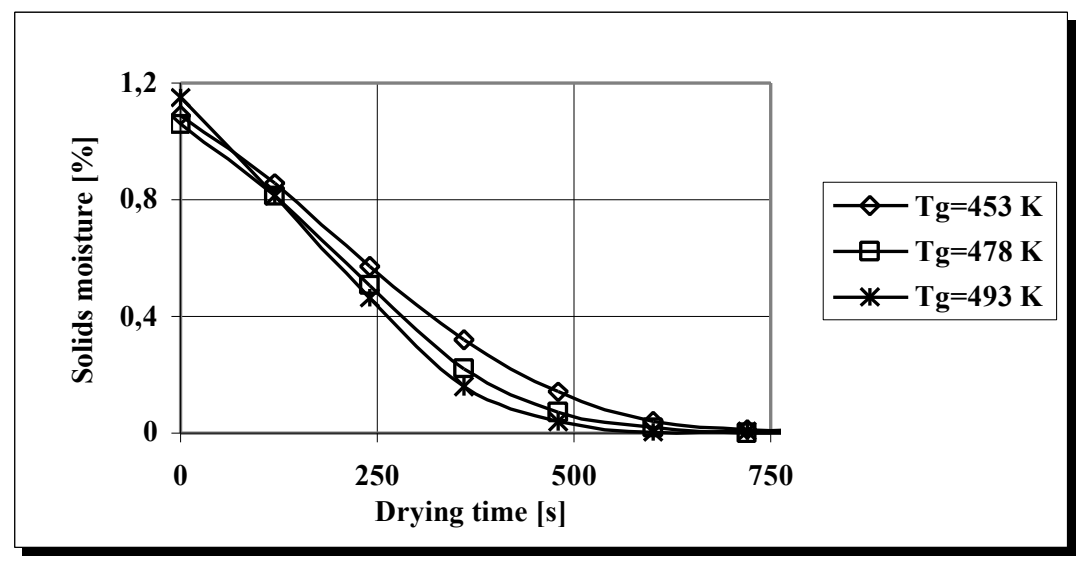

Fig. 4. Drying curve for calcite, initial moisture $1.0 \mathrm{~m}-\%$.

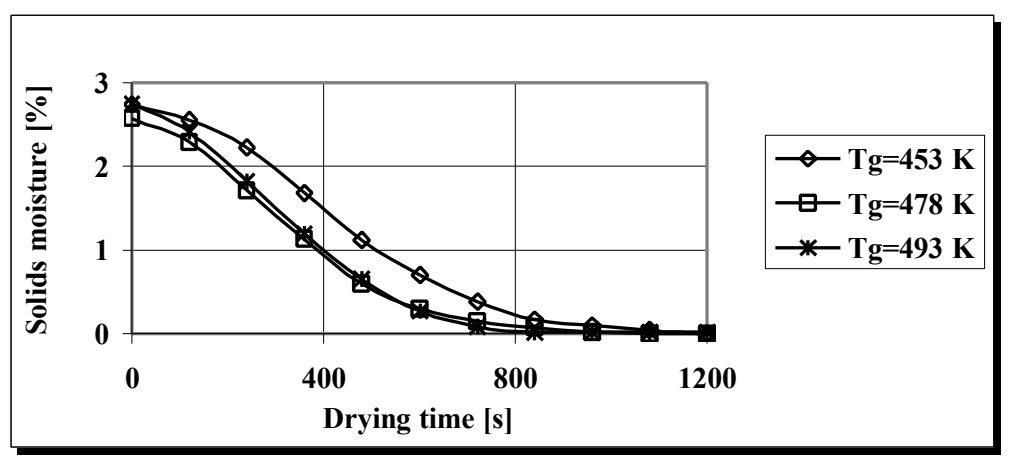

Fig. 5. Drying curve for calcite, initial moisture $2.5 \mathrm{~m}-\%$.

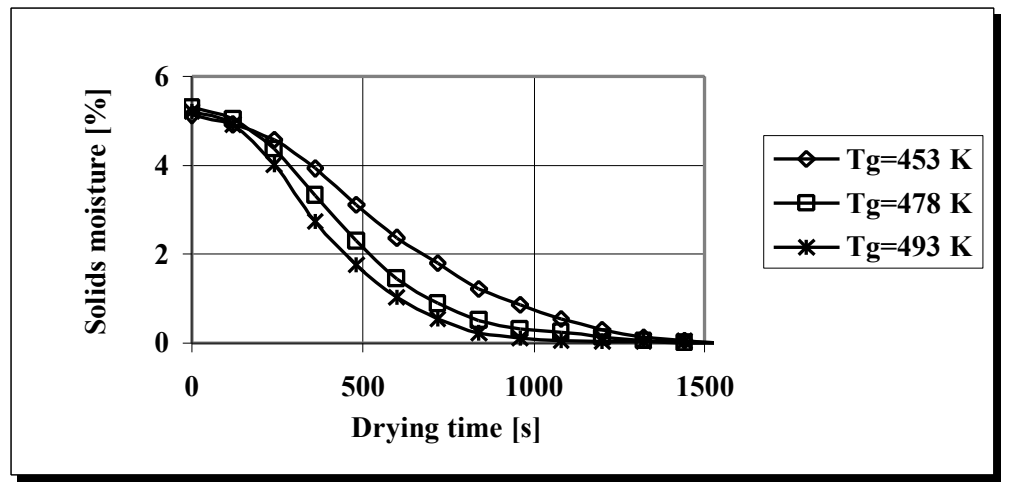

Fig. 6. Drying curve for calcite, initial moisture $5.0 \mathrm{~m}-\%$. 


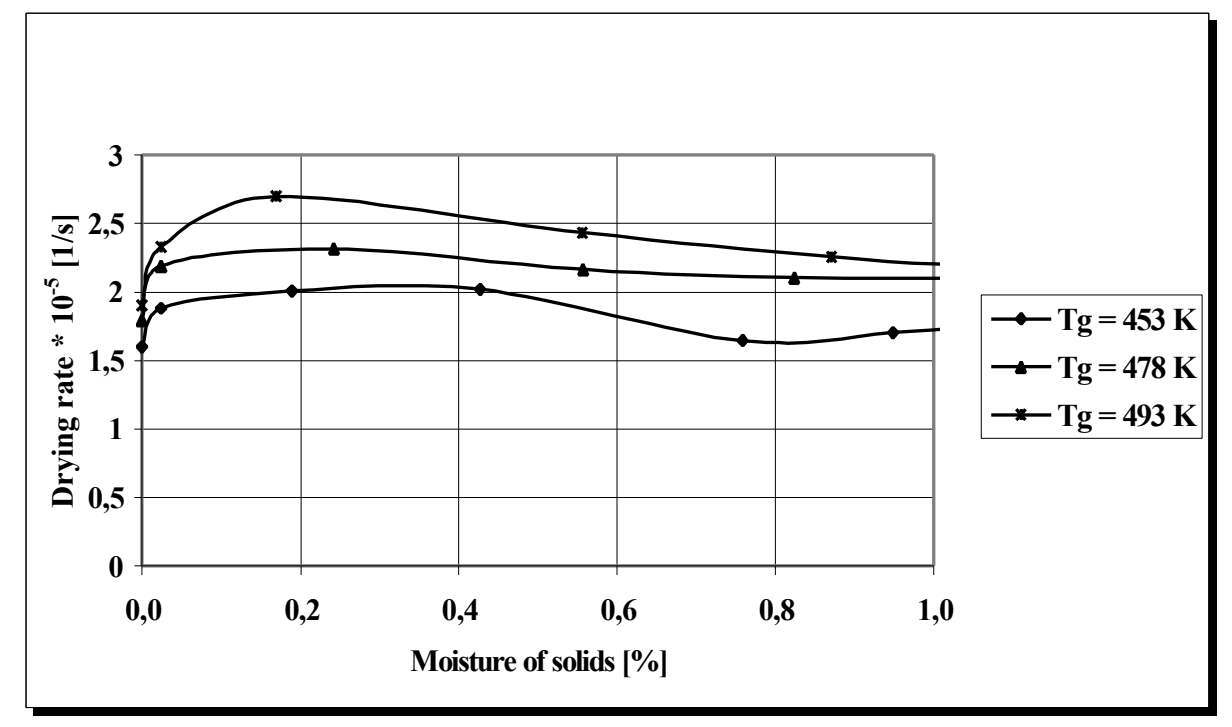

Fig. 7. Drying rate profile for calcite, initial moisture $1.0 \mathrm{~m}-\%$.

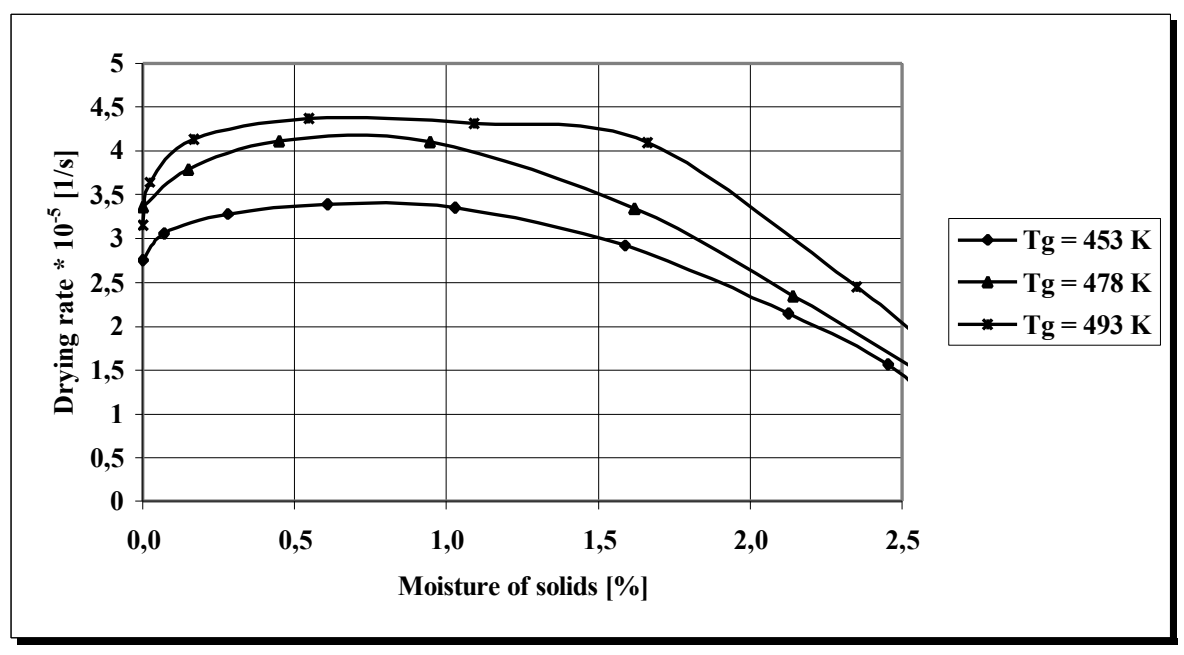

Fig. 8. Drying rate profile for calcite, initial moisture $2.5 \mathrm{~m}-\%$. 


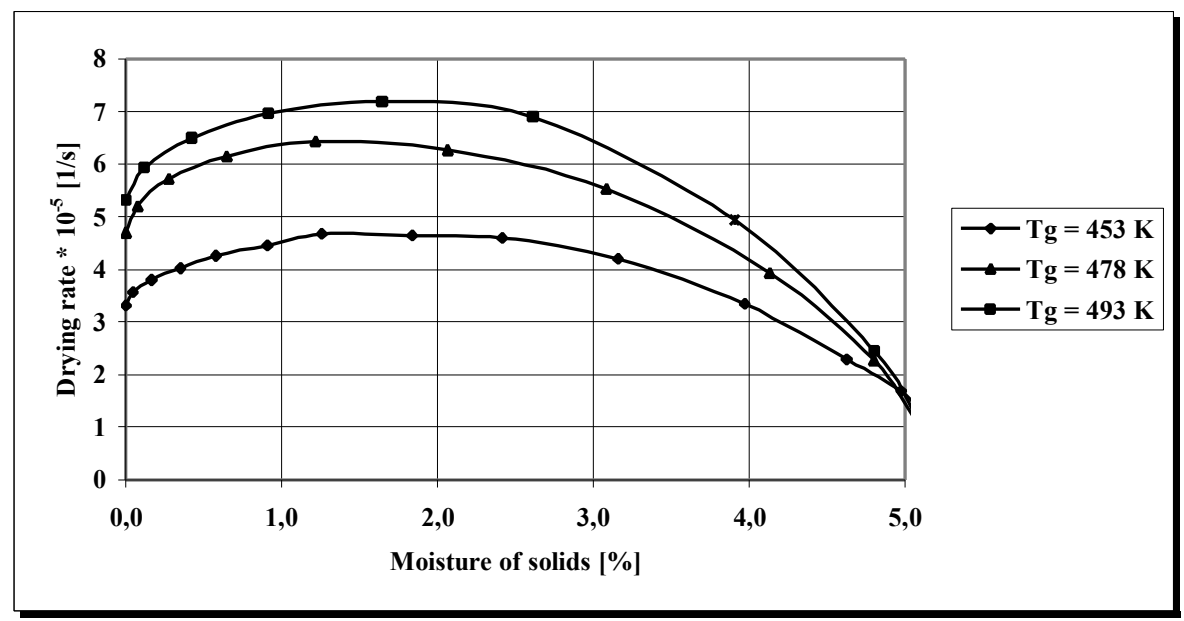

Fig. 9. Drying rate profile for calcite, initial moisture $5.0 \mathrm{~m}-\%$.

As shown in Figures 4...6, drying times increase with increasing initial moisture levels and decrease with increasing air temperatures. The drying rate curves in Figures $7 \ldots 9$ point to the existence of the three drying periods: preheating, constant rate and falling rate.

\subsection{Simulations}

\subsubsection{Steady state simulator}

To validate the model, steady state data were obtained from the pilot dryer. The parameters and steady state operating data are shown in Table 11. 
Table 11. Steady state values for the pilot plant rotary dryer used in the simulations.

\begin{tabular}{llll}
\hline Variable & Steady state value & Parameter & Steady state value \\
\hline $\mathrm{n}_{\mathrm{drum}}$ & $1.0 \mathrm{r} / \mathrm{min}$ & $\mathrm{c}_{\mathrm{g}}$ & $1.01 \mathrm{~kJ} / \mathrm{kg} \mathrm{K}$ \\
$\mathrm{v}_{\mathrm{g}}$ & $0.7 \mathrm{~m} / \mathrm{s}$ & $\mathrm{c}_{\mathrm{s}}$ & $0.84 \mathrm{~kJ} / \mathrm{kg} \mathrm{K}$ \\
$\mathrm{v}_{\mathrm{s}}$ & $4.78^{*} 10^{-3} \mathrm{~m} / \mathrm{s}$ & $\mathrm{k}_{1}$ & $1 * 10^{-3} 1 / \mathrm{s} ; \mathrm{k}_{2}=0$ \\
$\mathrm{~F}_{\mathrm{g}}$ & $0.12 \mathrm{~kg} / \mathrm{m}$ & $\mathrm{k}_{3}$ & $0.1 * 10^{-8} 1 / \mathrm{s} \mathrm{K}$ \\
$\mathrm{F}_{\mathrm{s}}$ & $8.77 \mathrm{~kg} / \mathrm{m}$ & $\mathrm{U}_{\mathrm{v}}$ & $0.27 \mathrm{~kJ}^{3} / \mathrm{s} \mathrm{m}^{3} \mathrm{~K}$ \\
$\mathrm{~T}_{\mathrm{g}, \text { in }}$ & $472 \mathrm{~K}$ & $\mathrm{~V}_{\mathrm{v}}$ & $0.19 \mathrm{~m}^{3} / \mathrm{m}$ \\
$\mathrm{T}_{\mathrm{g}, \text { out }}$ & $421 \mathrm{~K}$ & $\lambda$ & $2261 \mathrm{~kJ} / \mathrm{kg}$ \\
$\mathrm{T}_{\mathrm{s}, \text { in }}$ & $293 \mathrm{~K}$ & & \\
$\mathrm{~T}_{\mathrm{s}, \text { out }}$ & $360 \mathrm{~K}$ & & \\
$\mathrm{X}_{\mathrm{s}, \text { in }}$ & $2.4 \mathrm{~m}-\%$ & & \\
$\mathrm{X}_{\mathrm{s}, \text { out }}$ & $0.001 \mathrm{~m}-\%$ & & \\
\hline
\end{tabular}

The moisture content of the solids and the temperatures of the drying air and solids are presented as a function of position along the dryer in Fig.10. The simulated values for solids temperature, solids moisture and drying air temperature at the exit from the dryer are very close to those determined experimentally, while the steady state profiles follow those reported by Sharples et al. (1964), Langrish (1988) and Duchesne et al. (1997a). The output temperatures of the solids and drying air in con-current drying are generally reached near the inlet to the drum, where heat transfer is fastest. The maximum temperature of the solids can be several degrees higher than the final output temperature of the solids. 


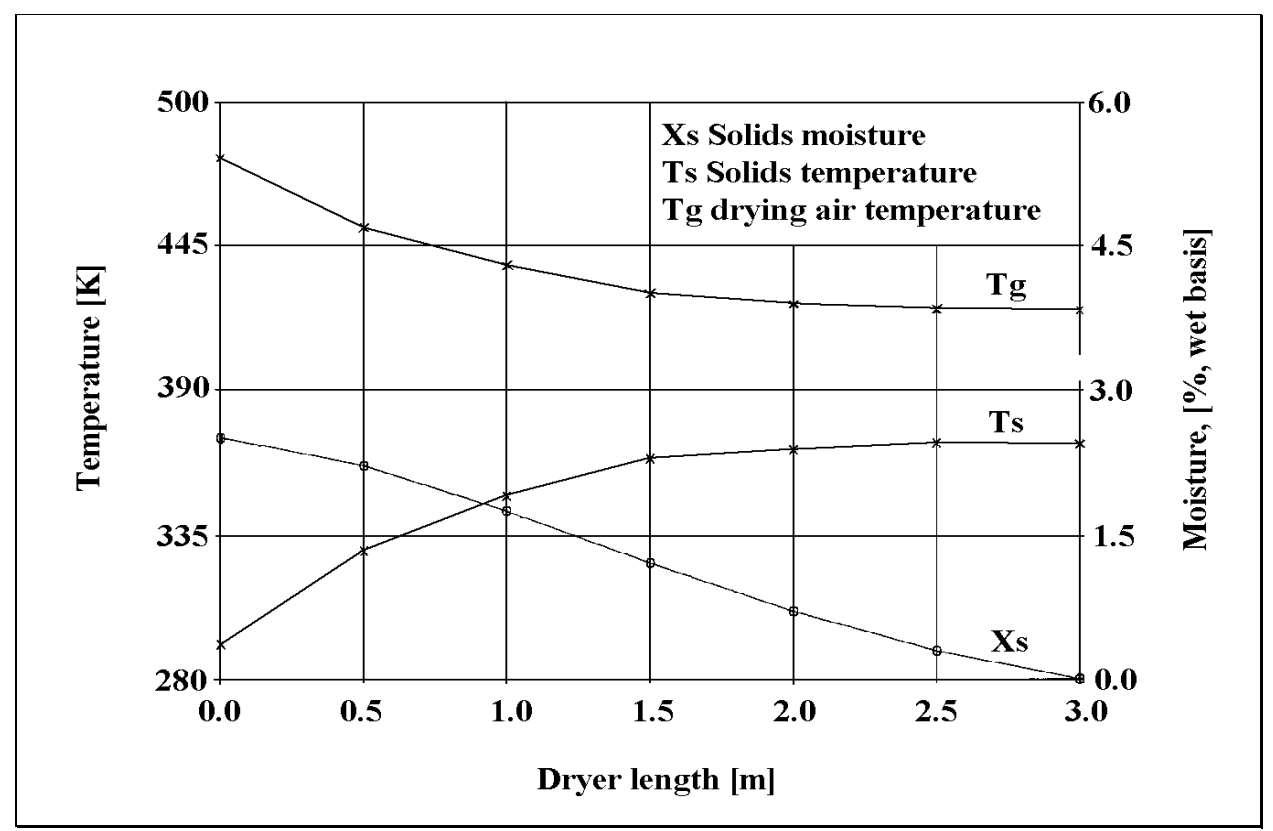

Fig. 10. Steady state distributions for the moisture in solids and the temperatures of solids and drying air, where $\Delta \mathrm{l}=0.5 \mathrm{~m}$.

\subsubsection{Dynamic simulator}

The purpose of dynamic simulations is to examine the effect of changes in the input variables and parameters of a model on its output variables. The main aim here was to determine the main variables to be manipulated in a control strategy for a rotary dryer. The steady state solution was chosen as the initial situation, and the relative sensitivities of the output variables to changes in various input variables, model parameters and drum dimensions were examined using the index (Duchesne et al. 1997a)

$$
\mathrm{J}=\frac{\left(\mathrm{y}-\mathrm{y}_{\mathrm{ref}}\right) / \mathrm{y}_{\mathrm{ref}}}{\left(\mathrm{p}-\mathrm{p}_{\mathrm{ref}}\right) / \mathrm{p}_{\mathrm{ref}}}
$$

where $\mathrm{J}$ is the sensitivity index, $\mathrm{y}_{\mathrm{ref}}$ and $\mathrm{y}$ are the values of the output variables before and after the change, $p_{\text {ref }}$ is the initial value of the input variable or parameter and $p$ is its new value. The sensitivity index is determined by changing one variable or parameter at a time by $+10 \%$, except that the change in the drying rate coefficient was $100 \%$, and then performing a complete simulation using the initial operating conditions as presented in Table 11. The results are presented in Table 12, which shows the effect of the various input variables, physical parameters and drum dimensions on the output variables. 
Table 12. Sensitivity indices of the output variables.

\begin{tabular}{llll}
\hline & $\begin{array}{l}\mathrm{X}_{\mathrm{s}, \text { out }} \\
\%\end{array}$ & $\begin{array}{l}\mathrm{T}_{\mathrm{s}, \text { out }} \\
\mathrm{K}\end{array}$ & $\begin{array}{l}\mathrm{T}_{\mathrm{g}, \text { out }} \\
\mathrm{K}\end{array}$ \\
\hline Variable & & & \\
Input moisture of solids & 14.71 & -0.05 & -0.03 \\
Input temperature of solids & -0.18 & 0.48 & 0.13 \\
Input temperature of drying air & -1.49 & 0.62 & 0.95 \\
Feed flow & 14.12 & -0.11 & -0.05 \\
Parameter & & & \\
Heat capacity of solids & -0.001 & 0.04 & -0.30 \\
Heat capacity of drying air & -0.002 & 0.01 & -0.02 \\
Heat of vaporization & 0.003 & -0.06 & 0.0004 \\
Volumetric heat & -0.00003 & -0.001 & -0.02 \\
coefficient transfer & & & 0.0002 \\
Drying rate coefficient $\mathrm{k}_{1}$ & -0.34 & -0.04 & 0.0003 \\
Drying rate coefficient $\mathrm{k}_{3}$ & 0.003 & & \\
\hline
\end{tabular}

The sensitivity analysis shows that the input temperature of the drying air, which correlates with fuel flow, has the great influence on the output variables. It is therefore obvious that this variable is selected as the main one to be manipulated when designing a control system for a rotary dryer, with the feed flow as an auxiliary manipulated variable. As expected, the input moisture of the solids has a major disturbing influence on their output moisture. It would therefore be important to measure it on-line in order to achieve good control. The effect of physical parameters on the output variables is not very great. Based on the sensitivity analysis, stepwise changes were made to the main variables to be manipulated and the main disturbance variable in order to validate the model. The simulated responses to step changes are presented in Figures 11...13.

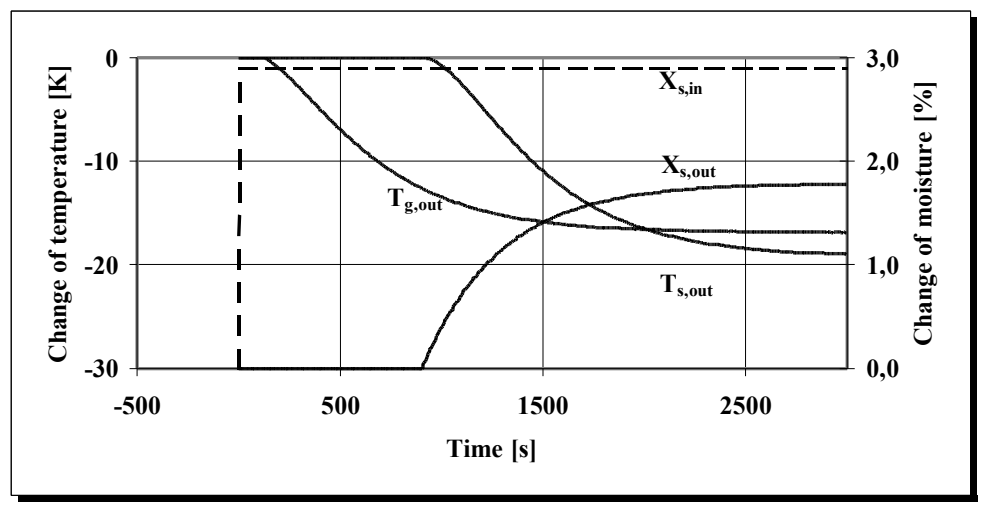

Fig. 11. Simulated output responses to a step change in the input moisture of solids from $2.4 \mathrm{~m}-\%$ to $5.3 \mathrm{~m}-\%$. 


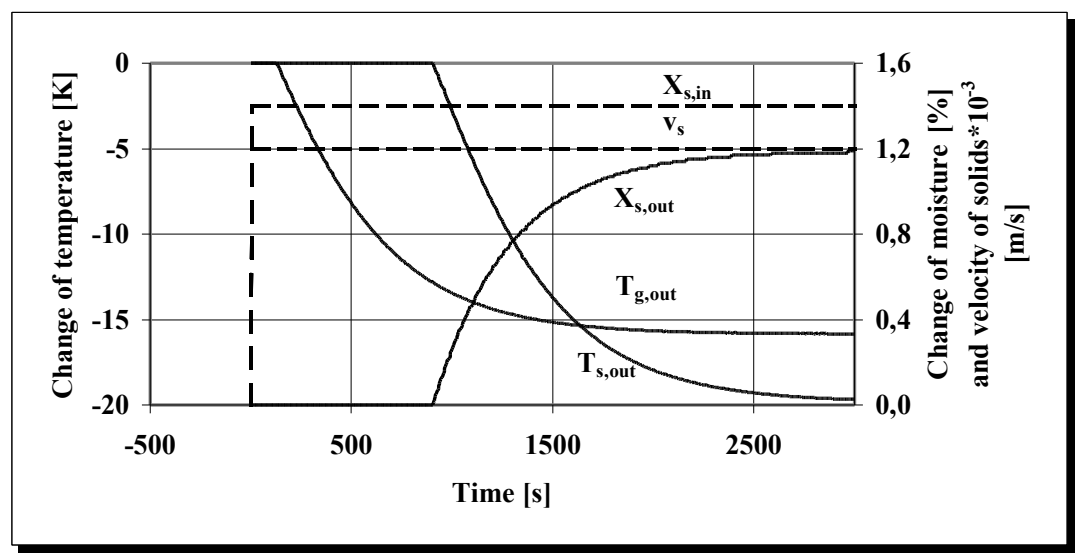

Fig. 12. Simulated output responses to a step change in the linear velocity of solids from $0.00478 \mathrm{~m} / \mathrm{s}$ to $0.00598 \mathrm{~m} / \mathrm{s}$ and in the initial moisture of solids from $2.2 \mathrm{~m}-\%$ to $3.6 \mathrm{~m}-\%$.

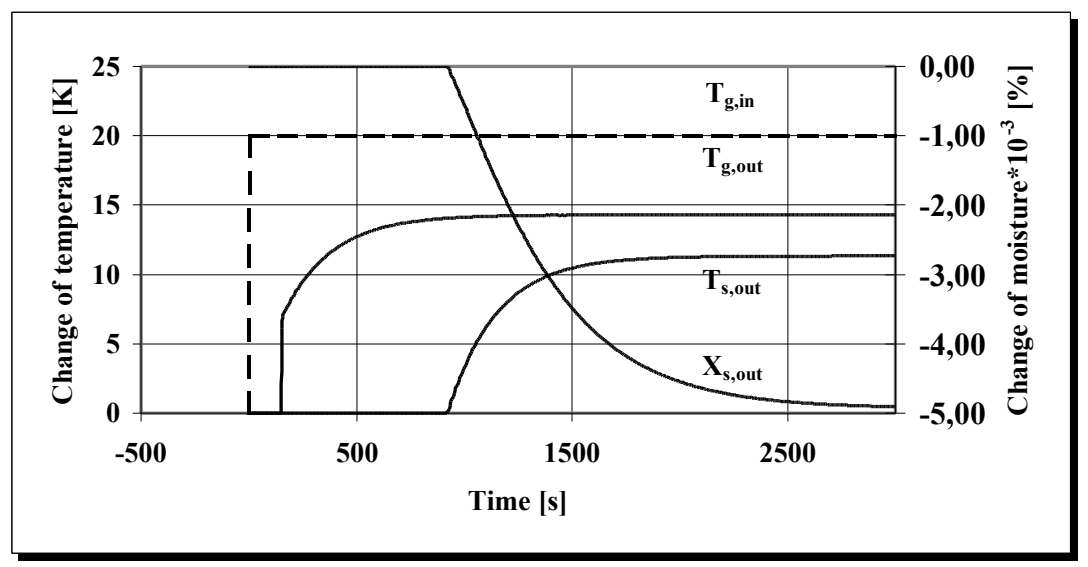

Fig. 13. Simulated output responses to a step change in the input temperature of the drying air from $463 \mathrm{~K}$ to $483 \mathrm{~K}$.

\subsubsection{Model experiments}

The experimental equipment used in this thesis, the pilot plant dryer, is described in Chapter 1. The moisture contents and temperatures of the calcite and drying air were measured at the inlet and outlet of the dryer. The open loop responses to step changes in the input variables are presented in Figures $14 \ldots 16$. 
(A) (B) (C) $\quad$ (D) (E)

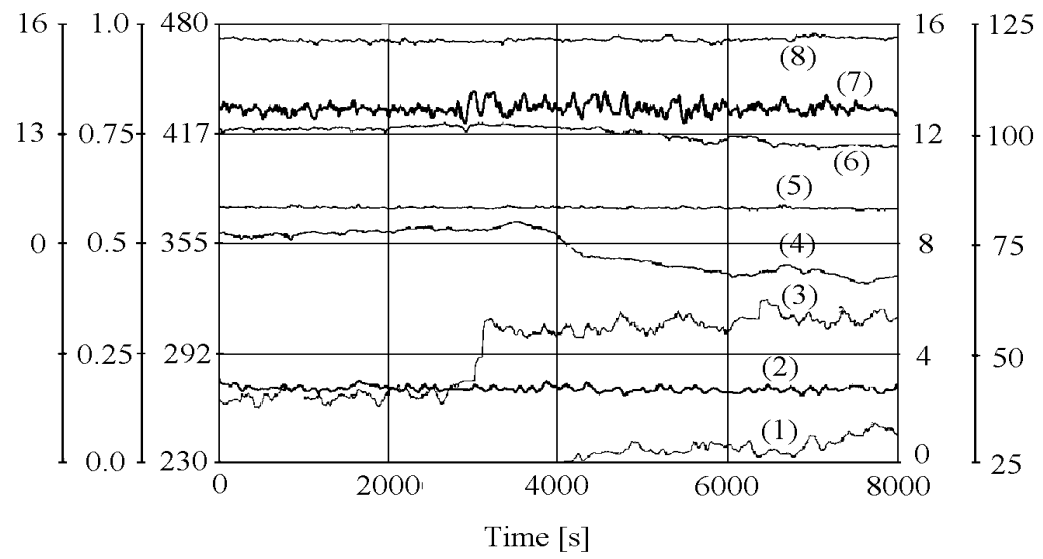

Fig. 14. Experimental responses to a step change in the initial moisture of solids.

The axes and responses in Figure 14 are denoted as follows:
(A)is the rotational speed of the drum $\left[1 / \mathrm{s}^{*} 10^{-3}\right]$,
(B) is the fuel flow $\left[\mathrm{kg} / \mathrm{s}^{*} 10^{-3}\right]$,
(C) is the temperature $[\mathrm{K}]$,
(D)is the moisture content of the solids [\%] ,
(E) is the feed flow $\left[\mathrm{kg} / \mathrm{s} * 10^{-3}\right]$

and

(1) is the output moisture content of the solids [\%],

(2) is the feed flow $\left[\mathrm{kg} / \mathrm{s}^{*} 10^{-3}\right]$,

(3) is the input moisture content of the solids [\%],

(4) is the output temperature of the solids $[\mathrm{K}]$,

(5) is the fuel flow $\left[\mathrm{kg} / \mathrm{s}^{*} 10^{-3}\right]$,

(6) is the output temperature of the drying air [K],

(7) is the rotational speed of the drum $\left[1 / \mathrm{s}^{*} 10^{-3}\right]$,

(8) is the input temperature of the drying air [K]. 
(A) (B) (C) (D) (E)

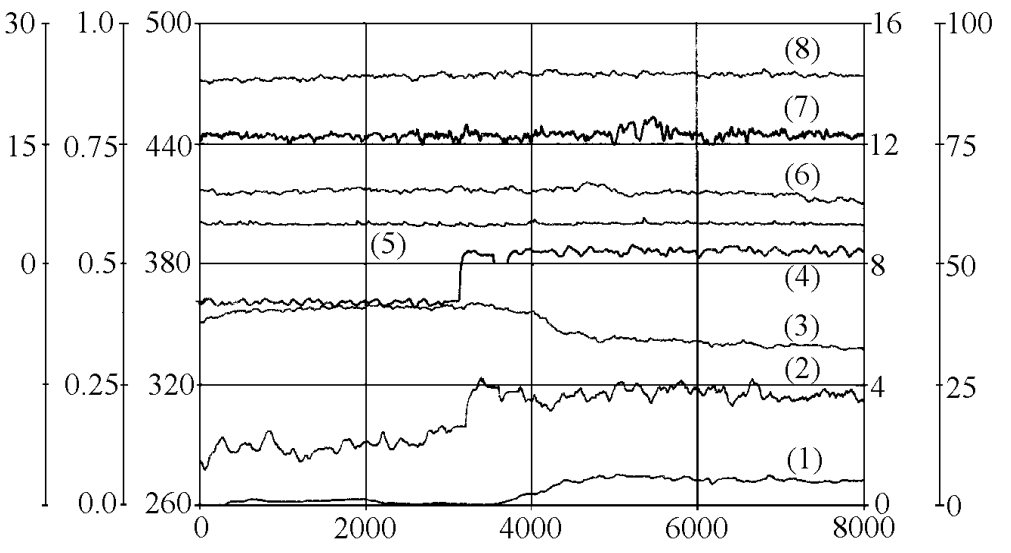

Time $[\mathrm{s}]$

Fig. 15. Experimental responses to simultaneous step changes in feed flow and moisture.

The axes and responses in Figure 15 are denoted as follows:

(A)is the rotational speed of the drum $\left[1 / \mathrm{s}^{*} 10^{-3}\right]$,

(B) is the fuel flow $\left[\mathrm{kg} / \mathrm{s} * 10^{-3}\right]$,

(C) is the temperature $[\mathrm{K}]$,

(D)is the moisture content of the solids [\%],

(E) is the feed flow $\left[\mathrm{kg} / \mathrm{s} * 10^{-3}\right]$

and

(1) is the output moisture content of the solids[\%],

(2) is the input moisture content of the solids [\%],

(3) is the output temperature of the solids [K],

(4) is the feed flow $\left[\mathrm{kg} / \mathrm{s}^{*} 10^{-3}\right]$,

(5) is the fuel flow $\left[\mathrm{kg} / \mathrm{s}^{*} 10^{-3}\right]$,

(6) is the output temperature of the drying air $[\mathrm{K}]$,

(7) is the rotational speed of the drum $\left[1 / \mathrm{s}^{*} 10^{-3]}\right.$,

(8) is the input temperature of the drying air [K]. 


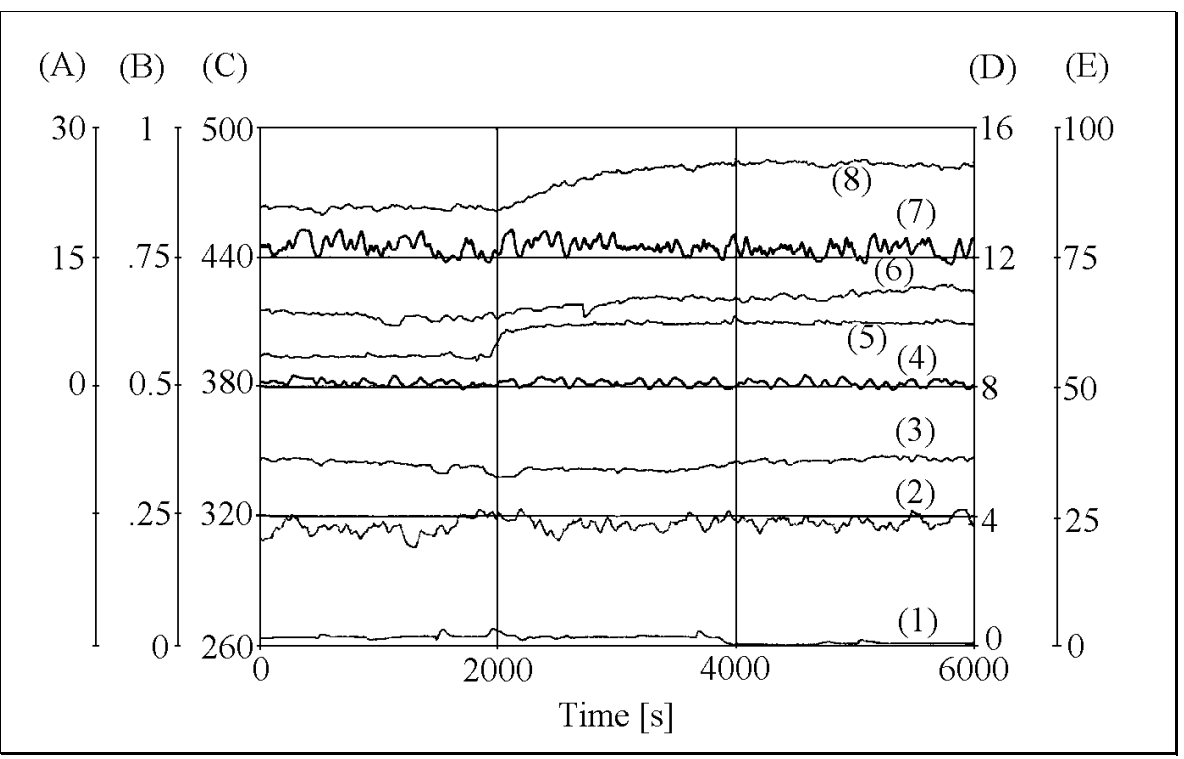

Fig.16. Experimental responses for a step change in fuel flow.

The axes and responses in Figure 16 are denoted as follows:

(A) is the rotational speed of the drum $\left[1 / \mathrm{s}^{*} 10^{-3}\right]$,

(B) is the fuel flow $\left[\mathrm{kg} / \mathrm{s}^{*} 10^{-3}\right]$

(C) is the temperature $[\mathrm{K}]$,

(D) is the moisture content of the solids [\%],

(E) is the feed flow $\left[\mathrm{kg} / \mathrm{s} * 10^{-3}\right]$

and

(1) is the output moisture content of the solids [\%],

(2) is the input moisture content of the solids [\%],

(3) is the output temperature of the solids $[\mathrm{K}]$,

(4) is the feed flow $\left[\mathrm{kg} / \mathrm{s} * 10^{-3}\right]$,

(5) is the fuel flow $\left[\mathrm{kg} / \mathrm{s}^{*} 10^{-3}\right]$,

(6) is the output temperature of the drying air [K],

(7) is the rotational speed of the drum $\left[1 / \mathrm{s}^{*} 10^{-3}\right]$,

(8) is the input temperature of the drying air $[\mathrm{K}]$.

The simulated and experimental output values for various variables are presented in Table 13. The results show that the model serves well to predict the performance of the pilot plant dryer. Only the first experimental and simulated values for the output moisture of the solids differ markedly, possibly due to the fact that the solids were 
overdried in this experiment before the step change in their input moisture content was made.

Table 13. Simulated and experimental values for the output variables after the step changes.

\begin{tabular}{lccc}
\hline Step change & $\begin{array}{c}\text { Solids moisture } \\
\%\end{array}$ & $\begin{array}{c}\text { Solids temperature } \\
\mathrm{K}\end{array}$ & $\begin{array}{c}\text { Air temperature } \\
\mathrm{K}\end{array}$ \\
\hline $\mathrm{X}_{\mathrm{s} \text {,in,exp }}$ & 1.2 & 346 & 410 \\
$\mathrm{X}_{\mathrm{s}, \text { in, simul }}$ & 1.8 & 341 & 404 \\
$\mathrm{X}_{\mathrm{s}, \text { in }}$ and $\mathrm{v}_{\mathrm{s} \text { exp }}$ & 1.1 & 341 & 408 \\
$\mathrm{X}_{\mathrm{s}, \text { in }}$ and $\mathrm{v}_{\mathrm{s}, \text { simul }}$ & 1.3 & 346 & 403 \\
$\mathrm{~T}_{\mathrm{g}, \text { in, exp }}$ & 0.2 & 352 & 423 \\
$\mathrm{~T}_{\mathrm{g}, \text { in, simul }}$ & 0.2 & 354 & 429 \\
\hline
\end{tabular}

A distributed parameter model for a rotary dryer was created based on mass, heat and momentum transfer equations. In order to perform steady state and dynamic simulations, the model was linearised in the neighbourhood of the operating point and applied to the pilot plant dryer. The model included parameters which were either determined experimentally or calculated from correlations presented in the literature. The drying rate and residence time of the solids were determined experimentally, while the volumetric heat transfer was assumed to be constant along the dryer and was determined from the correlation presented in the literature. It is highly probable, however, that it varies with the operating conditions prevailing in the rotary dryer, and should in effect increase with an increase in the air flow. On the other hand, an increase in the air flow rate reduces the residence time of the solids in the dryer, resulting in a reduction of the contact time between the air and solids, thereby opposing the beneficial effect of higher transfer coefficients.

The primary aim of developing the dynamic model and dynamic simulator was to optimise the operating conditions and to assess the design of various control strategies. A sensitivity analysis shows that the main variable that needs to be manipulated in order to control the output moisture content of the solids is the fuel flow, and that the main disturbance variable is the input moisture content. The feed flow can be used as an auxiliary variable to be manipulated, or else it can be a disturbance variable. The mathematical model developed in this thesis is shown by the simulated and experimental results to be successful in predicting the performance of the pilot plant dryer. The resulting model provides a good basis for developing and simulating advanced control strategies. 


\section{Control of a rotary dryer}

It is difficult to control a rotary dryer due to the long time delays involved. Accidental variations in the input moisture content, temperature or flow of the solids will disturb the process for long periods of time, until they are observed in the output variables, especially in the output moisture content. Therefore, pure feedback control is inadequate for keeping the most important variable to be controlled, the output moisture content of the solids, at its target value with acceptable variations. Increasing demands for uniform product quality and for economic and environmental aspects have necessitated improvements in dryer control. Interest has been shown in recent years in intelligent control systems based on expert systems, fuzzy logic or neural nets for eliminating process disturbances at an early stage. These systems add another dimension to the control of a drying process, the human element.

Little development work has been carried out to date on the control of rotary dryers, even though they have been used in industry for many decades. This may be because product quality was not appreciated in the past, because the significance of dryer control for product quality and dryer efficiency was not recognised or because no reliable method for the continuous measurement of moisture content was available. The complexity and highly non-linear dynamics of the drying process also makes it difficult to model a dryer.

The basic objectives for the development of dryer control are

- to maintain the desired product moisture content in spite of disturbances in drying operation,

- to maximise production with optimal energy use and at minimal costs so that the costs of investment in automation are reasonable compared with other equipment costs,

- to avoid overdrying, which increases energy costs and can cause thermal damage to heat-sensitive solids, and

- to stabilise the process. 


\subsection{Approaches to the control problem adopted in the literature}

Manual and automatic feedback systems were the most commonly used methods of dryer control until the advent of process computers in 1970's. In manual feedback control, which is the simplest form, an operator measures the moisture content at the exit from the dryer, mentally compares it with the desired value and adjusts the fuel flow. Automatic feedback control, which is still used in many older plants, is an improvement on manual feedback control in which the moisture content is measured and the fuel flow manipulated. The availability of process computers, better knowledge of dryer modelling and sensor technology have assisted in the development of combined feedforwardfeedback control and model-based control in the form of inferential control, internal model control and dynamic matrix control. Interest in developing control systems based on the operator's knowledge and historical data, e.g. expert systems, fuzzy logic and neural nets, has increased in recent years. The following review of the literature describes the development of rotary dryer control.

Perry (1963) investigated the instrumentation and control of a rotary dryer by distinguishing three kinds of measurement variables: conventional measurements such as the temperature of the drying gas, the pressure in the drum and the dew point of the flue gases, measurements required for product quality, such as the temperature and moisture content of the product, and measurements of the operating conditions, such as hold up, residence time and flow of the drying gas. The most common control loops are the control of fuel flow based on the input temperature of the drying gas, the control of flue gases based on the drum pressure. In the same year, Myklestad (1963b) used a static model to calculate the changes to be made to control variables such as the air flow, air temperature and feed flow in order to eliminate the effects of feed moisture disturbances on the product moisture content of a pumice dryer.

After the advent of process computers, Beck et al. (1971) used a computer to achieve smooth start up and safe shut down of a dryer, determining and simulating the control scheme on the basis of an experimental model with step tests and pseudo-random binary signals (PRBS). The paper describes the stages of the start up operations in detail, but does not include very much information on the control scheme and results. Control during normal operation was implemented by changing the fuel flow on the basis of the output temperature of the drying air.

Harbert $(1973,1974)$ suggested a temperature difference method for measuring and controlling the moisture content of the solids, on the principle that when hot air is used the temperature of the solids is lower than the dry bulb temperature of the drying air whereas when the solids are saturated their temperature reaches the dew point of the drying air. Moisture content increases as the solids temperature decreases. This method entails measuring the temperature of the solids and of the drying air. The difference between them correlates with the moisture content of the solids.

Shinskey (1974) presented various strategies for dryer control. Product moisture content is usually controlled through measurement of the output temperature of the drying air. This method is sensitive to changes in feed flow and fuel flow. According to Shinskey, it is important to limit the temperature of the drying gas, because there are solids which are sensitive to high temperatures to the extent of causing an explosion. One possible approach for avoiding this is to control the input temperature of the drying air by manipulating the fuel flow and keeping the output temperature of the drying air constant by adjusting the feed flow. This control system would maximise production, but it is 
dependent on reliable feed supply. Wright (1976) used a continuous infrared moisture analyser to measure the input and output moisture content of the solids and used the results to control the product moisture content via the feed flow or fuel flow.

Mann (1980) developed various control systems for a sugar beet dryer based on an experimentally identified linear, time-invariant process model. The algorithms for a multi-cascaded control system were designed on the basis of this model, and simulated control results were compared with those achieved with optimal feedback control. Even though the latter gave better control performance, the multi-cascaded control system based on identification of the drying process proved quite successful in industrial applications.

Pietranski et al. (1982) developed a hierarchical control system for a rotary dryer, with the aim of finding operating conditions that would minimise energy consumption. The system consisted of an expert system supervising a fuzzy logic controller which acted as the master element in a cascaded control system. The structure of the system is described in Figure 17. The proposed control system was tested with simulations for stepwise changes in fuel flow and air flow.

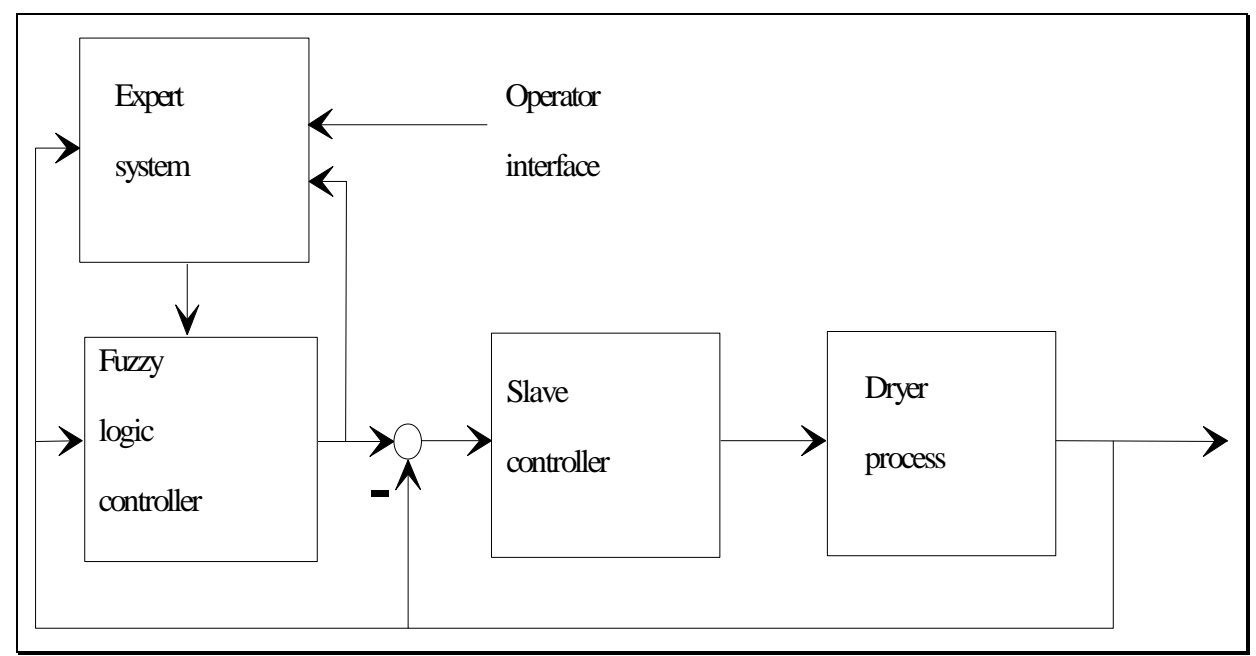

Fig. 17. Expert fuzzy-crisp dryer control (Pietranski et al. 1982).

Najim (1989) evaluated a learning system for controlling fuel flow, with the aim of maintaining the desired phosphate moisture content. The primary control variable was fuel flow and the auxiliary variable the rotation speed of the screw conveyor, which correlated with feed flow.

Robinson (1989a) proposed an inferential control strategy, which is an early modelbased approach and is useful if the moisture content cannot be measured directly. Inferential control uses the temperatures of the drying air and the solids together with a process model to determine the moisture content of the solids. Robinson (1989b, 1992) also developed a temperature-drop control for continuous, convective dryers based on a 
model in which the product moisture content is related to the drop in the temperature of the drying air during drying and to the dryer speed or feed flow, according to the equation

$$
\mathrm{X}_{\mathrm{s}, \text { out }}=\mathrm{K}_{1}(\mathrm{dT})^{\mathrm{q}}-\mathrm{K}_{2} / \mathrm{S}^{\mathrm{p}} \text {, }
$$

where $\mathrm{K}_{1}, \mathrm{~K}_{2}$, $\mathrm{q}$ and $\mathrm{p}$ are constants which are specific to a given product and dryer and $\mathrm{S}$ is the production rate. This implies that it is possible to determine the moisture content of the solids at any point inside a drum by measuring two temperatures, the temperature difference acting as a control variable. The model replaces all the variables affecting drying and the drying rate with a single variable, the temperature difference.

Douglas et al. (1992) used two PI controllers, one for the air flow and the other for the rotational speed of the dryer, i. e. controlling the drying time in order to achieve the desired product moisture content.

Duchesne et al. (1997b) developed and compared five control systems for a concurrent rotary dryer which also incorporated intelligent control methods. The simplest strategy consisted of two feedback loops with PI controllers. The first loop manipulated the fuel flow and kept the output moisture content of the solids at the desired level, and the second manipulated the secondary air flow and kept the output temperature of drying gas at the desired level. The optimal parameters for the PI controllers were determined by minimisation of the cost function, which included the terms of the sum of squares of the normalised deviations of the output moisture content of the solids and the output temperature of the drying gas, and also the term intended to prevent excessive variations in fuel flow. The second control loop was identical in structure to this but with the addition of a feedforward action based on a phenomenological model, and the remaining three used neural network models: a steady state neural model, a dynamic neural model and a combined PI and neural approach. The data for the neural models were generated with the process simulator developed by Duchesne et al. (1996). The steady state neural model comprising five input neurones with bias, five hidden neurones with bias and two output neurones acted as an open loop feedforward controller, to which an integrator was added to compensate for modelling errors and unexpected disturbances. The dynamic neural network model used dynamic data consisting of 13 input neurones with bias, five hidden neurones and two output neurones and was used as a one-step ahead predictor to calculate the values of the controlled variables at the next sampling instants. As the dynamics of solids moisture content are much slower than the dynamics of the drying gas, a hybrid controller was developed in which the output moisture of the solids was controlled using a dynamic neural model with one output and the drying gas temperature with a PI feedback controller. The systems were compared by means of a simulator based on a non-linear model of an industrial dryer and calculation of various performance indices. The results showed that the conventional control strategy with a feedforward action gave the best results provided that the input moisture content of the solids could be measured reliably. Where measurement was not possible, the best control system was a hybrid strategy in which a neural network controller manipulated the fuel flow in order to control the output moisture content of the solids and a PI controller manipulated the secondary air flow to control the output temperature of the drying gas. 


\subsection{Mill surveys}

Data for the design of automation for the pilot plant rotary dryer were collected from 40 rotary dryers used in the Finnish mining and mineral industries in the early 1980's. $50 \%$ of these were used for drying ore concentrates, $20 \%$ for drying fertilisers and $30 \%$ for drying sand. Data were collected on the structure, instrumentation and degree of automation of the dryers. Detailed results were reported by Yliniemi et al. (1980), who showed that rotary dryers were mainly con-current dryers with a very low degree of automation. The instrumentation was based on analogue technology, and only in one plant was a digital instrumentation system. The most common control system consisted of the control of fuel flow based on feed flow or the input or output temperature of the drying air. Control of the drying air flow was based on the temperature in the combustion chamber and control of the flue gases on the drum pressure. The control system of the Vuonos plant at Outokumpu, representing the most common scheme used in the Finnish mineral and mining industries in the 1980's, is illustrated in Figure 18.

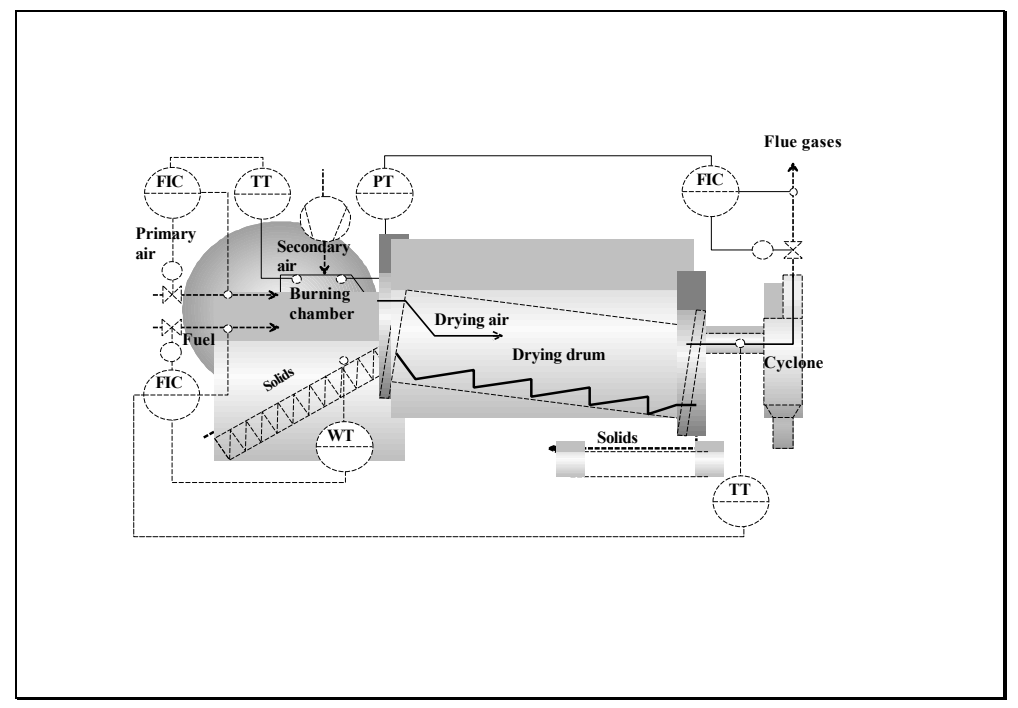

Fig. 18. Control scheme for the Vuonos plant at Outokumpu, representing the most common control system used in Finland in the 1980's.

A new inquiry carried out in January 1999 showed the greatest change in the control of rotary dryers to have been the changeover to digital instrumentation systems. Otherwise the main control loops based on conventional closed-loop PI algorithms were same as in the early 1980's. The inquiry also showed that industry is interested in developing its existing dryer control systems in order to improve dryer performance, even though one operator said "Our rotary dryer operates like the closet on a train". This reflects how reliable rotary dryers are in operation. 
Closed-loop manual or automatic feedback is still used for controlling product moisture content in older rotary dryers, despite of its inadequate performance in compensating for disturbances in input moisture content, temperature or flow of the solids. This is due to the long residence time of solids in a dryer. To overcome this problem, a predictive approach involving feedforward control combined with PI control can be used. The effectiveness of feedforward-feedback control depends on the accuracy of the system's model for predicting the response of the process to input and disturbance changes. As mathematical dryer models are generally complex and are laborious to develop, the idea of utilising the operator's experience and knowledge and historical data has increased interest in developing intelligent control systems in which conventional PI controllers are supervised by expert systems, fuzzy logic and neural nets. 


\section{Conventional control of the pilot plant rotary dryer}

\subsection{Feedback control}

A simple closed-loop feedback system based on the error between a set point value and the output moisture content of the solids measured by an infrared analyser was employed to control the output moisture content of the solids in the pilot plant dryer. The fuel flow was manipulated by reference to a general two-action PI controller (Ogata 1997)

$$
u(t)=K_{p} e(t)+\frac{K_{p}}{T_{i}} \int_{0}^{t} e(t) d t
$$

where $u(t)$ is the output from the controller, $e(t)$ is the error signal, $K_{p}$ is the proportional gain, and $\mathrm{T}_{\mathrm{i}}$ is the integral time. The corresponding digital PI algorithm in velocity form is

$$
? \mathrm{u}(\mathrm{k})=\mathrm{K}_{\mathrm{p}}\left\{\mathrm{e}(\mathrm{k})-\mathrm{e}(\mathrm{k}-1)+\frac{? \mathrm{~T}}{\mathrm{~T}_{\mathrm{i}}} \mathrm{e}(\mathrm{k})\right\}
$$

where

$$
\Delta \mathrm{u}(\mathrm{k})=\mathrm{u}(\mathrm{k})-\mathrm{u}(\mathrm{k}-1)
$$

and $\Delta \mathrm{T}$ is the sampling time. The optimal parameters for the PI controller were determined experimentally based on open loop step responses, with the aim of achieving a response in the output moisture content of the solids in which no effect of disturbances in the input variables could be observed.

The behaviour of the output moisture content and temperature of the solids in response to a step change in input moisture content is presented in Figure 19. This points 
to a notable increase in product moisture content and a decrease in product temperature after the residence time of the solids before the increase in fuel flow begins to influence the output variables. Feedback control causes oscillation, and the settling time before the set point product moisture content can be achieved is long. The control result can be assumed to be similar if a change in feed flow occurs, because the change in fuel flow is based on a calculation arising from the same control algorithm and on direct measurements.

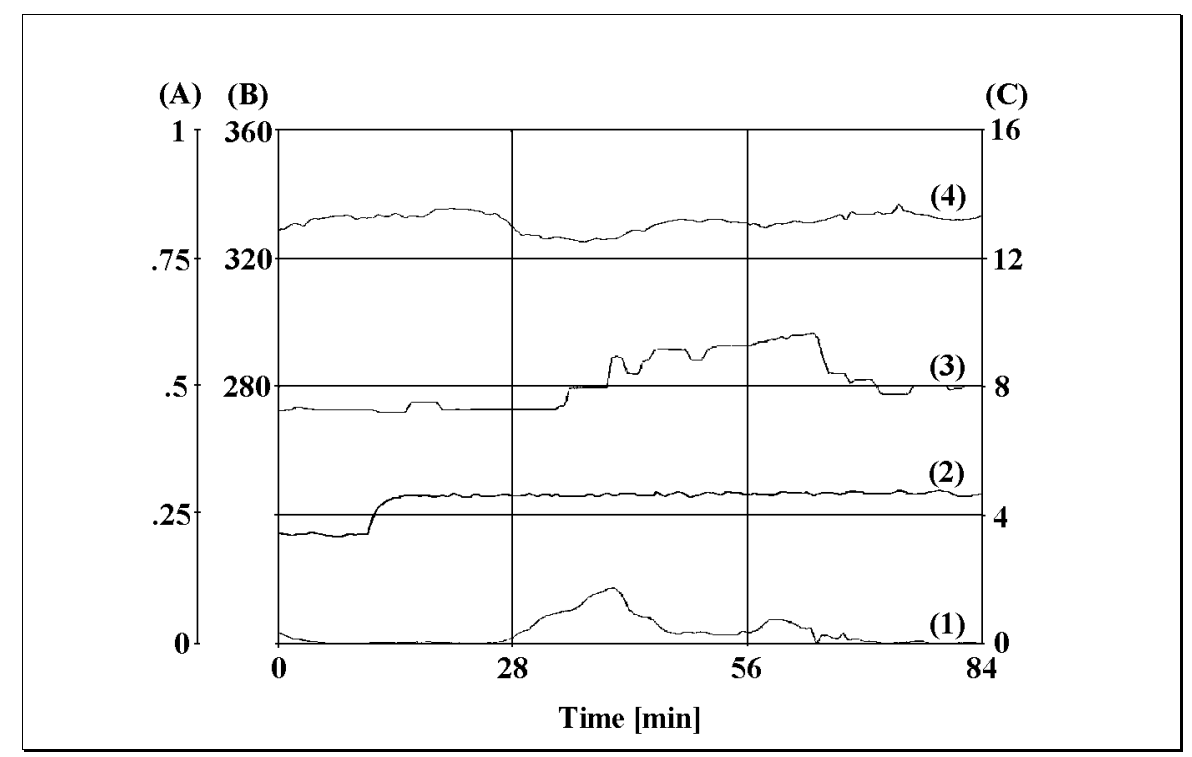

Fig. 19. Rotary dryer control achieved by the feedback PI approach.

The axes and responses are denoted as follows:
(A) is the fuel flow $\left[\mathrm{kg} / \mathrm{s} * 10^{-3}\right]$,
(B) is the temperature $[\mathrm{K}]$,
(C) is the moisture content of the solids [\%],

and

(1) is the output moisture content of the solids [\%],

(2) is the input moisture content of the solids [\%],

(3) is the fuel flow $\left[\mathrm{kg} / \mathrm{s} * 10^{-3}\right]$,

(4) is the output temperature of the solids [K].

This feedback control is used as basis when comparing the results achieved by more sophisticated methods, as the feedback control is still in use in many existing plants. 
There are probably no new dryers with only feedback control, however, on account of cost and quality requirements.

\subsection{Combined feedforward-feedback control}

In order to improve the control of a rotary dryer, disturbances in the input variables should be eliminated before they can be observed in the output variables. This can be done by adopting a predictive approach such as feedforward control. The feedforward controller requires a model from which the change to be made to the variable that needs to be manipulated can be calculated when disturbances occur. The function of the feedback element in the combined feedforward-feedback control strategy is to correct the action of the feedforward controller with reference to measurement and model inaccuracies. The structure of a feedforward-feedback control system which includes residence time control ispresented in Figure 20 .

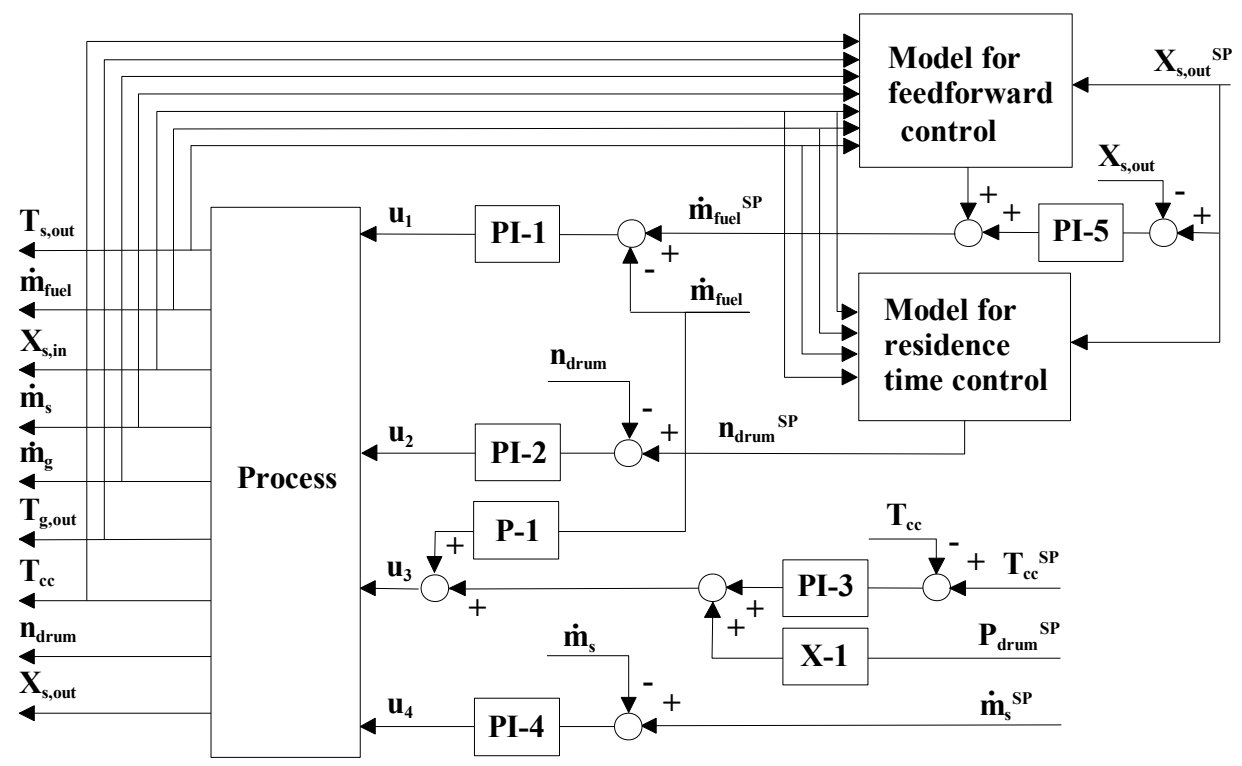

Fig. 20. Combined feedforward-feedback control system for the pilot plant dryer with residence time control.

The control strategy includes loops for fuel flow (PI-1, PI-5), residence time (rotational speed of the drum) (PI-2), drying air flow (P-1, PI-3, X-1) and mass flow (rotational speed of the screw conveyor) (PI-4). The P and PI controllers were tuned experimentally based on open loop step responses. The interval for the basic control loops is 20 seconds, that for the feedforward loop 8 minutes and that for the feedback 
loop 4 minutes. When residence time control is used, the corresponding intervals are $\tau / 3$ and $\tau / 6$, where $\tau$ is the residence time determined from the model equation (30).

When implementing the feedforward-feedback controller in the pilot plant dryer the model for its feedforward part, which is based on that developed in Chapter 3, is simplified by assuming that the enthalpy needed for drying can be calculated from the total energy balance, provided that the experimentally determined heat losses from the drum and combustion chamber are also taken into account. The heat required for drying the solids is calculated from the equation

$$
\Delta \mathrm{H}_{\text {fuel }}=? \mathrm{H}_{\mathrm{s}}+? \mathrm{H}_{\text {air }}+\mathrm{F} \text {, }
$$

where $\Delta \mathrm{H}_{\text {fuel }}$ describes the heat released in combustion, $\Delta \mathrm{H}_{\mathrm{s}}$ is the enthalpy change in the solids during drying, $\Delta \mathrm{H}_{\text {air }}$ is the enthalpy change in the air during drying and $\Phi$ are the heat losses in the drum and combustion chamber. The enthalpy $\Delta \mathrm{H}_{\text {fuel }}=\Delta \mathrm{H}_{\mathrm{ff}}$ is used in the feedforward controller.

The model equations for the feedforward controller may be grouped into two parts: those describing the change in enthalpy resulting from the state of the process, i.e. the change in enthalpy of the air and solids during drying, and those describing the change in enthalpy resulting from the vaporisation of water. The latter part of the model is emphasised by a gain factor used for calculating the set point for the fuel flow in the feedforward controller. The feedback element corrects this set point by reference to the continuous measurements of product moisture. To ensure that this correction takes place in the right direction in every situation, it is calculated from the equation

$$
? \mathrm{H}_{\mathrm{fb}}=\dot{\mathrm{m}}_{\mathrm{s}}\left(\mathrm{X}_{\mathrm{s}, \text { out }}^{\mathrm{sP}}-\mathrm{X}_{\mathrm{s}, \text { out }}\right)\left\{\mathrm{C}_{\mathrm{s}}\left(\mathrm{T}_{\mathrm{g}, \text { out }}-\mathrm{T}_{\mathrm{ref})}+?\right\}\right. \text {. }
$$

Combining the enthalpies calculated from the feedforward and feedback parts, the target value for the total enthalpy needed in drying is

$$
? \mathrm{H}=\mathrm{K}_{\mathrm{ff}} * ? \mathrm{H}_{\mathrm{ff}}+\mathrm{K}_{\mathrm{fb}} * ? \mathrm{H}_{\mathrm{fb}}
$$

and the set point for the fuel flow is

$$
\dot{\mathrm{m}}_{\text {fuel }} \mathrm{sP}=\frac{? \mathrm{H}}{\mathrm{HV}_{\text {fuel }}},
$$

where $\mathrm{HV}_{\text {fuel }}$ is the heating value of the fuel and the coefficients $\mathrm{K}_{\mathrm{ff}}$ and $\mathrm{K}_{\mathrm{fb}}$ are determined experimentally. The coefficient $\mathrm{K}_{\mathrm{ff}}$ corrects the model and measurement inaccuracies in the feedforward controller, and $\mathrm{K}_{\mathrm{fb}}$ is the gain in the PI controller (PI-5), where $\Delta \mathrm{H}_{\mathrm{fb}}$ is used as the error variable.

If the aim is to dry the solids to zero moisture content, one of the basic objectives of dryer control will be to eliminate overdrying, which will result in increased energy costs. Overdrying can also cause thermal damage to heat-sensitive solids. It is thus important to include supervision of the temperatures of the solids and the drying air in the control system. If the maximum output temperature of the drying air is exceeded, the secondary air flow is increased. If this is not enough, then the feed flow is reduced. If the maximum 
solids temperature is exceeded, the set point for fuel flow in the feedforward controller is reduced.

In this work residence time control is included in the feedforward-feedback control system and the rotational speed of the drum acts as an auxiliary manipulated variable in the control strategy. The model for determining the set point for the residence time of the solids is calculated from the equation

$$
\mathrm{t}^{\mathrm{SP}}=\frac{\left(\mathrm{X}_{\mathrm{s}, \text { in }}-\mathrm{X}_{\mathrm{s}, \text { out }}^{\mathrm{SP}}\right)}{\mathrm{k}_{\mathrm{v}} \mathrm{T}_{\mathrm{s}, \text { out }} \dot{\mathrm{m}}_{\text {fuel }}} * \dot{\mathrm{m}}_{\mathrm{s}},
$$

where the experimental constant $\mathrm{k}_{\mathrm{v}}$ describing the drying efficiency is determined experimentally and updated during the operation.

The behaviour of the control strategy described above was tested for a step change in the feed flow, the responses of the controlled and manipulated variables achieved with combined feedforward-feedback control being those presented in Figure 21.

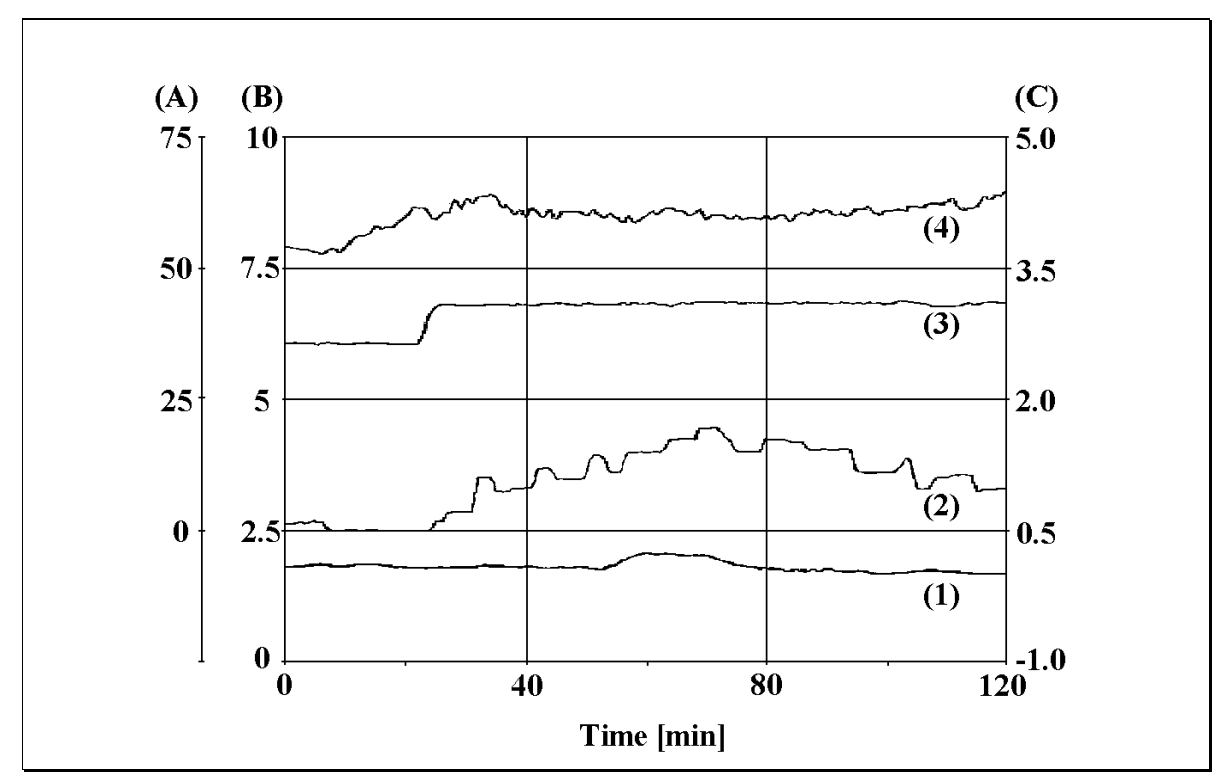

Fig. 21. Rotary dryer control achieved with the combined feedforward-feedback approach in the case of a step change in feed flow.

The axes and responses are denoted as follows:
(A) is the feed flow $\left[\mathrm{kg} / \mathrm{s} * 10^{-3}\right]$
(B) is the fuel flow $\left[\mathrm{kg} / \mathrm{s}^{*} 10^{-4}\right]$
(C) is the moisture content of the solids (\%) 
and

(1) is the output moisture content of the solids [\%],

(2) is the fuel flow $\left[\mathrm{kg} / \mathrm{s} * 10^{-4}\right]$,

(3) is the feed flow $\left[\mathrm{kg} / \mathrm{s}^{*} 10^{-3}\right]$,

(4) is the input moisture content of the solids [\%].

As shown in Figure 21, the fuel flow increases very rapidly after a step change caused by the feedforward controller. A small disturbance in product moisture content can be observed, but this is eliminated by the feedback controller. The result is similar if a change occurs in the input moisture content of the solids, as the calculation of fuel flow is based on the same measurements and the same model.

The behaviour of the control system when the rotational speed of the drum acts as the auxiliary variable to be manipulated is described in Figures 22 and 23. The several step changes were made both to the feed moisture content and feed flow during the same experiments in order to examine how the different control loops operate in disturbance situations.

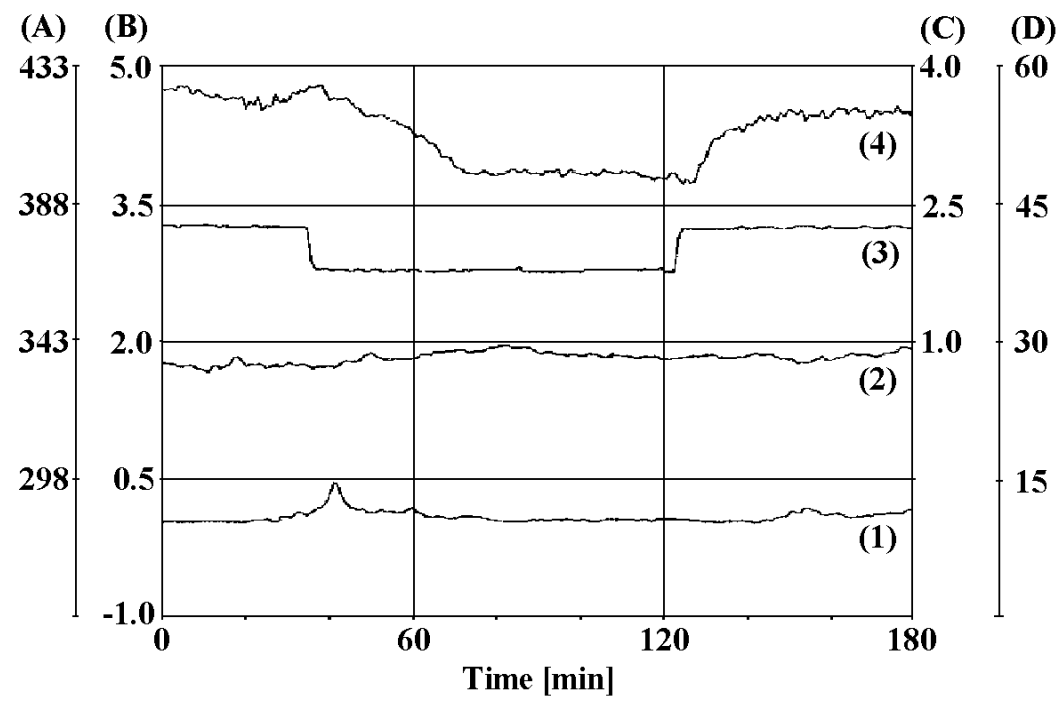

Fig. 22. Behaviour of the output variables achieved with feedforward-feedback and residence time control

The axes and responses are denoted as follows:

(A) is the temperature [K]

(B) is the moisturecontent of the solids [\%]. 
(C) is the fuel flow $\left[\mathrm{kg} / \mathrm{s}^{*} 10^{-3}\right]$

(D) is the feed flow $\left[\mathrm{kg} / \mathrm{s}^{*} 10^{-3}\right]$

and

(1) is the output moisture content of the solids [\%],

(2) is the output temperature of the solids $[\mathrm{K}]$,

(3) is the feed flow $\left[\mathrm{kg} / \mathrm{s} * 10^{-3}\right]$,

(4) is the input moisture content of the solids [\%].

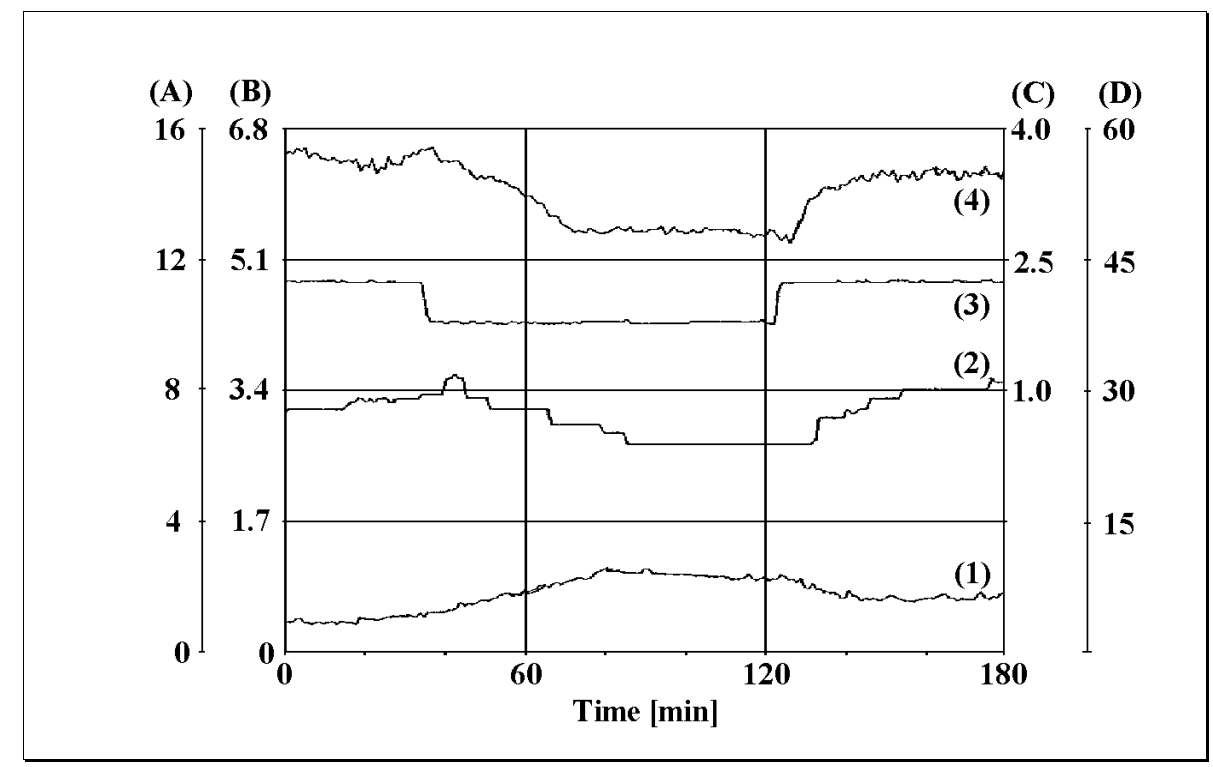

Fig. 23. Behaviour of the manipulated variables achieved with feedforward-feedback and residence time control.

The axes and responses are denoted as follows:
(A) is the rotational speed of the drum [1r/min]
(B) is the fuel flow $\left[\mathrm{kg} / \mathrm{s} * 10^{-3}\right]$
(D) is the moisture of the solids [\%]
(D) is the feed flow $\left[\mathrm{kg} / \mathrm{s} * 10^{-3}\right]$

and

(1) is the rotational speed of the drum [1/min]

(2) is the fuel flow $\left[\mathrm{kg} / \mathrm{s}^{*} 10^{-3}\right]$,

(3) is the feed flow $\left[\mathrm{kg} / \mathrm{s} * 10^{-3}\right]$, 
(4) is the input moisture content of the solids [\%].

As the responses of the output moisture content and temperature of the solids show, the control system works well. Disturbances in feed flow and feed moisture content can be eliminated from the output moisture content of the solids. The residence time control ensures that the product temperature is below the maximum all the time and overdrying does not occur.

Pure feedback PI control is unable to eliminate disturbances arising from the input moisture content of the solids, which can then be observed in the output moisture content once the residence time has elapsed. By adding a feedforward controller to determine the change in fuel flow immediately after the disturbance, the control performance can be greatly improved. It is evident that the effectiveness of the feedforward controller depends on the accuracy of the process model. The best result is achieved when residence time control is included in the system, particularly when the solids are dried to zero moisture content. In this case overdrying can be eliminated very efficiently. 


\section{Development of a fuzzy logic controller (FLC) for the pilot plant dryer}

Fuzzy logic is based on a mathematical theory developed by Zadeh in 1965. Initially the theory remained unnoticed, until Mamdani and his colleagues implemented the first control system based on fuzzy rules in a laboratory-scale steam engine in the 1970s. The first notable industrial application of the technique was developed for controlling a cement kiln in 1976, and since that time fuzzy logic has been applied to numerous control problems ranging from very small home appliances to large-scale process control systems.

Fuzzy logic is particularly suitable for process control if no model exists for the process or it is too complicated to handle or highly non-linear and sensitive in the operation region. As conventional control methods are in most cases inadequate for complex industrial processes such as rotary dryers, fuzzy logic is one of the most promising control approaches, especially as an add-on to conventional technology in hybrid control architectures. The main advantage is the possibility for utilising the operator's experience and knowledge in the controller in linguistic form. The arguments for using fuzzy logic for control purposes are set out in Figure 24.
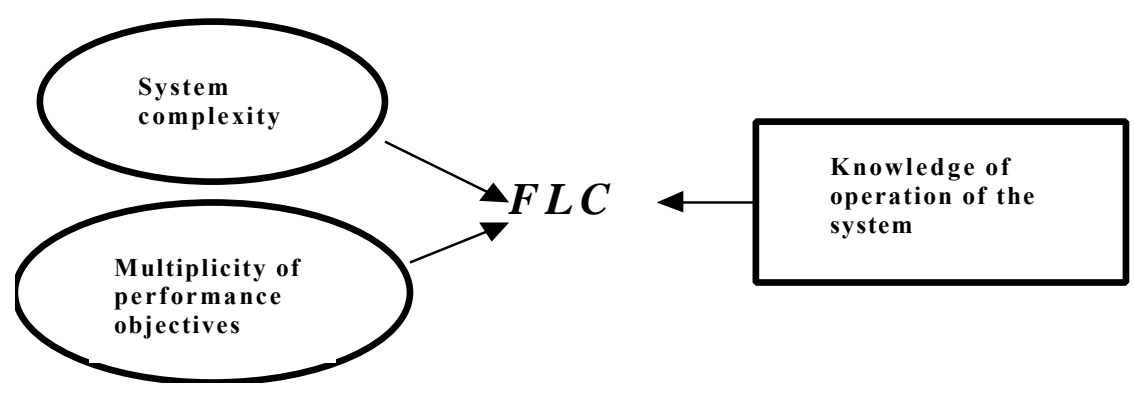

Fig. 24. Reasons for using fuzzy control (Langari \& Yen 1995). 
In view of the vast literature on fuzzy logic and its applications, only its fundamentals will be presented here, based on the book of Driankov et al. (1993) and the paper of Lee (1990) (see Appendix 4).

\subsection{Design and implementation of a fuzzy logic controller}

The basic configuration of a fuzzy logic controller consists of four principal components: a fuzzifier, a knowledge base (KB), including a data base and rule base, a decision maker, and a defuzzifier, as illustrated in Figure 25 (Lee 1990).

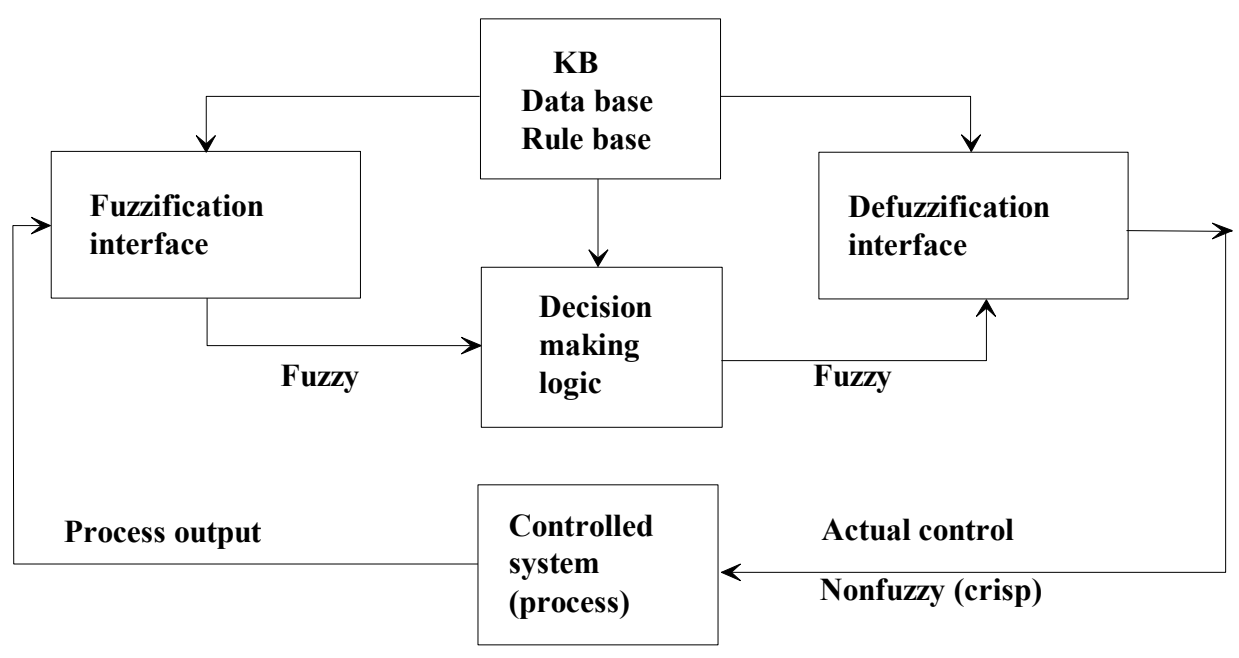

Fig. 25. Basic configuration of a fuzzy logic controller (FLC.)

The fuzzifier, or fuzzification interface, receives the measurements of the real-time input variables and transforms them by means of stored membership functions (MFs) into fuzzy input values in the corresponding universes of discourse. Each input has at least one suitable linguistic value or label in a fuzzy set, and each membership function determines the range of input data which corresponds to a label. The knowledge base includes a database providing the necessary definitions, such as membership functions, and a fuzzy control rule base characterising the goals of the control by means of linguistic rules. The decision maker evaluates all the applicable rules by checking whether their premises are true, and derives a truth value for the results. Finally, the defuzzifier, or defuzzification interface, converts the range of values for the output variables into the corresponding universes of discourse and produces a non-fuzzy or crisp control action from the inferred fuzzy action. The commonly used defuzzification methods are the max 
criterion, the mean of the maximum and the centre of area (COA), of which COA is the most common in control applications.

To achieve good control, the procedure proposed by Manikopoulos et al. (1995) was applied to the design of the FLC for the pilot plant dryer. The steps are the following:

Step 1: Definition of system functional requirements. In the light of the control investigations presented in Chapter 5, the conventional feedback PI approach is not satisfactory for controlling product moisture content in a rotary dryer, on account of the long delay time. Combined feedforward-feedback control gives better control performance, but it is difficult and time-consuming to develop an accurate model for the feedforward controller due to the complexity of the drying process. The aim of the FLC is to improve dryer control by converting the operator's experience and knowledge into a form of automatic control. The FLC can be a direct fuzzy controller or it can be part of a hybrid solution together with a conventional PID controller.

Step 2: Definition of system parameters. As a result of the sensitivity analysis based on the model simulations and pilot plant experiments, as presented in Chapter 3, the main controlled variable is known to be the output moisture content of the solid material and the main variable to be manipulated is the fuel flow, with the feed flow an auxiliary variable. The main sources of disturbances are feed moisture content and feed flow.

Step 3: Definition of system parameters in terms of fuzzy sets. The control performance of the FLC with different structures was studied here by means of both simulations and pilot plant experiments. The following input and output variables were used

\section{Simulation case:}

For direct FLC: (see Figure 28)

Inputs

- Error in the output moisture content of the solids, $\mathrm{e}_{\mathrm{k}}$ (Input1)

- Change in error $\Delta \mathrm{e}_{\mathrm{k}}$ (Input2)

Outputs

- Fuel flow (Output1)

- Change in feed flow (Output2)

For the hybrid controller: (see Figure 29)

Inputs

- Error in the output moisture content of the solids, $\mathrm{e}_{\mathrm{k}}$ (Input1)

- Change in error $\Delta \mathrm{e}_{\mathrm{k}}$ (Input2)

- $\quad$ Sum of errors $\delta e_{k}$ (Input3)

\section{Outputs}


- Fuel flow (Output1)

- Change in feed flow (Output2)

\section{Experimental case : (see Figure 35)}

\section{Inputs}

Output

- Error in the output moisture content of the solids, $\mathrm{e}_{\mathrm{k}}$ (INPUT1)

- Input moisture content of the solids (INPUT2)

- Input temperature of the drying air (INPUT3)

- $\quad$ Change in fuel flow (OUTPUT)

where

$$
\mathrm{e}_{\mathrm{k}}=\mathrm{X}_{\mathrm{s} \text {, out }}^{\mathrm{sP}}-\mathrm{X}_{\mathrm{s} \text {,out }}
$$

and

$$
\mathrm{de}_{\mathrm{k}}=\mathrm{S}_{\mathrm{i}=1}^{\mathrm{k}-1} \mathrm{e}_{\mathrm{i}}
$$

For fuzzification, the input and output variables of the FLC are divided into the following fuzzy classes:

$\begin{array}{ll}\text { NB } & \text { negative big } \\ \mathrm{N} & \text { negative } \\ \mathrm{NS} & \text { negative small } \\ \mathrm{NVS} & \text { negative very small } \\ \text { ZO } & \text { zero } \\ \mathrm{PVS} & \text { positive very small } \\ \mathrm{PS} & \text { positive small } \\ \mathrm{P} & \text { positive } \\ \mathrm{PB} & \text { positive big } \\ \mathrm{L} & \text { low } \\ \mathrm{M} & \text { medium } \\ \mathrm{H} & \text { high } \\ \mathrm{VS} & \text { very small } \\ \mathrm{S} & \text { small } \\ \mathrm{B} & \text { big } \\ \text { VB } & \text { very big. }\end{array}$

Both trapezoidal and bell-shaped membership functions (MFs) are used for variables. The min-max fuzzy inference method is used for fuzzification. 
Step 4: Formulation of control rules. It is stated in the literature that it is better to select a rather small rule base for the FLC, to make the tuning procedure easier, especially when implementing the first fuzzy logic solution for an application (von Altrock 1994). An attempt is similarly made here to keep the number of both MFs and control rules as low as possible. The control rule base is of the form:

\section{Simulation case:}

For direct FLC:

IF Input1 is $\{\mathrm{PB}, \mathrm{P}, \mathrm{PS}, \mathrm{PVS}, \mathrm{ZO}, \mathrm{NVS}, \mathrm{NS}, \mathrm{N}, \mathrm{NB}\}$ AND Input 2 is $\{\mathrm{P}, \mathrm{ZO}, \mathrm{N}\}$ THEN Output1 is $\{\mathrm{H}, \mathrm{M}, \mathrm{L}\}$.

For the hybrid controller:

IF Input1 is $\{\mathrm{PB}, \mathrm{B}, \mathrm{ZO}, \mathrm{N}, \mathrm{NB}\}$ AND Input2 is $\{\mathrm{P}, \mathrm{ZO}, \mathrm{N}\}$ AND Input3 is $\{\mathrm{B}, \mathrm{ZO}, \mathrm{S}\}$ THEN Output1 is $\{\mathrm{H}, \mathrm{M}, \mathrm{L}\}$ AND Output2 is $\{\mathrm{B}, \mathrm{ZO}, \mathrm{S}\}$.

The number of control rules is 27 for the direct FLC and 45 for the hybrid controller.

\section{Experimental case:}

IF INPUT1 is $\{\mathrm{P}, \mathrm{ZO}, \mathrm{N}\}$ AND INPUT2 is $\{\mathrm{H}, \mathrm{M}, \mathrm{L}\}$ AND INPUT3 is $\{\mathrm{H}, \mathrm{G}, \mathrm{L}\}$ THEN OUTPUT is $\{\mathrm{VB}, \mathrm{B}, \mathrm{ZO}, \mathrm{S}, \mathrm{VS}\}$. The number of control rules is 27.

Step 5: Selection of defuzzification method. Various defuzzification methods exist, and the choice depends greatly on the kind of application involved. There is no mathematical way of proving the correctness of a certain method. The centre of area method (COA) is commonly used in control applications, and it is used here to transform the outputs of the fired rules into crisp outputs for controlling the fuel flow valve and the rotational speed of the screw conveyor, which correlates with the feed flow.

Step 6: Running of simulations. Simulations were carried out to test whether satisfactory control performance could be achieved using both direct FLC and a hybrid controller. The control systems were implemented with Simulink ${ }^{\circledR}$ and the fuzzy logic controller with the Matlab Fuzzy Logic Toolbox ${ }^{\circledR}$. The FuzzyCon and FuzzyTune tools (Myllyneva \& Juuso 1995) were used for preliminary testing of the FLC.

Step 7: Connecting with the actual process and control experiments. The FLC was implemented on a workstation connected to the pilot plant dryer via a Damatic $\mathrm{XD}^{\circledR}$ instrumentation system. Data transfer between the workstation and the pilot plant dryer took place through a XIS ${ }^{\circledR}$-reporting program. The control experiments were carried out with stepwise disturbances in feed moisture content and feed flow. 


\subsubsection{Tuning of the fuzzy logic controller}

The goal of tuning is to obtain a fast response with no overshoot, no oscillation and negligible steady-state error. The tuning of the FLC included modification of its design parameters, which are listed by Isomursu (1995) in the following way:

- Scaling factors of the input and output variables. Those that describe input normalisation and output denormalisation correspond to the gain coefficients in a conventional controller. They have a powerful influence on the dynamics of a closed-loop system, i.e. its rise time, amplitude of oscillation, overshoot, etc.

- The set of control rules. The number of control rules or the weight assigned to any particular rule can be modified.

- The membership functions of the variables. The shape and mapping, i.e. location and scaling, of MFs can affect the control performance.

The FLC design parameters can be tuned on-line or off-line. The basic principles of the two methods are presented in Figures 26 and 27.

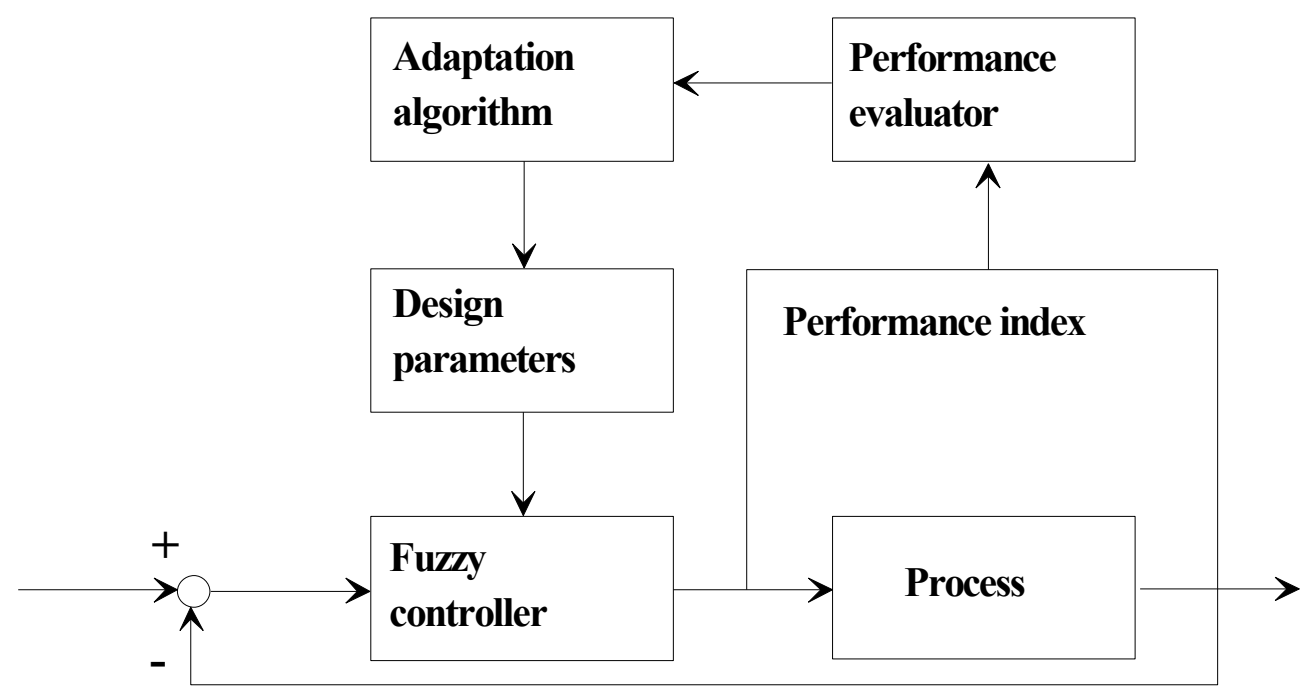

Fig. 26. Structure of on-line FLC tuning .

On-line tuning is carried out by adding a construction to the control system which modifies the design parameters during operation. According to Isomursu (1995), the online tuning procedure consists of a performance evaluator and an adaptation algorithm. The evaluator detects changes in the process by means of either on-line identification of the process model or measured process data. The actual changes are made to the design parameters by an adaptation algorithm using a performance index. 


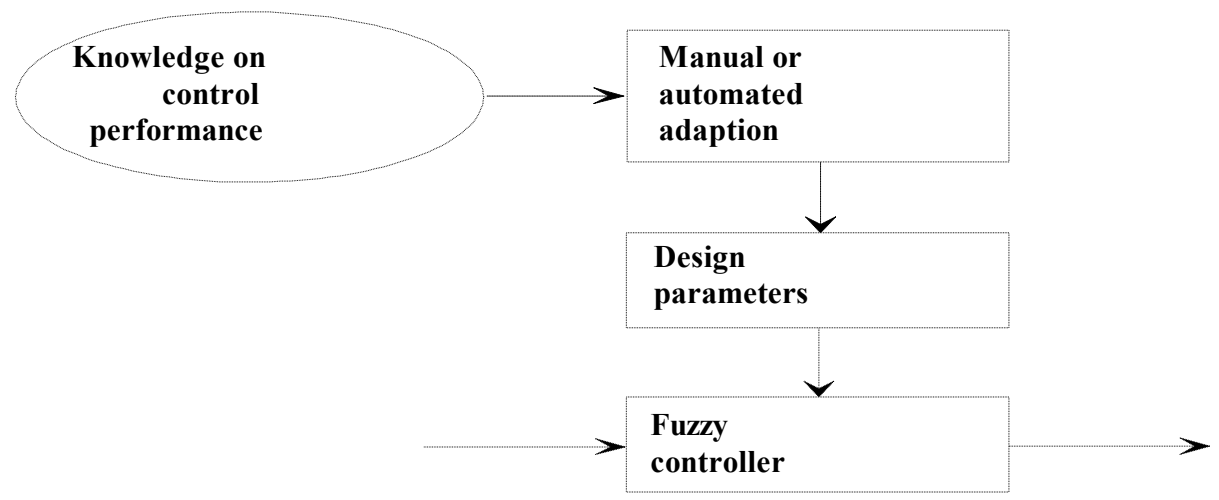

Fig. 27. Structure of off-line FLC tuning .

In off-line tuning there is no real time feedback. The basic principle is to utilise information received from process experts on how to control the process. A more detailed literature review on the most important implementations of tuning methods is given by Isomursu (1995).

In this application, preliminary tuning of the FLC was carried out off-line based on the modification of MFs and control rules using FuzzyCon and FuzzyTune and pilot plant experimental data. Tuning during operation was based on trial-and- error examination of the responses of the output variables.

\subsection{Simulation results}

The control ability of the FLC developed for the pilot plant dryer was first examined with simulations. The FLC can operate alone or be a part of a hybrid solution. The structure of the direct FLC is presented in Figure 28.

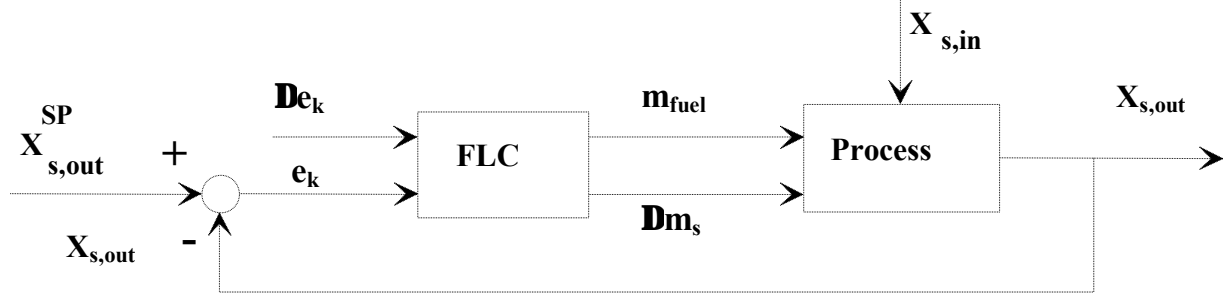

Fig. 28. Structure of the FLC for the pilot plant dryer. 
As seen in Figure 28, the direct FLC includes two inputs: error in the output moisture content of the solids and the change in this error. The controller outputs determine the fuel flow and the change in feed flow.

When serving as a part of a hybrid controller, the FLC includes three inputs: error in the output moisture content of the solids, the change in the error and sum of the errors, as indicated in Figure 29.

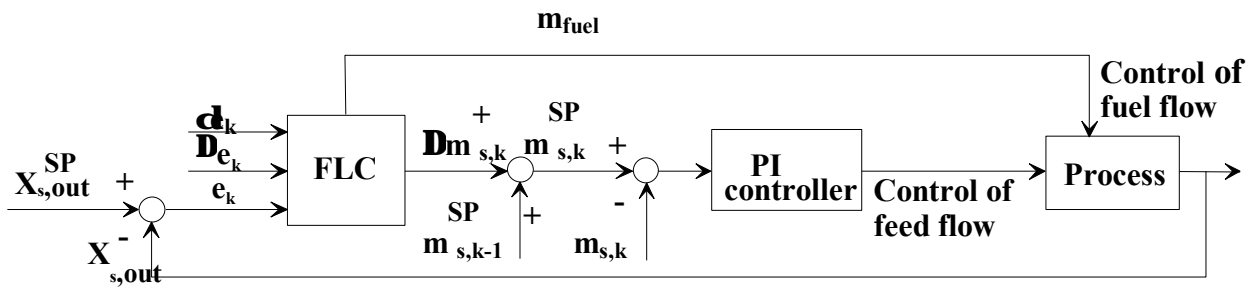

Fig. 29. Structure of the hybrid controller incorporating FLC and PI controllers.

The influence of design parameters such as the shape and mapping of MFs on control behaviour was studied by means of stepwise changes in the input moisture content of the solids. The responses obtained using the direct FLC when the intersection point of each pair of adjacent trapezoidal MFs was 0.5 or less are shown in Figures 30 and 31.

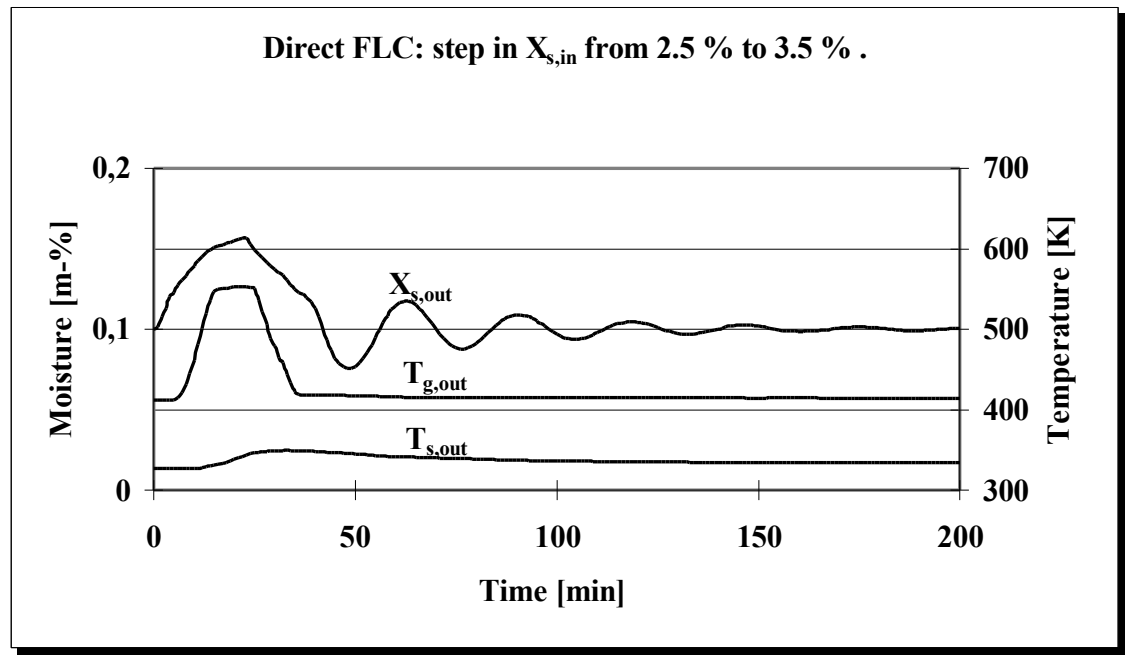

Fig. 30. Simulated responses of the direct FLC when the intersection point of two adjacent trapezoidal MFs is less than 0.5 . 


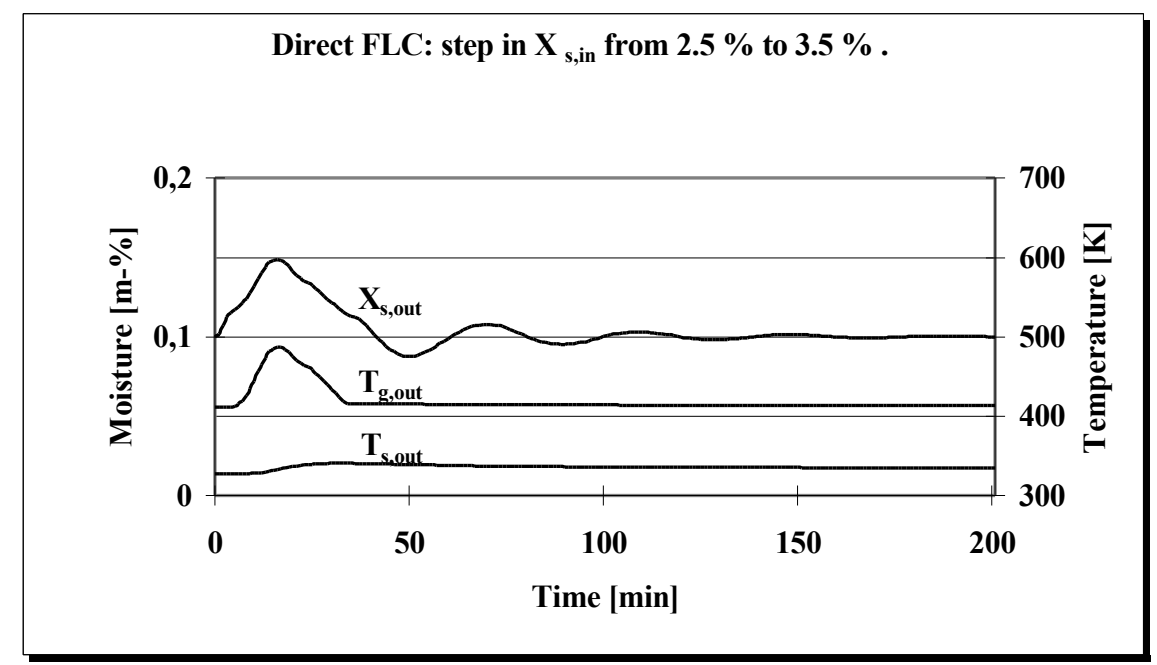

Fig. 31. Simulated responses of the FLC, when the intersection point of two adjacent trapezoidal MFs is 0.5 .

The responses show less oscillation when the intersection point of each pair of adjacent MFs is 0.5 than when it is less than 0.5.

The control responses when two adjacent bell-shaped MFs with variables of 0.5 are used are presented in Figure 32.

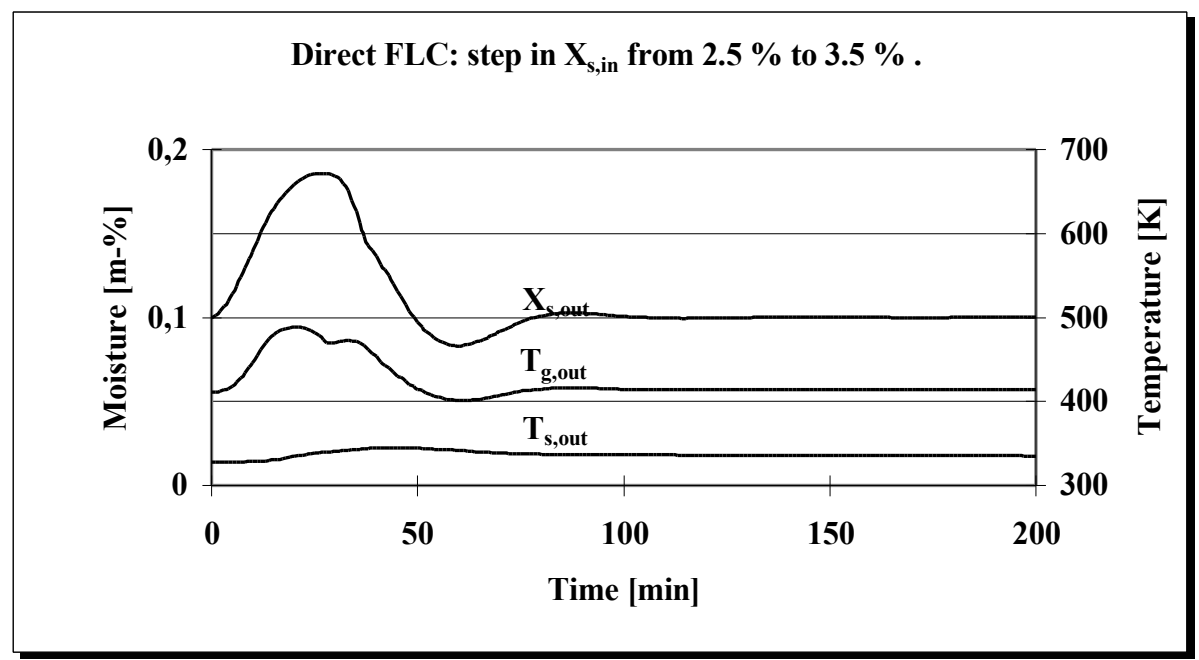

Fig. 32. Simulated responses of the FLC with bell-shaped MFs. 
Hybrid controller of FLC and PI: step in $X_{s, \text { in }}$ from $2.5 \%$ to $3.5 \%$.

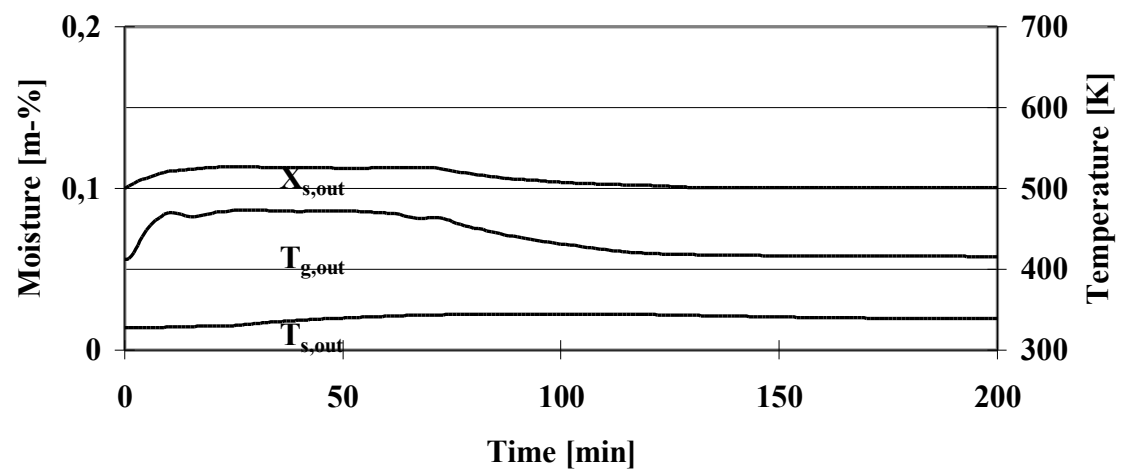

Fig. 33. Simulated responses of a hybrid controller with trapezoidal MFs.

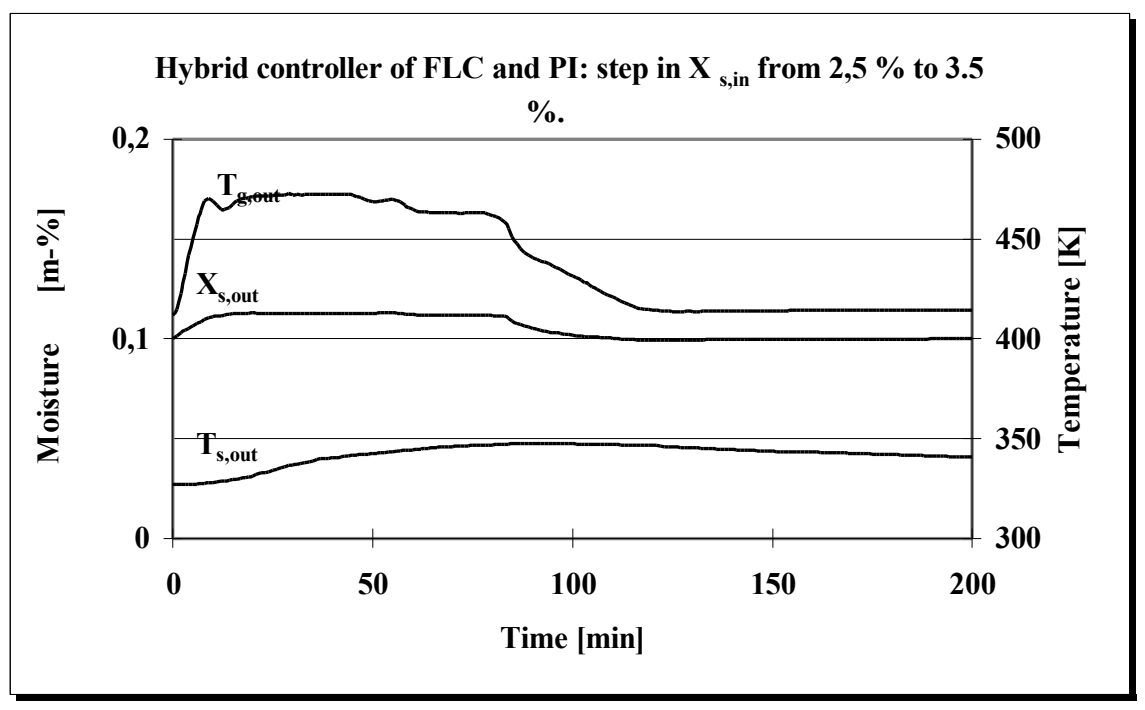

Fig. 34. Simulated responses of a hybrid controller with bell-shaped MFs.

Comparison of the responses presented in Figures 31 and 32 indicates that the use of trapezoidal MFs results in responses with less overshoot and oscillation than with bellshaped MFs. 
The control performance of the hybrid controller was studied for a step change in the input moisture content of the solids with both trapezoidal and bell-shaped MFs (Figures 33 and 34). As seen in Figures 31 and 34, the hybrid controller clearly reduced the overshoot and eliminated the oscillation. The trapezoidal MFs produced responses with less oscillation and overshoot than did bell shaped MFs.

The control performance in different situations (Figures 30...34) was also estimated quantitatively, by calculating a performance index IAE (Integral Absolute Error) for the output moisture content of the solids. As before, the qualitative examination demonstrated, and the performance index values presented in Table 14 confirm, that a hybrid controller using a FLC and a PI controller in which the MFs are trapezoidal and their intersection point is equal to or greater than 0.5 is the best solution for controlling the pilot plant rotary dryer.

Table 14. IAE Performance index for the FLC and the hybrid controller.

\begin{tabular}{llll}
\hline Figure & Controller & $\begin{array}{l}\text { Membership } \\
\text { function }\end{array}$ & IAE \\
\hline 32 & FLC & Trapezoidal & 0.0233 \\
33 & FLC & Trapezoidal & 0.0146 \\
34 & FLC & Bell-shaped & 0.0277 \\
35 & Hybrid of FLC and PI & Trapezoidal & 0.0103 \\
36 & Hybrid of FLC and PI & Bell-shaped & 0.0111 \\
\hline
\end{tabular}

Rotary dryer simulations using either direct FLC or the hybrid controller provided encouraging results as far as use of the FLC technique for experimental control of the pilot plant dryer was concerned, showing that trapezoidal M's with the intersection of adjacent labels at 0.5 or higher would be a good basis for the design of a FLC

\subsection{Experimental results}

As a consequence of the simulation findings, the FLC/PI hybrid controller was selected for use in the pilot plant dryer with the aim of keeping the output moisture content of the calcite at its target value. The structure of the FLC as presented in Figure 35 was altered for the experimental studies, because for practical reasons the feed flow cannot be used as the variable to be manipulated, on account of the fact that the input moisture content of the solids changes with any change in the rotational speed of the screw conveyor, because the solids are mixed with water above the screw conveyor. The fuel flow is therefore used as the variable to be manipulated, and the feed flow is the disturbance variable. As calcite is dried to zero moisture content, the input variables of the FLC were changed to make it possible to use the whole rule base. 


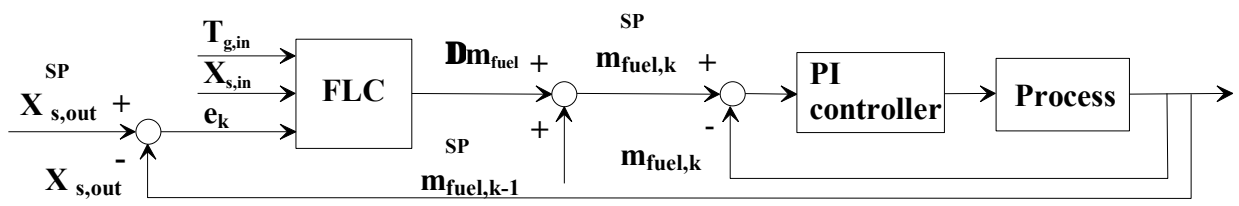

Fig. 35. Structure of the FLC/PI hybrid controller used in the experimental studies.

Both the input and output moisture content is measured on-line with infrared analysers. The FLC determines the change in fuel flow, which is added to the previous set point value to give a new set point for the fuel flow to the PI controller. The FLC was designed to operate under conditions in which the input moisture content of the solids is $2.5-4 \mathrm{~m}-\%$ and the output moisture content $0-0.1 \mathrm{~m}-\%$, the target value being $0 \mathrm{~m}-\%$. The preliminary design parameters, i.e. the control rules and the mapping of MFs, were determined with FuzzyCon using the simulation results, and are presented in Figure 36 and Table 15.
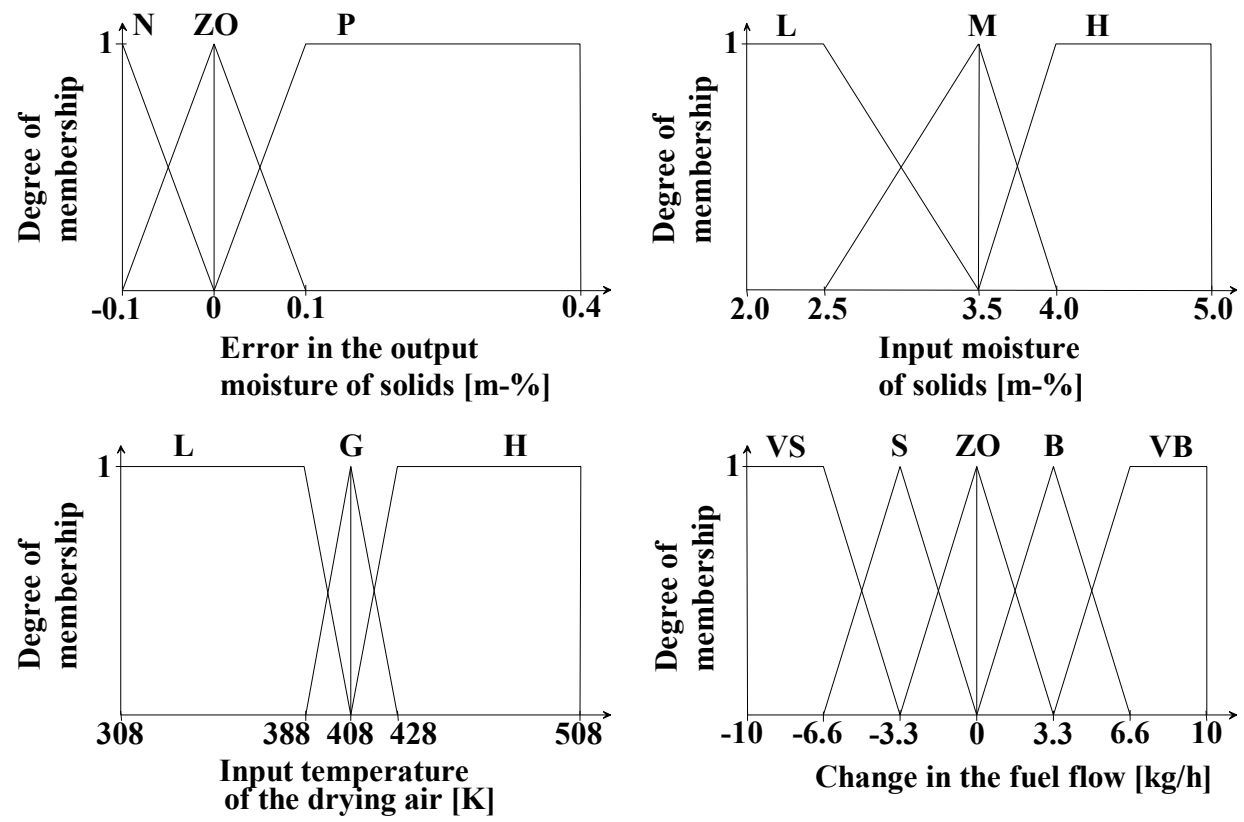

Fig. 36. Preliminary membership functions of the variables for the FLC/PI hybrid controller used in the experimental studies. 
Table 15. Preliminary rule base for the hybrid controller.

\begin{tabular}{|c|c|c|c|c|c|c|c|c|}
\hline Rule & & $\mathrm{X}_{\mathrm{s}, \mathrm{in}}$ & & $\Delta X_{s, \text { out }}$ & & $\mathrm{T}_{\mathrm{g}, \mathrm{i}}$ & & $\Delta \mathrm{m}_{\text {fuel }}$ \\
\hline 1 & IF & low & AND & positive & AND & low & THEN & zero \\
\hline 2 & IF & medium & AND & positive & AND & low & THEN & big \\
\hline 3 & IF & high & AND & positive & AND & low & THEN & very big \\
\hline 4 & IF & low & AND & zero & AND & low & THEN & big \\
\hline 5 & IF & medium & AND & zero & AND & low & THEN & big \\
\hline 6 & IF & high & AND & zero & AND & low & THEN & very big \\
\hline 7 & IF & low & AND & negative & AND & low & THEN & big \\
\hline 8 & IF & medium & AND & negative & AND & low & THEN & very big \\
\hline 9 & IF & high & AND & negative & AND & low & THEN & very big \\
\hline 10 & IF & low & AND & positive & AND & good & THEN & small \\
\hline 11 & IF & medium & AND & positive & AND & good & THEN & zero \\
\hline 12 & IF & high & AND & positive & AND & good & THEN & big \\
\hline 13 & IF & low & AND & zero & AND & good & THEN & zero \\
\hline 14 & IF & medium & AND & zero & AND & good & THEN & big \\
\hline 15 & IF & high & AND & zero & AND & good & THEN & big \\
\hline 16 & IF & low & AND & negative & AND & good & THEN & big \\
\hline 17 & IF & medium & AND & negative & AND & good & THEN & big \\
\hline 18 & IF & high & AND & negative & AND & good & THEN & big \\
\hline 19 & IF & low & AND & positive & AND & high & THEN & small \\
\hline 20 & IF & medium & AND & positive & AND & high & THEN & small \\
\hline 21 & IF & high & AND & positive & AND & high & THEN & small \\
\hline 22 & IF & low & AND & zero & AND & high & THEN & small \\
\hline 23 & IF & medium & AND & zero & AND & high & THEN & zero \\
\hline 24 & IF & high & AND & zero & AND & high & THEN & zero \\
\hline 25 & IF & low & AND & positive & AND & high & THEN & small \\
\hline 26 & IF & medium & AND & positive & AND & high & THEN & small \\
\hline 27 & IF & high & AND & positive & AND & high & THEN & big \\
\hline
\end{tabular}

The step experiments depicted in Table 16 were performed to study the influence of the design parameters on control behaviour. 
Table 16. Step experiments performed on the pilot plant dryer using the hybrid controller.

\begin{tabular}{ccc}
\hline Figure & \multicolumn{2}{c}{ Variable } \\
& & Step change \\
\hline 37 & Input moisture content of solids & $3.2 \mathrm{~m}-\%$ to $3.7 \mathrm{~m}-\%$ at time $140 \mathrm{~min}$ \\
38 & Input moisture content of solids & $2.5 \mathrm{~m}-\%$ to $3.3 \mathrm{~m}-\%$ at time $100 \mathrm{~min}$ \\
39 & Input moisture content of solids & $2.5 \mathrm{~m}-\%$ to $3.2 \mathrm{~m}-\%$ at time $110 \mathrm{~min}$ \\
40 & Input moisture content of solids & $2.5 \mathrm{~m}-\%$ to $3.3 \mathrm{~m}-\%$ at time $60 \mathrm{~min}$ and \\
& & $3.3 \mathrm{~m}-\%$ to $2.7 \mathrm{~m}-\%$ at time $220 \mathrm{~min}$ \\
41 & Feed flow & $149 \mathrm{~kg} / \mathrm{h}$ to $160 \mathrm{~kg} / \mathrm{h}$ at time $60 \mathrm{~min}$ \\
\hline
\end{tabular}

It can be observed from Figure 37 that the control was not able to keep the calcite at its target value, i.e entirely dry, after a step disturbance in the input moisture content of the solids. The membership function of the input temperature of the drying air was therefore expanded to the range $313 \ldots 513 \mathrm{~K}$, but this was still not enough, as shown by the experiment presented in Figure 38. As the solid matter did not stay dry and the settling time was still long, the membership function of the input moisture content of the solids was also altered (see Figure 42). As there was still quite a lot of oscillation in the responses, as seen in the experiment presented in Figure 39, especially in the fuel flow, rule number 19 was altered during operation (at time $240 \mathrm{~min}$ ) so that the change in the fuel flow was VS instead of S. This gave smoother responses, and the fuel flow was quite stable.

The control behaviour for step changes in the input moisture content of the solids and in the feed flow with respect to the final design parameters is described in Figures 40 and 41, And the MFs of the different input and output variables used are presented in Figure 42. The range of the input temperature of the drying air was widened still further in order to ensure that the solids were dry. The rule base for these experiments was the same as in the experiment presented in Figure 39. As shown in Figure 40, the control behaves well, and the fuel flow in particular reacts quickly to disturbances, although resulting in quite a small oscillation in the output variables. The reactivity of the fuel flow to a step decrease in the input moisture content of the solids is slower than that to a step increase, due to the non-symmetrical membership function of the input moisture content of the solids (see Figure 42).

In Figure 41, where an increase in the feed flow occurs, the fuel flow also reacts very fast, but the control is not stable because the input moisture content of the solids also begins to decrease. This disturbance later causes oscillation in both the manipulated and the output variables. 

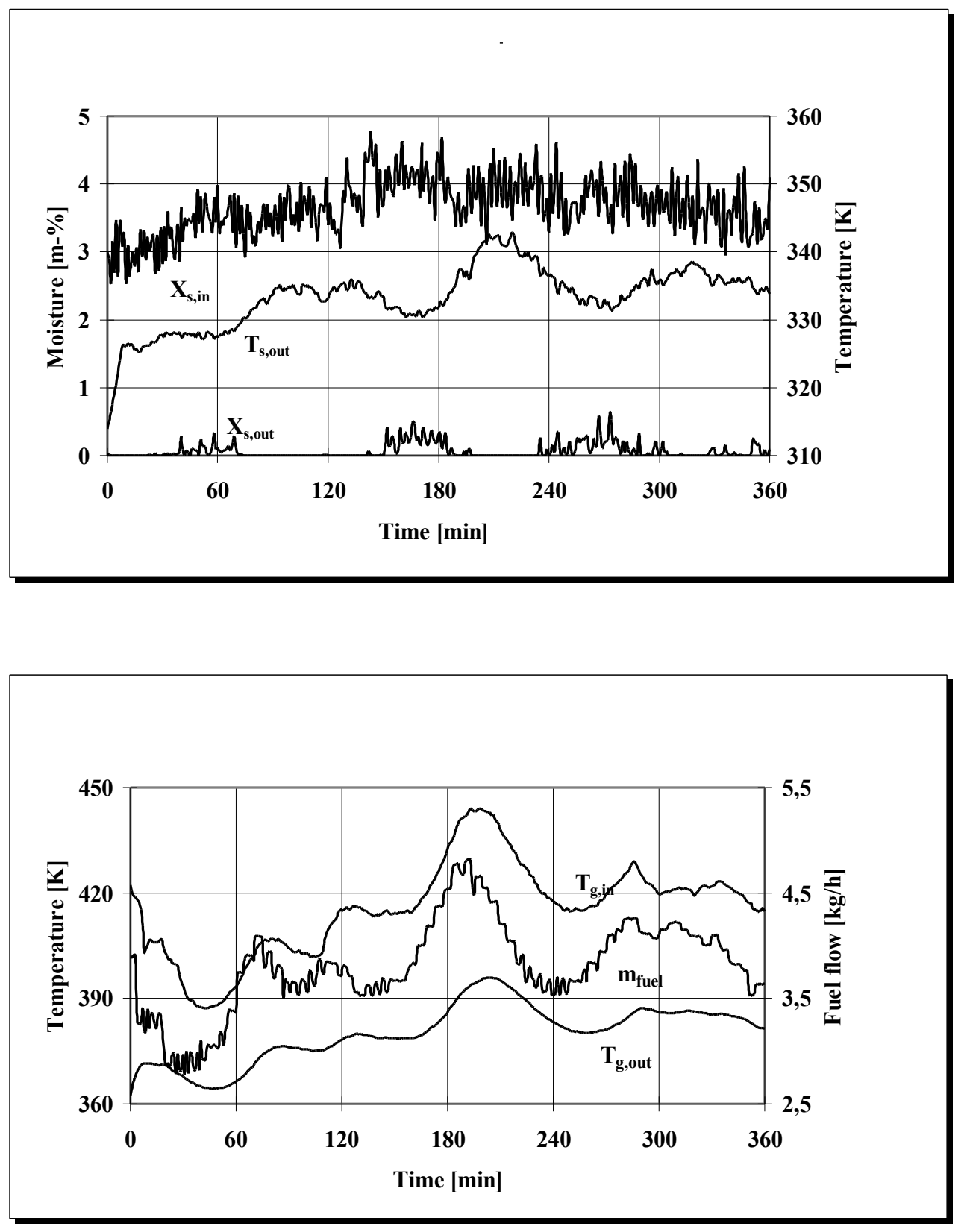

Fig. 37. Responses of the hybrid controller to a step change in the input moisture content of the solids from $3.2 \mathrm{~m}-\%$ to $3.7 \mathrm{~m}-\%$ at time $140 \mathrm{~min}$. 

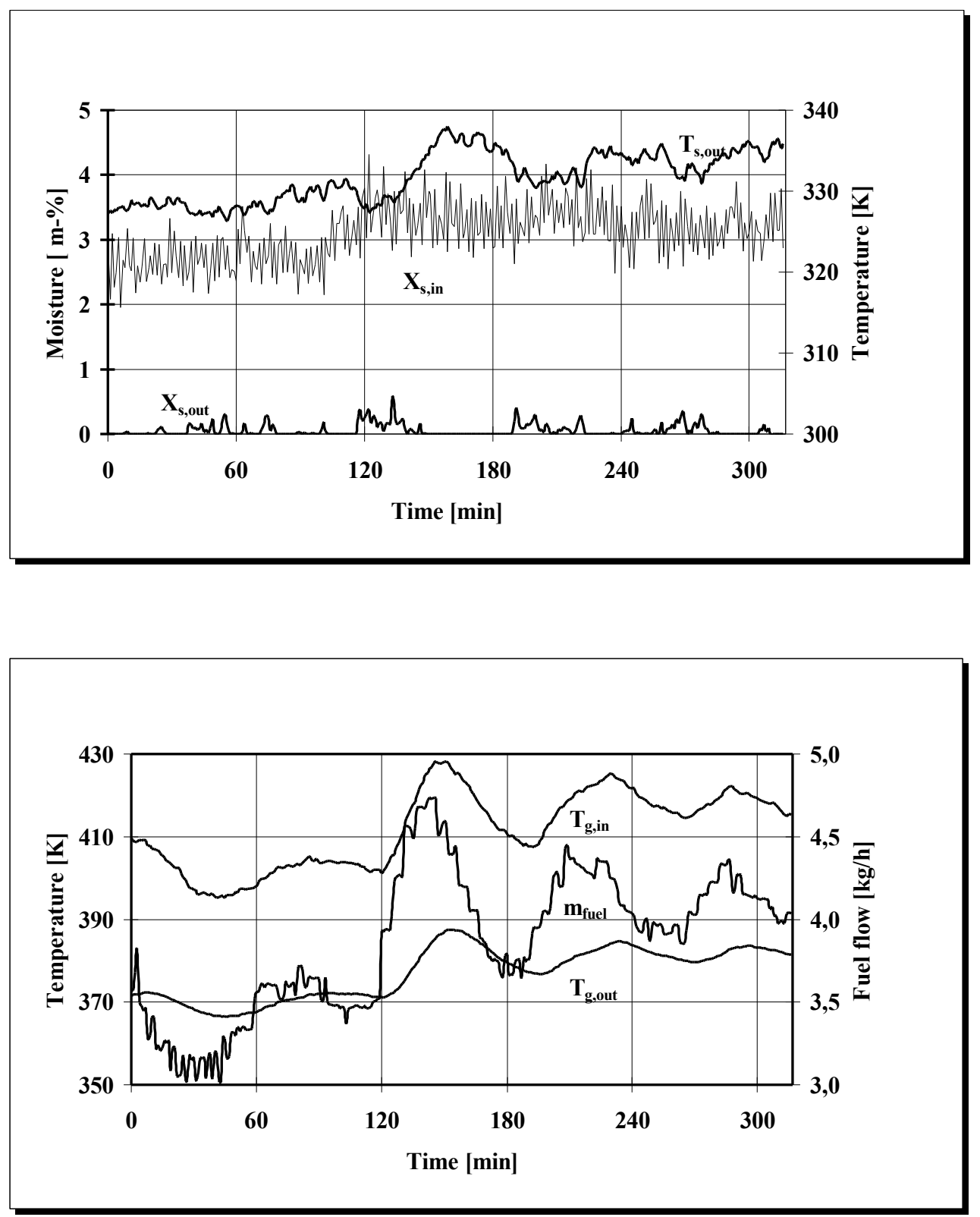

Fig. 38. Responses of the hybrid controller to a step change in the input moisture content of the solids from $2.5 \mathrm{~m}-\%$ to $3.3 \mathrm{~m}-\%$ at time $100 \mathrm{~min}$. 

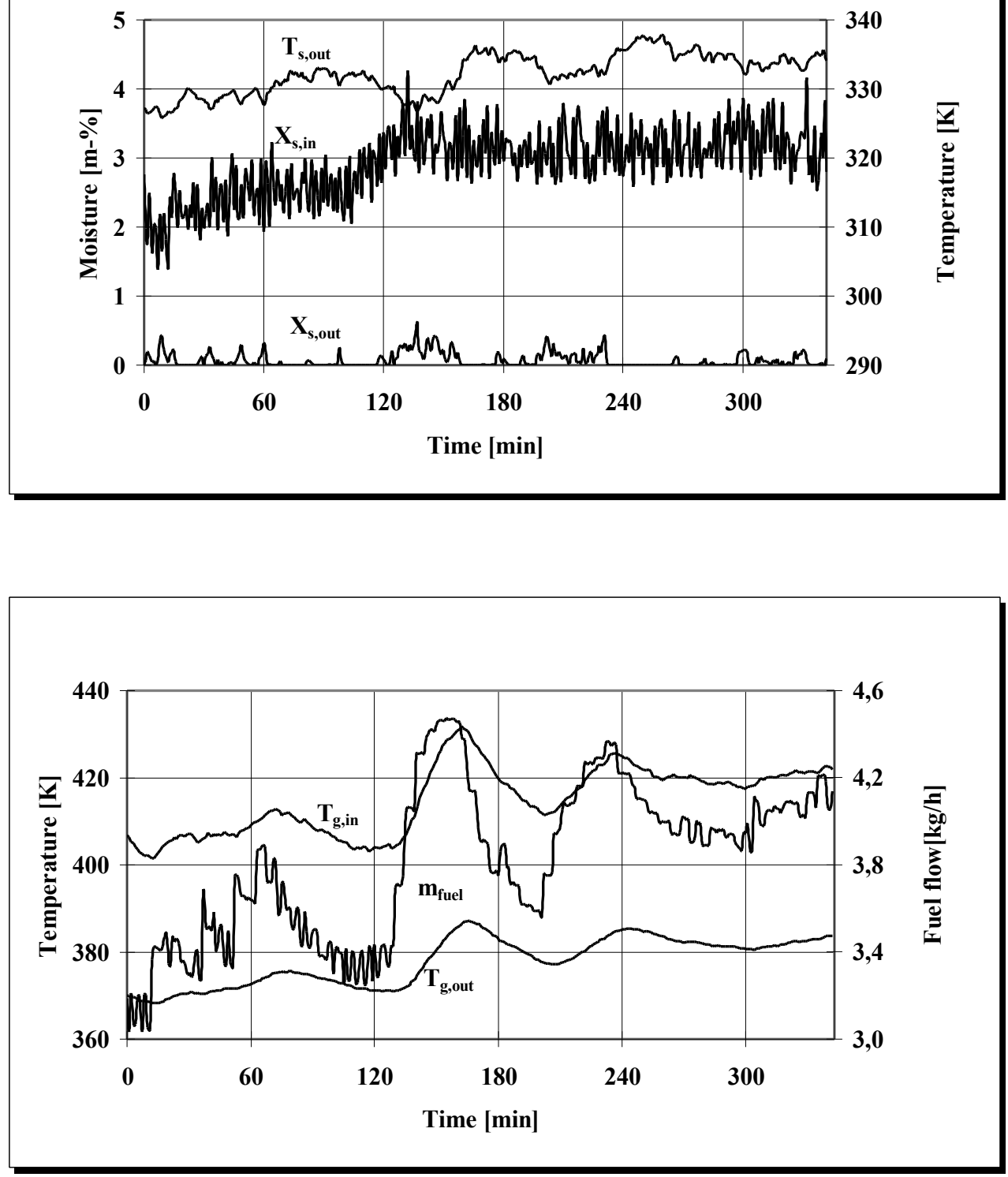

Fig. 39. Responses of the hybrid controller to a step change in the input moisture content of the solids from $2.5 \mathrm{~m}-\%$ to $3.2 \mathrm{~m}-\%$ at time $110 \mathrm{~min}$. 

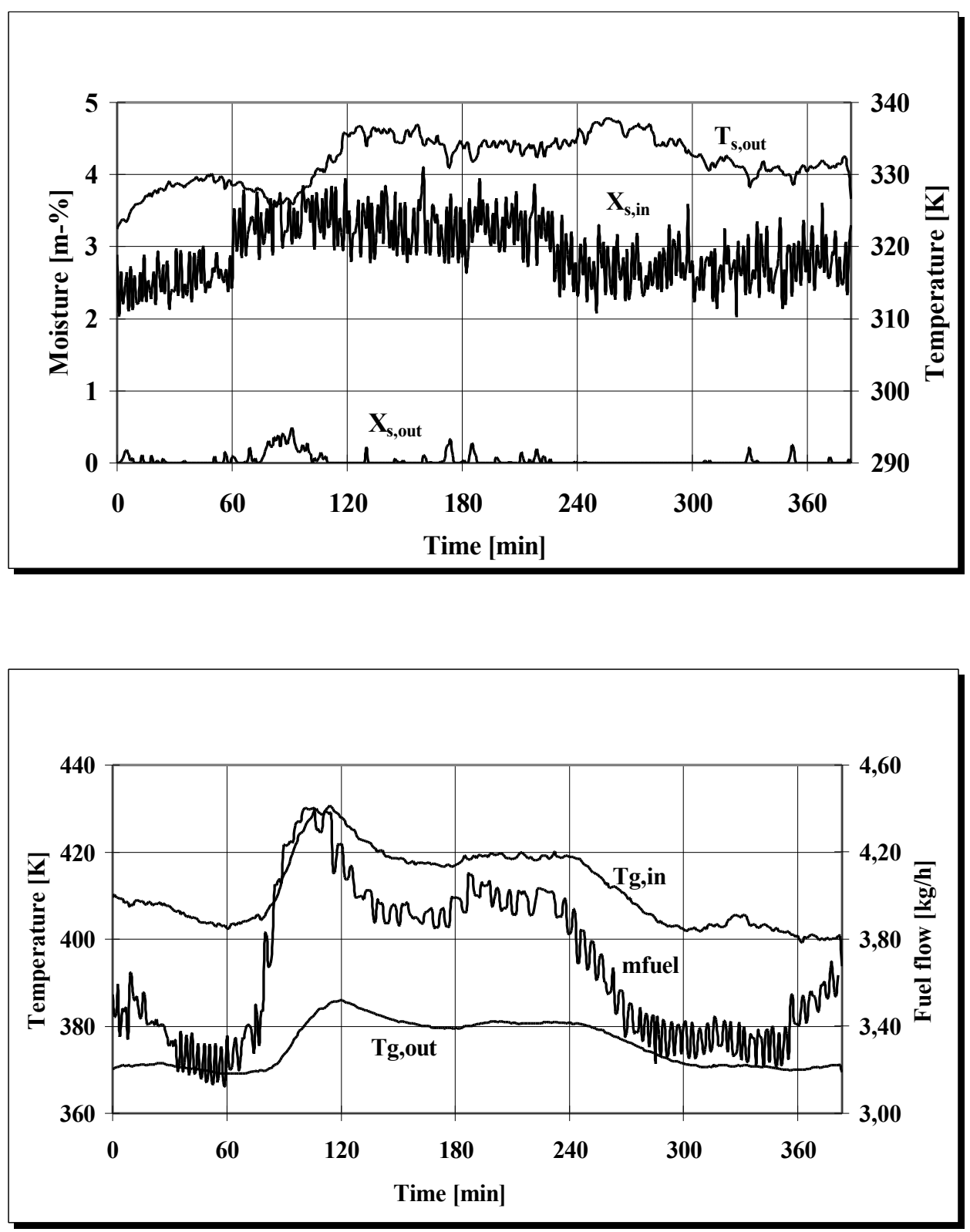

Fig. 40. Responses of the hybrid controller to step changes in the input moisture content of the solids from $2.5 \mathrm{~m}-\%$ to $3.3 \mathrm{~m}-\%$ at time $60 \mathrm{~min}$ and from $3.3 \mathrm{~m}-\%$ to $2.7 \mathrm{~m}-\%$ at time 220 min. 

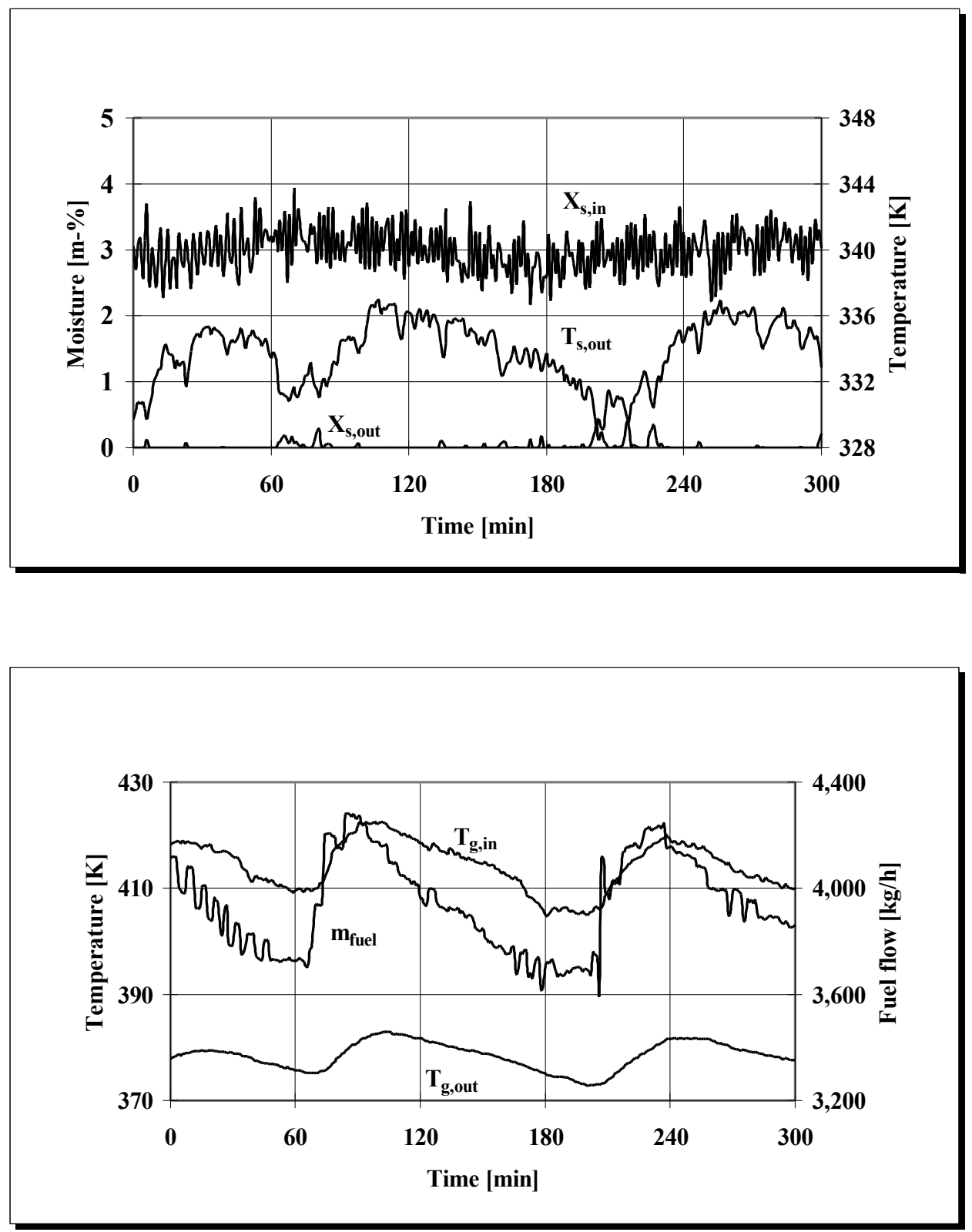

Fig. 41. Responses of the hybrid controller to a step change in the feed flow from $149 \mathrm{~kg} / \mathrm{h}$ to $160 \mathrm{~kg} / \mathrm{h}$ at time $60 \mathrm{~min}$.

The final MFs for the variables are presented in Figure 42 . 

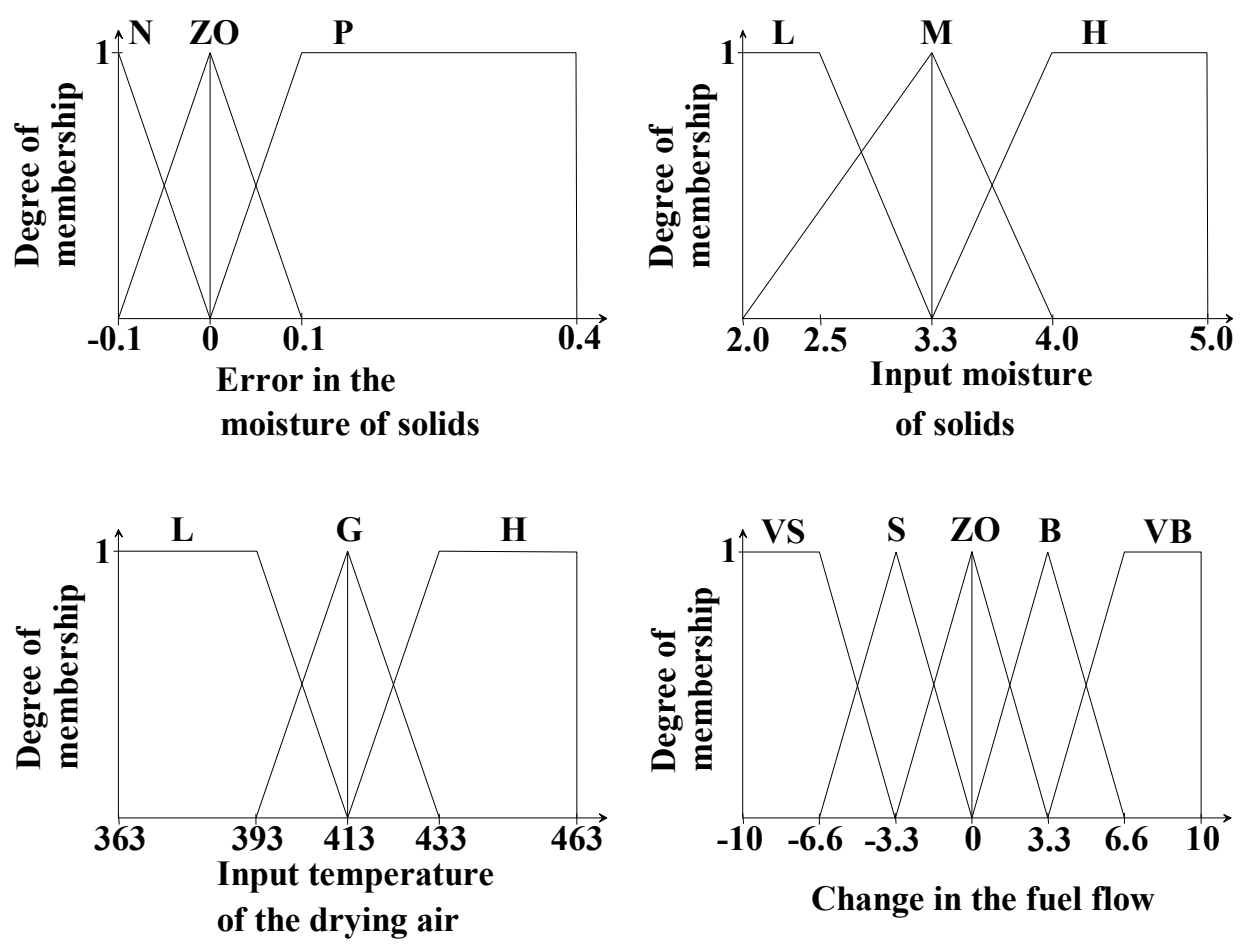

Fig. 42. Final membership functions for the input and output variables of the hybrid controller.

The simulations and control experiments with the pilot plant dryer show that a hybrid controller consisting of fuzzy and conventional control modules in which FLC performs high-level control determining the set point values for the PI controllers, can be used with a rotary dryer, although some oscillation can be seen in the output moisture content of the solids. The control performance could be improved by adding rules, MFs and input variables, but this would increase the complexity of the FLC. One of the main principles in this application was to keep the structure of the FLC simple and still to achieve satisfactory control performance. 


\section{Development of a neural network controller for the pilot plant dryer}

Neural computing is one of the fastest growing areas of artificial intelligence. Techniques based on neural networks have been developed in many fields ranging from banking and speech recognition to process identification and control, and they have also been recognised as one of the most powerful tools for developing intelligent control systems, particularly for non-linear processes about which incomplete knowledge and imprecise information is available. They therefore offer a very attractive approach to the control of multivariable, highly non-linear drying processes.

Numerous types of network exist, but each type consists of the same features, i.e. nodes, which are simple non-linear elements, layers and connections that are connected to each other by weighted links. Different network architectures and training methods are used depending on the problem to be solved. Architecture means the provision of sufficient specifications for a neural network developer to build, train, test and operate the network. It includes a description of the number of layers, the number of neurones in each layer, the transfer function of each layer and the connections between the layers. Training or learning involves either the adaptation of weights or the addition or removal of connections between neurones. In any case, training of the neural network means finding a configuration of weights such that the desired target of the system can be reached. Training algorithms can be classified into supervised and unsupervised ones. In the first case, the required outputs corresponding to a certain input set are known in advance and the initial weights are set randomly, while in the latter no external reference signals (training set) are used.

Networks can be divided into two main classes in terms of their architecture: feedforward networks and recurrent networks. Dynamic, or recurrent networks differ from feedforward ones in that their structure incorporates feedback. Two basic recurrent networks can be found in the literature: Elman networks and Hopfield networks. Elman networks are useful in signal processing, for example, while Hopfield networks are of interest in a theoretical sense but are seldom used in practise. It has been shown in a number of papers that a feedforward network has the potential to approximate any nonlinear function and that a two-layered feedforward network can uniformly approximate 
any continuous function to an arbitrary degree of exactness provided that the hidden layer(s) contain a sufficient number of neurones (Wang et. al.1993).

The most popular architecture for engineering applications is a multilayer feedforward neural network, often called a backpropagation network. Tanomaru (1992) lists some basic reasons why multilayer neural networks (MNN) are particularly attractive for process control. One of these is that the basic algorithm for learning, i.e. identification of the connection weights, is a backpropagation algorithm. This is a modified version of the gradient descent method widely applied to optimal control problems, and is therefore familiar to control engineers. The inputs of the network are formed using a discrete time history of process inputs and outputs.

Backpropagation networks are discussed in more detail in Appendix 5, since this approach is also used in the present application. The description is based on the papers of Bhat \& McAvoy (1990), Bhat et al. (1990) and Morris et al. (1994).

A large number of control structures based on neural networks have been proposed in the literature for different fields of engineering, but only one article can be found which describes their application to the control of a rotary dryer and their testing with simulations (Duchesne et al. 1997b). Hunt et al. (1992) reviewed various neural network architectures for use in the modelling, identification and control of non-linear systems.

\subsection{Design and implementation of a neural controller for the pilot plant dryer}

\subsubsection{Structure of the neural network controller for simulation studies}

The neural network developed for controlling the rotary dryer is a multilayer feedforward network, as in the most engineering applications, and acts as a high-level controller giving the set point for the PI controller that supervises the fuel flow. The other PI controller is used to supervise the feed flow. The structure of the control system is presented in Figure 43.

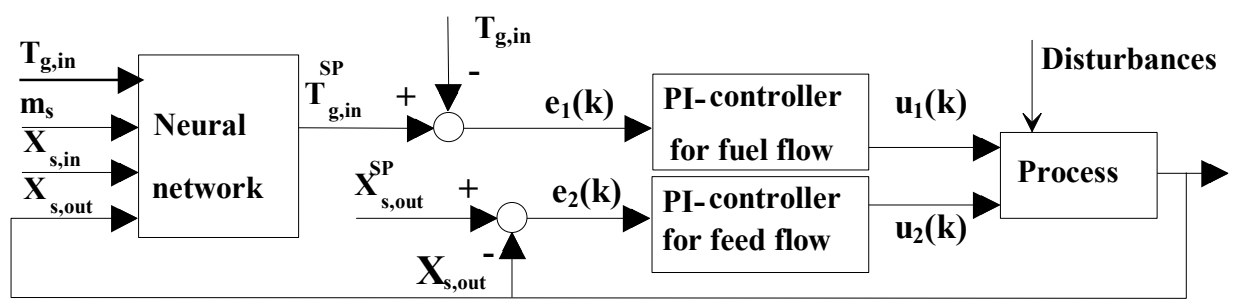

Fig. 43. Structure of the neural network-based control system for the pilot plant rotary dryer. 
The neural network is trained to identify the inverse dynamics of the process and is then employed as a controller. This direct inverse control is based on the process input and output signals, and its general training scheme is shown in Figure 44.

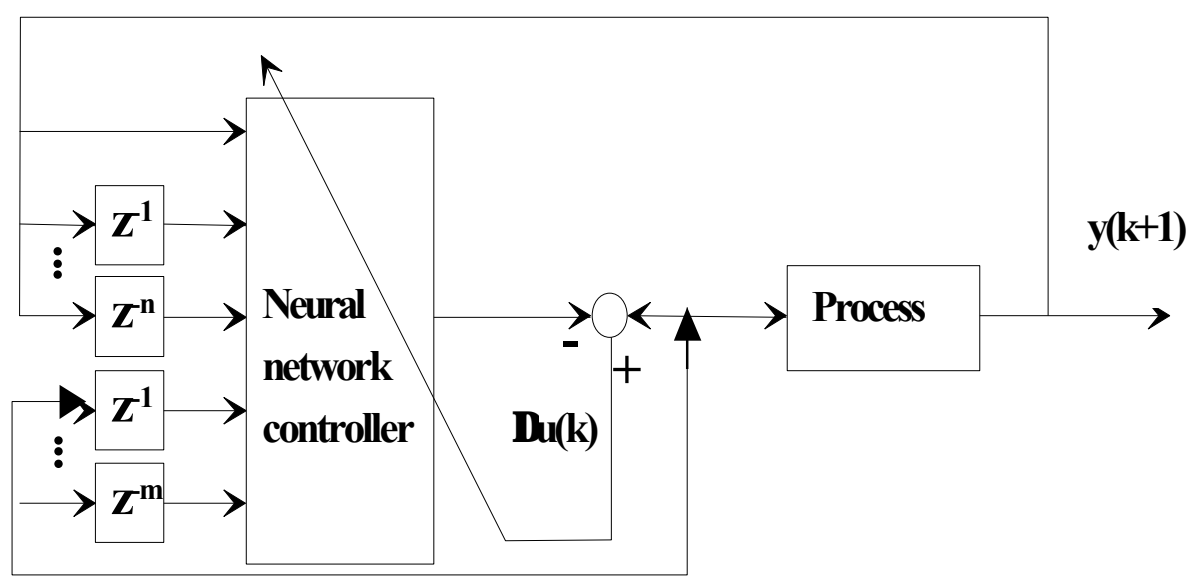

$\mathbf{u}(\mathbf{k})$

Fig. 44. Direct inverse control using feedforward networks.

The training of the network was based on a backpropagation algorithm, and the training and testing data were collected from the pilot plant dryer. Before its use as a controllers, the network was trained off-line by making step changes in the input moisture content of the solids, and a sampling time of one minute was achieved. Root mean squared error (RMS) was used to calculate the performance of the network. The inputs for the inverse model during off-line training were the current and past input and output values, the same were used during operation of the network. The output of the neural network is the input temperature of the drying air, which correlates with the fuel flow.

The architecture of the neural network, consisting of three layers, two hidden layers with biases and the output layer, is presented in Figure 45. 


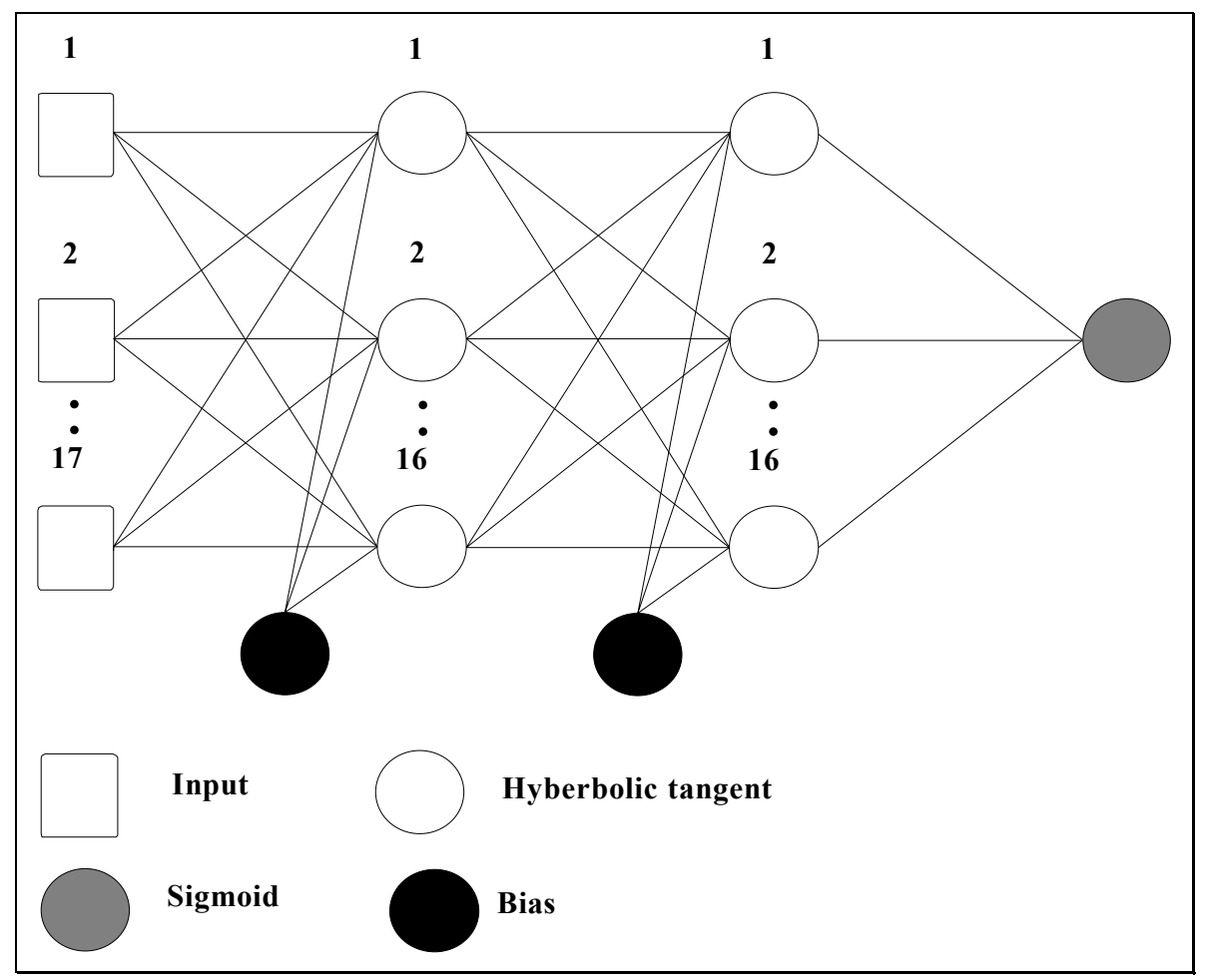

Fig. 45. Architecture of the neural network for controlling the pilot plant rotary dryer.

The number of neurones in hidden layers is 16 , with the transfer function of the hyperbolic tangent sigmoid. The sigmoid transfer function is used in the output layer. It is important that transfer functions are differentiable.

The 17 inputs to the neural network are the following:

- Input moisture content of the solids and four past values.

- Output moisture content of the solids and five past values.

- Feed flow and three past values.

- Input temperature of the drying air and previous value.

All the inputs are scaled between 0 and 1, which means that the output of the network also lies between 0 and 1 . The weights are updated during operation, i.e. the network is adaptive.

The behaviour of the control system was examined with pilot plant dryer simulations, as described for a step change in the input moisture content of the solids in Figure 46. 

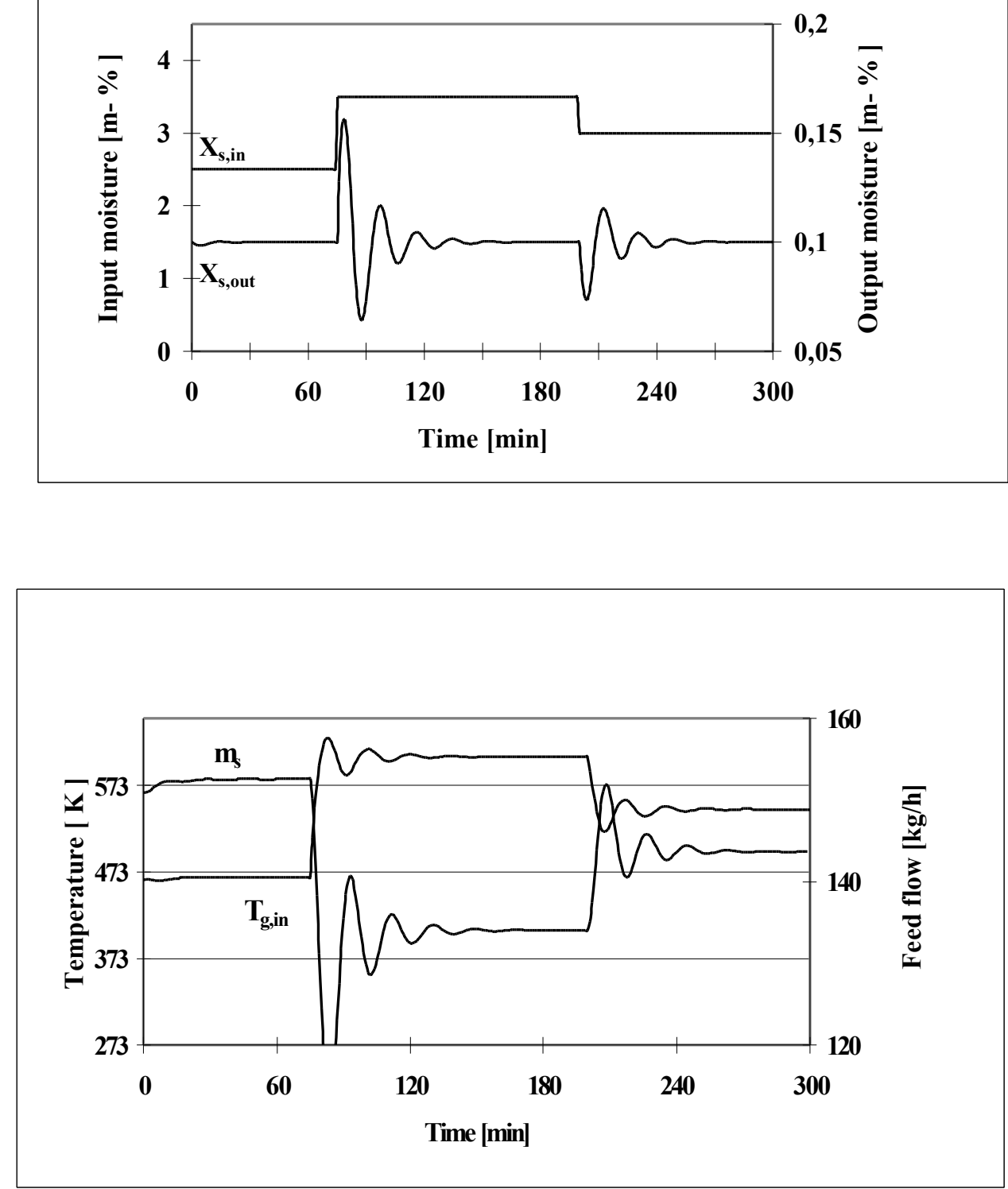

Fig. 46. Simulated responses to a step change in the input moisture content of the solids using the neural network- based hybrid controller. 


\subsubsection{Structure of the neural controller for experimental studies}

Based on the simulations, a neural network-based hybrid controller was also implemented for experimental studies on the control of the pilot plant dryer, but its architecture was altered and control of the feed flow was not supported. If the feed flow, i.e. the rotational speed of the screw conveyor, is manipulated, the input moisture content of the solids changes at the same time, causing a disturbance, as the solids are mixed with water above the screw conveyor. The number of neurones in the two hidden layers was reduced from 17 to 10 in order to shorten the training time. The output temperature of the solids was included in the inputs to the network in order to check for overdrying if the solids are to be dried to zero moisture content. After the above changes, the ten inputs to the neural network were the following:

- Input moisture content of the solids and two past values.

- Output moisture content of the solids and two past values.

- Output temperature of the solids and previous value.

- Input temperature of the drying air and previous value.

The weights of the neural network were updated during the operation. The error between the set point and the measured values for the output moisture content of the solids was used as the error of the backpropagation algorithm. If this error was zero, it was important to examine whether overdrying had occurred. If the solids temperature exceeded the maximum temperature determined in advance, the weight calculations were based on the error between the maximum and measured temperatures of the solids.

The network architectures and specification parameters for both the simulation case and the experimental case are presented in Tables 17 and 18.

Table 17. Neural network architecture.

\begin{tabular}{ll}
\hline & Architecture \\
\hline Simulation case & $\mathrm{N}^{2}(17,16,16,1)$ \\
Experimental case & $\mathrm{N}^{2}(10,14,14,1)$ \\
\hline
\end{tabular}

Table 18. Neural network specification for the neural controller

\begin{tabular}{ll}
\hline Specification & Neural controller \\
\hline Network architecture & Multilayer feedforward \\
Learning paradigm & Backpropagation \\
Transfer function & Tansig for hidden layers and logsig for output layer \\
Training data & Historical I/O data from pilot plant dryer \\
Testing data & Historical I/O data from pilot plant dryer \\
Input signal for training & Step \\
\hline
\end{tabular}


The control behaviour in response to a step change in the input moisture content of the solids from 3 to $3.7 \mathrm{~m}-\%$ at time $120 \mathrm{~min}$ is presented in Figure 47 .
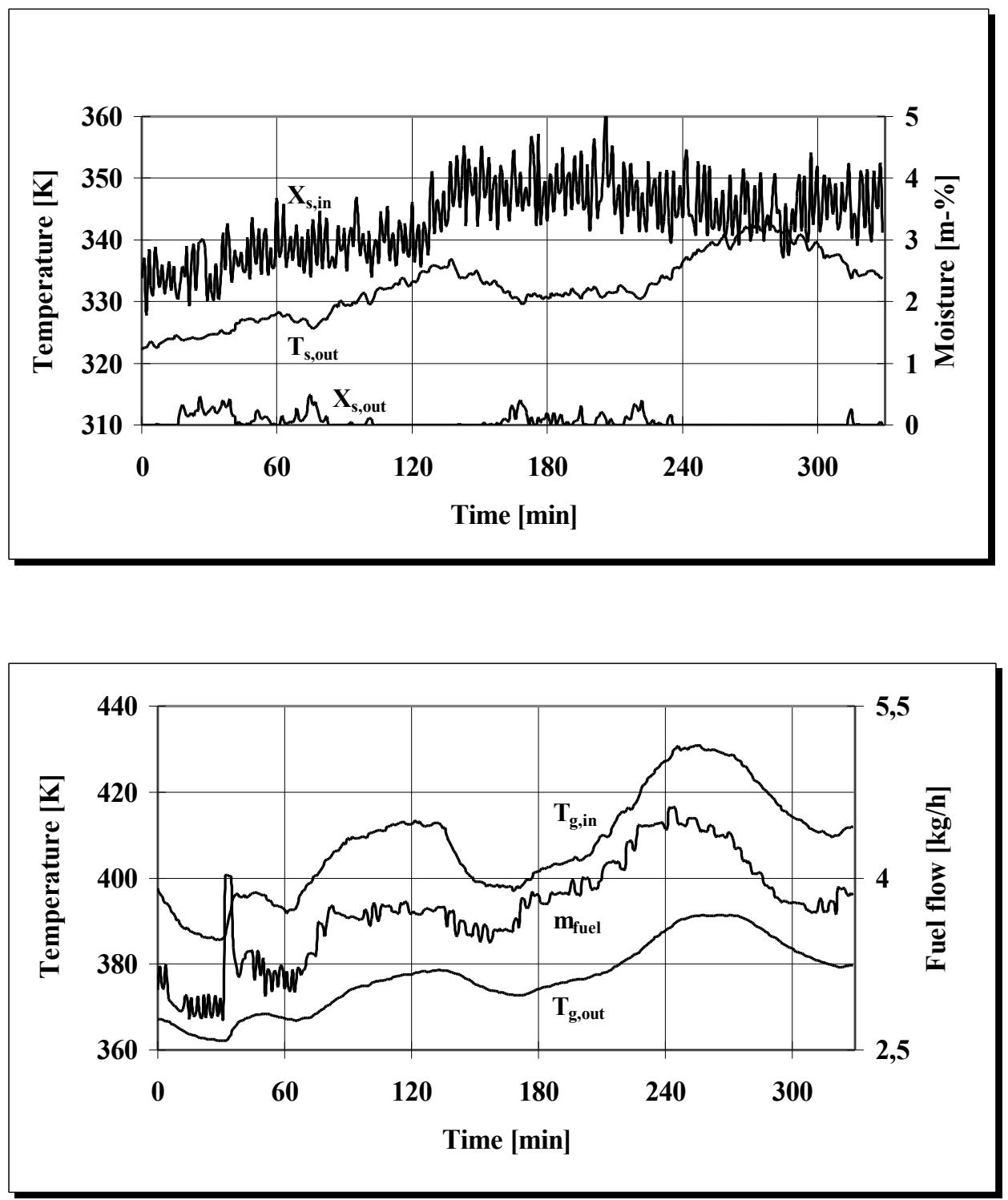

Fig. 47. Experimental responses to a step change in the input moisture content of the solids in the neural network-based hybrid controller. 
On the figure shows the control to be slower than in the corresponding fuzzy control experiment (see Figure 40), and more oscillation can be observed in the output temperature and moisture content of the solids. This experiment did show, however, that the network-based hybrid controller operates in the correct way, even though additional tuning is needed.

Both simulation and experimental results show that a neural network controller can be used with the pilot plant rotary dryer, as also demonstrated by Yliniemi et al. (1998). The system tested was a supervisory controller giving a set point value to the PI controller for manipulating the fuel flow. The problem is that a feedforward nonlinear neural network requires a lot of computation time for training, and a lot of reliable data from the process. 


\section{Discussions and conclusions}

The objective of this research was to examine the control of a rotary dryer with the aim of developing new control systems for achieving better operation. The need for improving control systems has traditionally been powered by a demand for more accurate, cost effective production. This is still a major driving force, but environmental aspects also exercise an important influence on this development today. It is known that rotary drying is a common, but highly non-linear, complex and energy-intensive process, and that its control is still based on a simple feedback PID concept, which is not sufficient, due to the long delay time of the dryer. The development of model-based control systems has proved difficult and time-consuming, because of the complexity of the process, which in addition to thermal drying, also includes the progress of the solids through the dryer. Intelligent methods such as fuzzy logic and neural networks, combined with conventional control methods, are attractive approaches for both the modelling and control of rotary dryers, because they make it possible to utilise experience, knowledge and historical data, of which a great deal is available.

The research environment, a pilot plant rotary dryer located at the Control Engineering Laboratory of the University of Oulu, was used for the experimental studies, and the mathematical model including both analytical heat, mass and momentum transfer equations for the drum and an empirical equation for the drying rate was developed for determining the main variables to be manipulated and for the control simulations. The dynamic, distributed parameter model was linearised in the neighbourhood of the operating conditions in order to obtain a linear, lumped parameter model. The behaviour of the model, validated with real data from the pilot plant dryer, corresponded well to the measured behaviour.

The research was conducted on the assumption that fuzzy logic and neural networks can provide good solutions for improving the control of a rotary dryer. To verify this assumption, various variants on intelligent hybrid control systems were implemented in the pilot plant dryer and their control performance was examined both with simulations and by means of pilot plant experiments.

The performance of the various controllers in the experiments was evaluated qualitatively, because the quantitative comparison is difficult due to 
- poor repeatability of the control experiments, as the pilot plant dryer closely resembles a real industrial plant,

- it is difficult to run the process under exactly the same steady state conditions before the step experiments, and

- the solid material is not entirely homogeneous.

The structures, advantages and disadvantages of the various controllers are discussed below :

1) Conventional feedback PI controller: The simple feedback PI controller of the pilot plant dryer is based on the error between the set point and measured output moisture content of the solids. Due to the long delay time of the dryer, a step disturbance in the feed moisture content was reflected in the output moisture content of the solids before the main variable manipulated, fuel flow, was able to react to the disturbance. As PI control is very familiar to operators, is easy to implement for onevariable control and does not require disturbance identification or measurement, it is nevertheless still in use in many rotary dryers.

2) Conventional model-based feedforward-feedback controller: The feedforward controller, based on a mathematical model, calculates a set point for the PI controller that regulates fuel flow. The feedback PI controller based on the error between the measured and set point values for the output moisture content of the solids corrects the fuel flow if needed. This control system operates well, because it is possible to react to disturbances before the process feels them. The construction of the feedforward controller requires not only the identification and measurement of disturbances but also a process model, and development of a mathematical model for the feedforward part requires a priori knowledge of the process, and is therefore cumbersome and timeconsuming. There is no general purpose model which describes the dynamic behaviour of heat, mass and momentum transfer in rotary dryers. The models are specific to a certain dryer or product, and therefore the feedforward controller has to be programmed separately for each dryer, causing both additional work and costs. The accuracy of the control is dependent on that of the system model.

3) FLC/PI Hybrid controller: In the fuzzy logic-based hybrid controller the FLC acts as the supervisory controller, determining the change to be made to the fuel flow, which is added to the previous set point for the PI controller, resulting in a new set point. The FLC includes three inputs, each having three trapezoidal membership functions, and one output with five trapezoidal membership functions. The number of control rules is 27. It employs the MIN-MAX fuzzification method and the COA defuzzification method. Preliminary tuning of the design parameters took place off-line using the tools FuzzyCon and FuzzyTune and the final tuning during operation. The experiments showed good control performance even though the structure of the FLC was kept simple. If one wished to implement a more complex FLC, in order to examine overdrying, for example, it would be good to add the output temperature of the solids to the input variables, and it would also be interesting to examine the use of the rotational speed of the drum, i.e. the residence time of the solids as the output variable of the FLC. The FLC is easy to implement because there are a lot of commercial software 
tools available at moderate prices, and it is able to achieve non-linear control behaviour. The system is also very attractive for the control of a rotary dryer because a lot of empirical knowledge that has accumulated with experience is available. Experienced operators know how to operate a rotary dryer without a mathematical model.

4) NN/PI Hybrid controller: In the neural network-based hybrid controller a multilayered feedforward neural network acts as the supervisory controller determining the set point for the PI controller that regulates fuel flow. The architecture of the neural network is $\mathrm{N}^{2}(10,14,14,1)$, the training of which is based on the backpropagation algorithm. The data for training and testing were collected from the pilot plant dryer, and the adaptive, i.e. on-line weight updating, neural network controller is based on inverse process modelling. The pilot plant experiments showed that the controller reacts to disturbances in the correct way, but because training requires a lot of computation, its design has to include a compromise solution between complexity and control performance. Fuzzy logic-based control systems are developed on the assumption that the operators have a mental model and accurate knowledge of the drying process. The neural network controller learns directly from the operation and develops relationships from the input it receives, but it requires a lot of reliable data.

The performance achieved by the controllers discussed above in terms of the output moisture content of the solids in the pilot plant dryer may be evaluated from Figure 19 for the feedback PI controller, Figure 21 for the combined feedforward-feedback controller, Figures 40 and 41 for the FLC/PI hybrid controller and Figure 47 for the NN/PI hybrid controller. The following control system characteristics should be considered:

- accuracy, describing how well the output moisture content of the solids conforms to its target value after disturbances,

- stability, describing the behaviour of process variables such as oscillation,

- $\quad$ speed of control, describing how fast the main variable manipulated, fuel flow, reacts to disturbances,

- costs of control, based on examination of the behaviour of fuel flow. If the solid material is dried to zero moisture content, any overdrying can be detected from its output temperature.

The evaluation results are presented in Table 19, where the markings (--) ,(-), (+) and $(++)$ denote very poor, poor, good and very good. 
Table 19. Characteristics of the dryer control systems.

\begin{tabular}{|c|c|c|c|c|}
\hline Factor/Controller & Feedback PI & $\begin{array}{l}\text { Combined } \\
\text { feedforward- } \\
\text { feedback } \\
\text { controller }\end{array}$ & $\begin{array}{l}\text { FLC/PI hybrid } \\
\text { controller }\end{array}$ & $\begin{array}{l}\text { NN/PI hybrid } \\
\text { controller }\end{array}$ \\
\hline Accuracy & - & ++ & + & + \\
\hline Stability & - & ++ & ++ & - \\
\hline Speed of control & -- & ++ & ++ & + \\
\hline Costs of control & -- & ++ & + & + \\
\hline
\end{tabular}

It can be concluded from the qualitative evaluation that the model-based feedforwardfeedback system gives very stable control, as is shown by the fact that the calculation of the change made to the fuel flow after correction by the feedback PI controller is accurate. Especially when this is combined with residence time control, it is possible to supervise overdrying very efficiently, as Figure 23 shows. The problem is that development of the model for the feedforward part requires a great deal of theoretical and experimental knowledge about the dryer. Also, implementation and operation of the control system requires besides a large amount of programming work and control hardware that will perform the complex computation in real time

The FLC/PI hybrid controller behaved well even though its FLC structure was kept quite simple with regard to the number of input variables, MFs and control rules. It would be possible to improve the control performance by increasing the complexity of the FLC. The choice between complexity and control performance is dryer-specific. This control system is very attractive because the operator's experience and knowledge, of which a great deal is available, can be used for both new and existing dryers.

The NN/PI hybrid controller gives acceptable performance, and more reliable data and a more complex network architecture would be required to improve the control results. Again the balance between complexity of the network and control performance has to be estimated on a dryer-specific basis. 


\section{References}

Baker C G J (1983) Cascading rotary dryers. In Mujumdar A S (ed) Proc.Drying'83. Hemisphere Publishing, Washington, USA, 2 :1-48.

Beck M S, Bunn P R, Gough N E \& Wormald C N (1971) Computer control of a pilot scale rotary solids drier. Preprints $3^{\text {rd }}$ IFAC/IFIP Conference on Digital Computer Applications to Process Control, Helsinki, Part 2: XII-4:1-7.

Bhat N \& McAvoy T.J (1990) Use of neural nets for dynamic modeling and control of chemical process systems. Computers chem. Engng.14:573-582.

Bhat N, Minderman P.A, McAvoy Jr.T \& Wang N.S (1990) Modeling chemical process systems via neural computation. IEEE Systems Magazine (4):24-29.

Brasil G C \& Seckler M M (1988) A model for the rotary drying of granular fertilizers. Proc. $6^{\text {th }}$ Int. Drying Symposium, Versailles, OP.247-256.

Deich V G \& Stal'skii V V (1975) Optimum control of drying processes in a rotary drum drier. Theor. Found. Chem Engng. 9(1):85-90.

Driankov D, Hellendoorn H \& Reinfrank M (1993) An Introduction to Fuzzy Control. Springer-Verlag, New York.

Douglas P L, Kwade A, Lee P L, Mallick S K \& Whaley M G (1992) Modelling, simulation and control of rotary sugar dryers. In Mujumdar A. S (ed) Proc.Drying'92. Elsevier Science Publishers B.V., Holland, 3:1928-1933.

Douglas P L, Kwade A, Lee P L, Mallick S K (1992) Simulation of a rotary dryer for sugar crystalline. Drying Technology 11(1):129-155.

Duchesne C, Thibault J \& Bazin C (1996) Modeling of the solids transportation within an industrial rotary dryer: A simple model, Ind.Eng.Chem.Res. 35:2334-2341.

Duchesne C, Thibault J \& Bazin C (1997a) Modelling and dynamic simulation of an industrial rotary dryer. Dev.Chem.Eng.Mineral Process 5(3/4):155-182.

Duchesne C, Thibault J \& Bazin C (1997b) Dynamics and assessment of some control strategies of a simulated industrial rotary dryer. Drying Technology 15(2):477-510.

Friedman S J \& Marshall W R Jr.(1949a) Studies in rotary drying- Part 1. Holdup and dusting. Chem Eng Progress 45 (8):482-493.

Friedman S J \& Marshall W R Jr.(1949b) Studies in rotary drying- Part 2. Heat and mass transfer. Chem Eng Progress 45 (9):573-588. 
Garside J, Lord L W \& Reagan R (1970) The drying of granular fertilizers. Chem Engng Sci 25:1133-1147.

Hallström A (1985) Drying of porous granular materials. Dissertation, Lund University, Department of Chemical Engineering.

Harbert F C (1973) Control of dryers by the temperature difference technique. Instruments and Control Systems 46 (9):71-72

Harbert F C (1974) Automatic control of drying processes: Moisture measurement and control by the temperature difference method. Chem Eng Sci 29:888-890.

Hirosue H \& Shinohara H (1982) Residence time distribution of particles in rotary dryers and coolers - A brief review. Proc.Drying'82,36-41.

Hunt K.J, Sbarbaro D, Zbikowski R \& Gawthrop P.J (1992) Neural networks for control systems- A survey. Automatica 28:1083-1112.

Isomursu P (1995) A software engineering approach to the development of fuzzy control systems. VTT Publications 230.

Juuso E, Koskinen J, Yliniemi L \& Leiviskä K (1998) Linguistic equation method applied for fuzzy modelling of a rotary dryer. Proc.TOOLMET'98- Tool Environments and Development Methods for Intelligent Systems. Oulu. 145-155.

Kamke F A \& Wilson J B (1986a) Computer simulation of a rotary dryer. Part I: Retention time. AIChe Journal 32(2):263-268.

Kamke F A \& Wilson J B (1986b) Computer simulation of a rotary dryer. Part II: Heat and mass transfer. AIChe Journal 32:269-275.

Kelly J J \& O'Donnell P (1968) Dynamics of granular material rotary dryers and coolers. ICE Symp Ser 29: 33-41.

Kelly J J \& O'Donnell P (1977) Residence time model for rotary drums. Trans IChemE 55:243-252.

Kelly J J (1995) Rotary drying. In: Mujumdar A S (ed) Handbook of Industrial Drying, Marcel Dekker, Inc., New York, 1:161-183.

Kisakurek B (1972) The preparation of generalized drying curves for porous solids. Dissertation thesis. Chicago.

Kisakurek B (1982) Mathematical models for the drying of porous materials. In Mujumdar A S (ed) Proc.Drying'82. Drying Research Limited, Wolverhampton, England, 1:22-29.

Koskinen J, Yliniemi L \& Leiviskä K (1998) Fuzzy modelling of a pilot plant rotary dryer. Proc.UKACC International Conference on CONTROL'98, Swansea, 1:515-518.

Kuramae M \& Tanaka T (1977) An analysis of the volumetric heat transfer coefficient for a rotary dryer. Heat Transfer Jpn.Research 6(1):66-80.

Langari R \& Yen J (1995) Introduction to fuzzy logic. In:Yen J, Langari R \& Zadeh L A (ed) Industrial Applications of Fuzzy logic and Intelligent Systems, 1:3-39.IEEE Press, Inc., Piscataway, NJ.

Langrish T A G (1988) The mathematical modelling of cascading rotary dryers. Dissertation, University of Oxford.

Lee C C (1990) Fuzzy logic in control systems: Fuzzy logic controllers. Part I. IEEE Trans.Syst.Man.Cybern. 20:404-435.

Luyben W \& Wenzel L A (1988) Chemical Process Analysis: Mass and Energy Balances. Prentice Hall, Inc., Houston.

Manikopoulos C N, Zhou M C \& Nerurkar S S (1995) Design and implementation of fuzzy logic controllers for a heat exchanger in a water-for-injection system. Journal of Intelligent and Fuzzy Systems. 3: 43-47. 
Mann W (1980) Digital control of a rotary dryer in the sugar industry. Proc. $6^{\text {th }}$ IFAC/IFIP Conference on Digital Computer Applications, Dusseldorf, 73-90.

Miskell F \& Marshall W R (1956) A study of retention time in a rotary dryer. Chem Eng Progress 52(1):35-J - 38-J.

McKetta J J \& Cunningham W A (1983) Encyclopedia of Chemical Processing and Design. Marcel Dekker, Inc., New York.

McCormick P Y (1962) Gas velocity effects on heat transfer in direct heat rotary dryers. Chem Eng Progress 58(6):57- 62.

Morris A J, Montague G A \& Willis M J (1994) Artificial neural networks: Studies in process modelling and control. Trans IChemE 72(1)Part A: 3-19.

Myklestad O (1963a) Heat and mass transfer in rotary dryers. Chem Eng Progress Symp Series 59:129-137.

Myklestad O (1963b) Moisture control in rotary dryers. Chem Eng Progress Symp Series 59:138-144.

Myllyneva J \& Juuso E K (1995) FuzzyCon and FuzzyTune: Control and tuning in PC environment. Proc. European Working Group Meeting "FALCON-Fuzzy algorithms for Control", Mallorca.

Najim K, Najim M, Koehret B \& Quazzani T (1976) Modelization and simulation of a phosphate dryin furnace. Proc. $7^{\text {th }}$ Annual Conference on Modeling and Simulation, Pittsburg, 690-697.

Najim K (1989) Modelling and learning control of a rotary phosphate dryer. Int: J. Systems Sci., 20:1627-1636.

Ogata K (1997) Modern Control Engineering. $3^{\text {rd }}$ edition, Prentice-Hall,Inc., USA.

Perry J H (1963) Chemical Engineers' Handbook . McGraw-Hill,Inc,New York, 22-1-22107.

Perry \& Chilton (1973) Chemical Engineers' Handbook. $5^{\text {th }}$ edition, McGraw-Hill Kogakusha,Tokyo.

Pietranski J F, Marsolan N F \& King K-H (1982) Expert fuzzy process control of a rotary dryer. Proc. American Control Conference, New York, 1359-1362.

Platin B E, Erden A \& Gulder Ö L (1982) Modelling and design of rotary dryers. Proc. Drying'82, 2:466-477.

Prutton C F, Miller C O \& Schuette W H (1942) Factors influencing rotary dryer performance. Trans. AIChe 38:251-257.

Reay D (1979) Theory in the design of dryers. Chem Eng July:501-506.

Reay D (1989) Fluid flow, residence time simulation and energy efficiency in industrial dryers. Proc. Drying'89, 1-8.

Robinson J W (1989a) The Delta T- A new drying model for pulp and paper. Proc.TAPPI Engineering Conference, Atlanta, 183-187.

Robinson J W (1989b) The Delta T- A new concept in dryer. Proc.American Association of Textile Chemists and Colorists, Philadelphia, 276-279.

Robinson J W (1992) Improve dryer control. Chem Eng. Progress. December:28-33.

Rumelhart D E, Hinton G E \& Williams R J (1986) Learning internal representations by error propagation. Parallel Distributed processing. MIT Press, Cambridge, MA.

Saeman W C \& Mitchell J R (1954) Analysis of rotary dryer and cooler performance Chem Eng.Progress 50 (9):467-475.

Schofield F R \& Glikin P G (1962) Rotary dryers and coolers for granular fertilizers. Trans IChemE 40:183-190. 
Sharples K, Glikin P G \& Warne R (1964) Computer simulation of rotary driers. Trans. Instn. Chem.Engrs 42:T275-T284.

Sherritt R G, Caple R, Behie L A \& Mehrotra A K (1993) The movement of solids through flighted rotating drums. Part I. Model formulation. Can Journal Chem Engng 71:337-346.

Shinskey F G (1974) Process control systems with variable structure. Control Engineering, August:63-66.

Strumillo C \& Kudra T (1986) Drying: Principles, Applications and Design. Gordon and Breach Science Publishers, Montreaux, p 71.

Tanomaru J (1992) Process control by on-line trained neural controllers. IEEE Trans on Ind Electronics 39(6):511-521.

Thorne B \& Kelly J J (1980) Mathematical model for the rotary drier. In Mujumdar A S (ed) Proc.Drying' 80. Hemisphere Publishing, Washington, USA, 1:160-169.

Thorpe G R (1972) The mathematical modelling of driers. Ph.D.Thesis, University of Nottingham.

van Brakel J (1980) Mass transfer in convective drying. In Mujumdar A S (ed) Proc.Drying' 80 . Hemisphere Publishing, Washington, USA, 1:217-267.

van Krevelen D W \& van Hoftijzer P J (1949a) Drying of granulated materials. Part II. Drying of granules in rotary dryers. Journal of the Society of Chemical Industry (J:S:C:I) 68:91-97.

van Krevelen D W \& Hoftijzer P J (1949b) Drying of granulated materials. Part I. Drying of a single granule. Journal of the Society of Chemical Industry (J:S:C:I) 68:59-66.

von Altrock C (1994) Fuzzý logic applications in Europe. In: Yen J, Langari R \& Zadeh L (ed) Industrial Applications of Fuzzy Logic and Intelligent Systems 4:275-310. IEEE Press, Piscataway, NJ.

Wang F Y, Cameron I T, Litster J D, Douglas P L. (1993) A distributed parameter approach to the dynamics of rotary drying processes. Drying Technology 11(7):16411656.

Wright D J (1976) Continuous moisture measurement in mining processes. Proc. Instrumentation in the Mining and Metallurgy Industries, Vancouver, 8-10.

Yliniemi L, Arola A \& Jutila E (1980) Rakeisen materiaalin kuivauksessa käytettävät rumpukuivaimet Suomen vuori- ja mineraaliteollisuudessa. Report 51.Oulun yliopisto, prosessitekniikan osasto.

Yliniemi L, Jutila E A \& Uronen P (1981) Modelling and control of a pilot- plant rotary drier used for drying of industrial concentrates. Proc.IFAC $8^{\text {th }}$ World Congress, Kyoto, 22:198-203.

Yliniemi L, Lehto I, Uronen P \& Leiviskä K (1984) Rakeisen materiaalin jatkuvatoiminen kosteuden mittaus. Vuorimiesyhdistys, Helsinki, 76 p.

Yliniemi L \& Koskinen J (1995) Rumpukuivaimen sumea säätö. Raportti B No 1. Oulun yliopisto, säätötekniikan laboratorio.

Yliniemi L \& Leiviskä K (1995) Simulation of a rotary dryer with multimedia. Proc. EUROSIM'95, Vienna, 1335-1340.

Yliniemi L, Koskinen J \& Leiviskä K (1998) Advanced control of a rotary dryer. Preprints Automation in Mining, Mineral and Metal Processing 1998. IFAC Symposium, Bologne, 127-132. (to be published also in Proceedings 1999). 

Appendices 



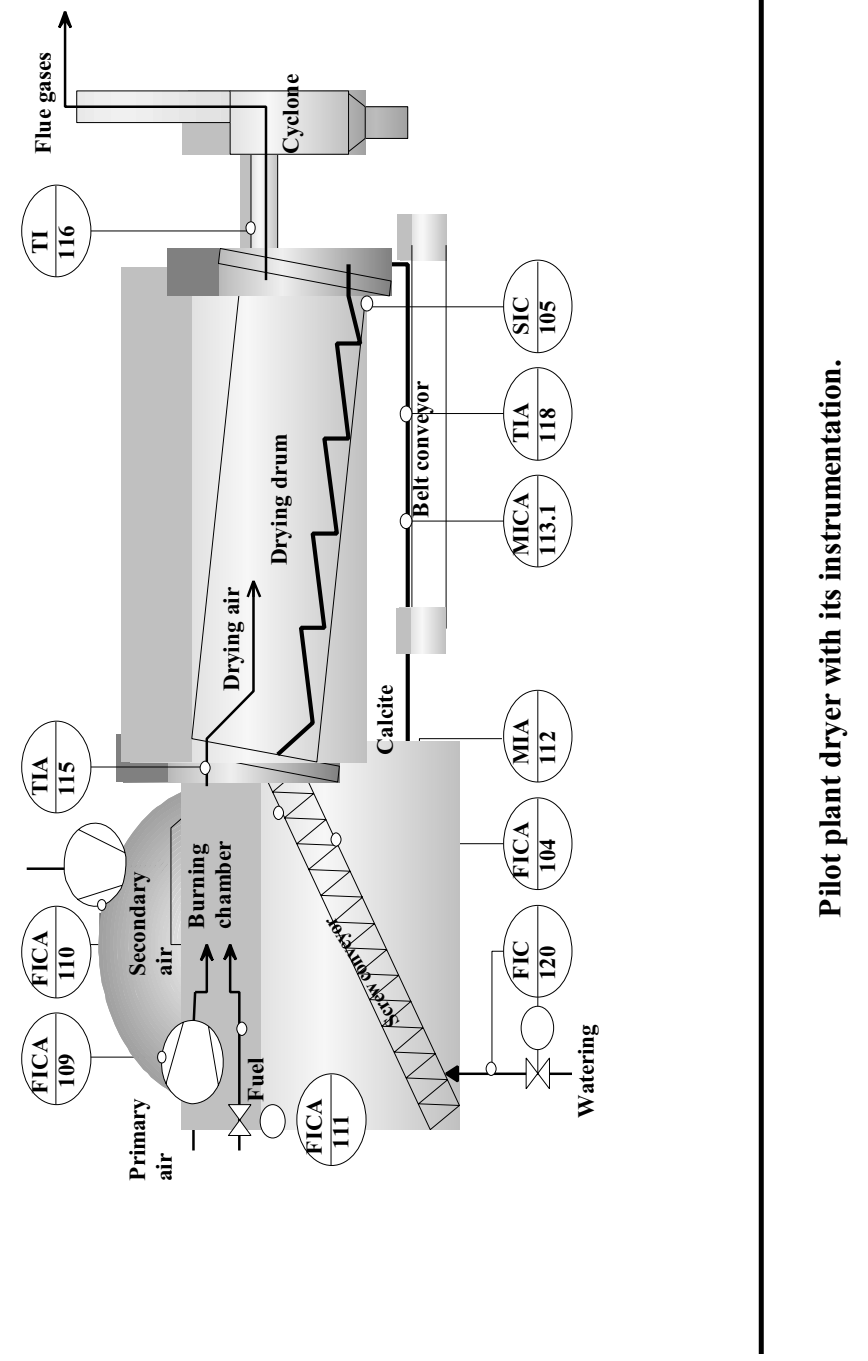





\section{APPENDIX 2}

\begin{tabular}{|c|c|c|c|}
\hline Measurement/Control & Instrument/Type 1 & Manufacturer & Range \\
\hline $\begin{array}{l}\text { Input temperature of } \\
\text { drying air } \\
\text { TIA-115 }\end{array}$ & $\begin{array}{l}\text { Pt-100 Sensor } \\
\text { Temp-EL R }\end{array}$ & Valmet & $(0-400){ }^{\circ} \mathrm{C}$ \\
\hline $\begin{array}{l}\text { Output temperature of } \\
\text { drying air } \\
\text { TI-116 }\end{array}$ & $\begin{array}{l}\text { Pt-100 Sensor } \\
\text { Temp-EL R }\end{array}$ & Valmet & $(0-400){ }^{\circ} \mathrm{C}$ \\
\hline $\begin{array}{l}\text { Output temperature } \\
\text { of solids } \\
\text { TIA-118 }\end{array}$ & $\begin{array}{l}\text { Pt-100 Sensor } \\
\text { Temp-EL R }\end{array}$ & Valmet & $(0-200){ }^{\circ} \mathrm{C}$ \\
\hline $\begin{array}{l}\text { Output moisture of } \\
\text { solids } \\
\text { MICA-113.1 }\end{array}$ & IR-M1000 & Chino & $(0-2) \mathrm{m}-\%$ \\
\hline $\begin{array}{l}\text { Input moisture of } \\
\text { solids } \\
\text { MIA-112 }\end{array}$ & $\begin{array}{l}\text { Type } 24 \\
\text { Gain type SA }\end{array}$ & Pier-Electronic & $(0-10) \mathrm{m}-\%$ \\
\hline $\begin{array}{l}\text { Fuel flow } \\
\text { FICA-111 }\end{array}$ & $\begin{array}{l}\text { Rotameter } \\
\text { Motor element } \\
\text { Ballvalve }\end{array}$ & $\begin{array}{l}\text { Rota KG } \\
\text { Honeywell }\end{array}$ & $(0-0.1) \mathrm{kg} / \mathrm{min}$ \\
\hline $\begin{array}{l}\text { Flow of } \\
\text { secondary air } \\
\text { FICA-110 }\end{array}$ & $\begin{array}{l}\text { Blower } \\
\text { Stepping motor }\end{array}$ & Zhiel-Aberg & $(0-0.4) \mathrm{m}^{3} / \mathrm{min}$ \\
\hline $\begin{array}{l}\text { Flow of } \\
\text { primary air } \\
\text { FICA-109 }\end{array}$ & Fan & Oilon & $(0-0.02) \mathrm{m}^{3} / \mathrm{min}$ \\
\hline $\begin{array}{l}\text { Flow of } \\
\text { dewatering } \\
\text { FIC-120 }\end{array}$ & $\begin{array}{l}\text { Turbine flow- } \\
\text { meter, Model 400-L } \\
\text { Model } 480 \text { controller }\end{array}$ & McMillan & $(0.013-0.1) \mathrm{dm}^{3} / \mathrm{min}$ \\
\hline $\begin{array}{l}\text { Rotational speed } \\
\text { of screw conveyor } \\
\text { FICA-104 }\end{array}$ & $\begin{array}{l}\text { Measuring generator } \\
\text { Worm gear motor }\end{array}$ & & $(1.4-4) \mathrm{rpm}$ \\
\hline $\begin{array}{l}\text { Rotational speed } \\
\text { of drum } \\
\text { SIC-105 }\end{array}$ & $\begin{array}{l}\text { Direct-current control } \\
\text { unit } \\
\text { Measuring generator } \\
\text { Direct-current motor }\end{array}$ & & $(0-10.5) \mathrm{rpm}$ \\
\hline
\end{tabular}



APPENDIX 3
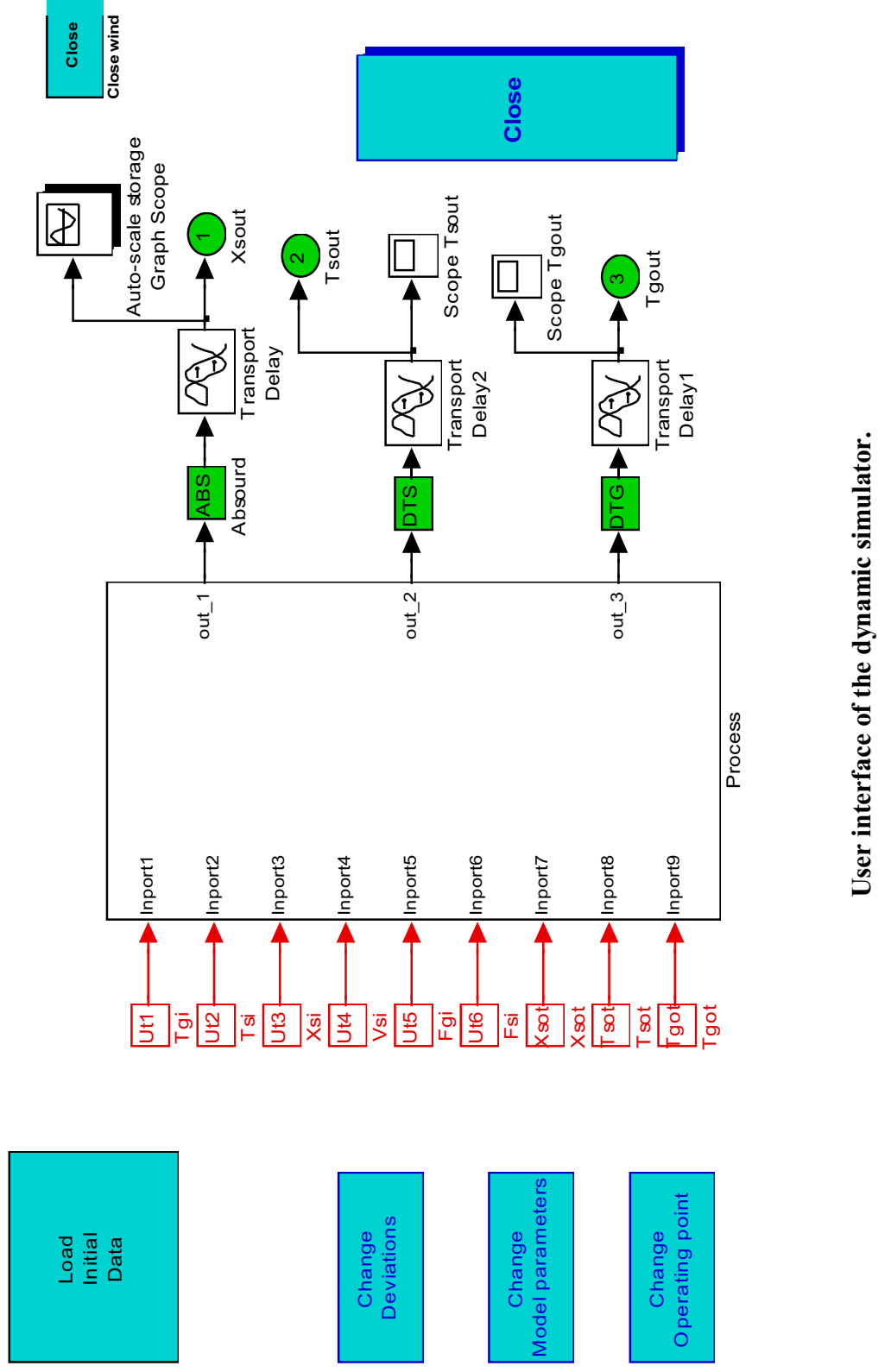



\section{APPENDIX 4}

\section{Basics of fuzzy logic}

Where classical binary logic is based on classical set theory, fuzzy logic is based on fuzzy set theory and is an example of a multivalued logic. In fuzzy set theory, "normal" sets are called crisp sets in order to distinguish them from fuzzy sets.

Let $\mathrm{C}$ be a crisp set defined in the universe of discourse $\mathrm{U}$, then for any element $\mathrm{u}$ of $\mathrm{U}$, either $\mathrm{u} \in \mathrm{C}$ or $\mathrm{u} \notin \mathrm{C}$. This means that in the classical theory an element either belongs entirely to a set or not at all. For any crisp set $\mathrm{C}$ it is possible to define a characteristic function $\mu_{c}: U \rightarrow\{0,1\}$. Let $F$ be a fuzzy set. Then it is not necessarily the case that either $\mathrm{u} \in \mathrm{F}$ or $\mathrm{u} \notin \mathrm{F}$. An element can belong partially to a set and also belong to many sets at the same time. In fuzzy set theory the characteristic function is generalised to a membership function that assigns to every $u \in U$ a value from the unit interval $[0,1]$ instead from the two-element set $\{0,1\}$. Thus a fuzzy set $\mathrm{F}$ in $\mathrm{U}$ may be represented as a set of ordered pairs of a generic element $u$ and its grade of membership function :

$$
\mathbf{F}=\left\{\left(\mathbf{u}, \mu_{\mathbf{F}}(\mathbf{u})\right) \mid \mathbf{u} \in \mathbf{U}\right\}
$$

The operations of fuzzy sets are determined through a membership function, the most common shapes being trapezoidal, triangle and bell-shaped (Gaussian). A fuzzy set is referred to as fuzzy singleton if it has a single point in $U$ with $\mu_{\mathrm{F}}=1.0$. In particular, the element $\mathrm{u}$ in $\mathrm{U}$ at which $\mu_{\mathrm{F}}=0.5$ is called the crossover point.

Let $A$ and $B$ be two fuzzy sets in $U$ with the membership functions $\mu_{\mathrm{A}}$ and $\mu_{\mathrm{B}}$ respectively. The set theory operations of union, intersection and complement for fuzzy sets are defined via their membership functions as follows:

the membership function of the union $A \cup B$ is defined for all $u \in U$ by

$$
\mu_{\mathrm{A}} \cup_{\mathrm{B}}(\mathbf{u})=\max \left\{\mu_{\mathrm{A}}(\mathbf{u}), \mu_{\mathrm{B}}(\mathbf{u})\right\},
$$

the membership function of the intersection $A \cap B$ is defined for all $u \in U$ by

$$
\mu_{\mathrm{A}} \cap \mathbf{B}(\mathbf{u})=\min \left\{\mu_{\mathrm{A}}(\mathbf{u}), \mu_{\mathrm{B}}(\mathbf{u})\right\},
$$

and the membership function of the complement of a fuzzy set $A$ is defined for all $u \in U$ by

$$
\mu_{-}=1-\mu_{\mathrm{A}}(\mathbf{u}) \text {. }
$$

The use of fuzzy sets provides a basis for a systematic means of handling vague and imprecise concepts. In particular, fuzzy sets can be employed to represent linguistic variables. A linguistic variable can be regarded either as a variable whose value is a fuzzy number or as a variable whose values are defined in linguistic terms. A fuzzy variable is characterized by $(\mathrm{x}, \mathrm{T}(\mathrm{x}))$, in which $\mathrm{x}$ is the name of the variable; $\mathrm{T}(\mathrm{x})$ is the term of the set, i.e. the set of names of linguistic values of $x$ with each value being a fuzzy number 
defined in U. If temperature is interpreted as a linguistic variable, for example, then its term set $\mathrm{T}$ (temperature) could be

$T($ temperature $)=\{$ very cold, cold, comfortable, hot, very hot,$\ldots\}$

where each term in $\mathrm{T}$ (temperature) is characterized by a fuzzy set in a universe of discourse U.

Fuzzy logic contains two important rules of logical inference, the generalized modus ponens (GMP) and the generalized modus tollens (GMT) :

\section{$\underline{\text { GMP }}$}

premise: $x$ is $A^{\prime}$,

implication :if $x$ is $A$ then $y$ is $B$, conclusion: $y$ is $B$ '

\section{GMT}

premise: $y$ is $B$,

implication : if $x$ is $A$ then $y$ is $B$,

conclusion: $x$ is $A$ '.

where $A, A^{\prime}, B, B^{\prime}$ are linguistic variables.

The GMP mechanism is based on one-level forward data-driven inference and is useful for fuzzy logic controllers, whereas the GMT mechanism is closely related to backward goal-driven inference and it is commonly used in expert systems. 


\section{APPENDIX 5}

\section{Backpropagation networks}

The training of a multilayer feedforward network, often called a backpropagation network, occurs in two stages: a feedforward stage and a backpropagation stage. The feedforward propagation stage starts from the input values and calculates the activation levels of all neurones in the hidden layer by means of weighted sums and a threshold function, which is usually a sigmoid. The output values of the network are obtained from the output layer. The weights of the network are then adjusted in the backpropagation stage. Calculations start from the output layer and propagate through the whole network. The algorithms performing the training are discussed in more detail below.

\section{Feedforward stage}

The governing equations for training a multilayer feedforward network, as derived by Rumelhart and McClelland (1986), are presented in Figure 1.

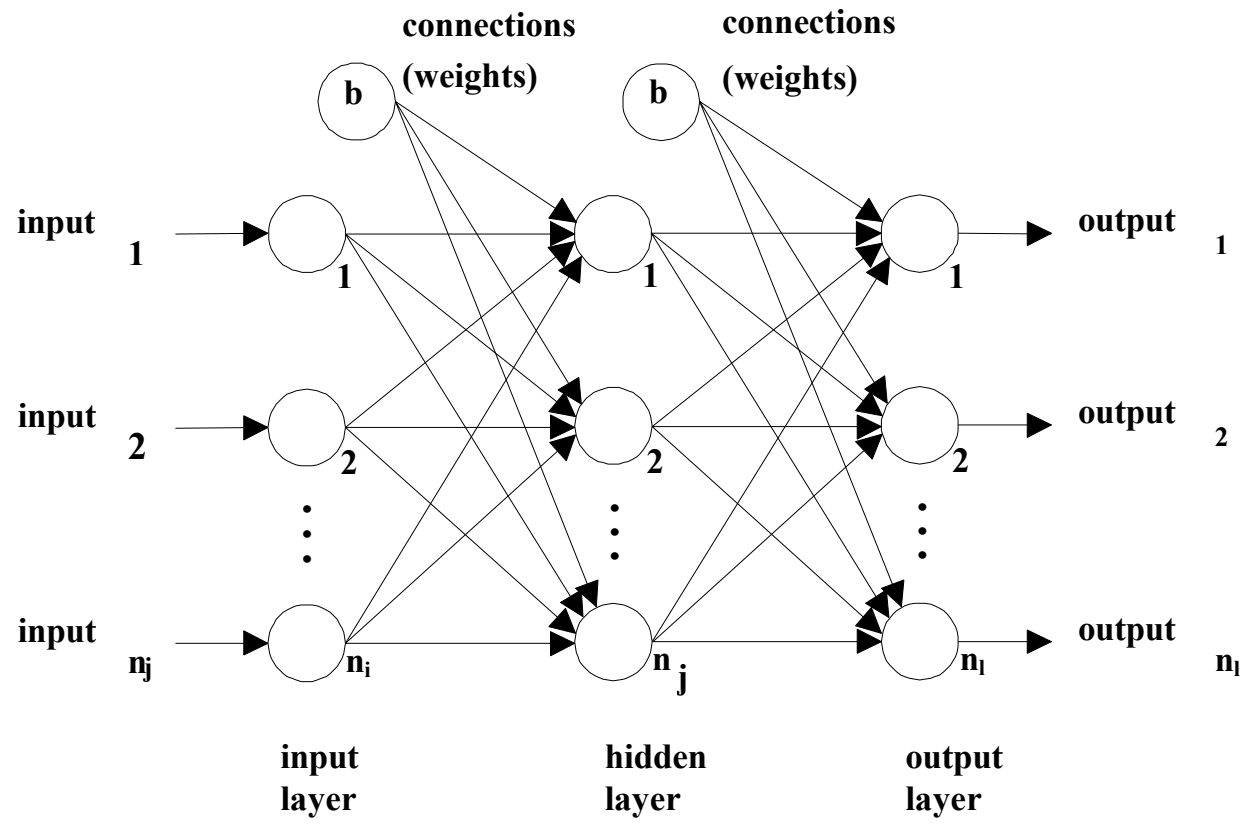

Fig.1. Backpropagation network structure. 
The attributes of individual neurones or connections are represented by lowercase letters with subscripts as follows. The letter i denotes an input, o an output, w a connection weight, and $\mathrm{n}$ the number of neurones in a layer. The subscripts $\mathrm{i}, \mathrm{j}$, and 1 refer to the input, hidden and output layers, and $\mathrm{b}$ is a bias.

The neurones in the input layer simply store the input values, while those in both hidden layers and in the output layer perform two calculations. Firstly, they multiply all inputs and a bias (equal to a constant value of 1) by a weight and sum the result as

$$
\mathrm{i}_{\mathrm{j}}=\sum_{\mathrm{i}} \mathrm{o}_{\mathrm{i}} \mathrm{w}_{\mathrm{ji}},
$$

and secondly, they calculate the output of a hidden neurone, $\mathrm{o}_{\mathrm{j}}$, as a sigmoid function of $\mathrm{i}_{\mathrm{j}}$ :

$$
\mathrm{o}_{\mathrm{j}}=\frac{1}{1+\mathrm{e}^{-\mathrm{i}_{\mathrm{j}}}} .
$$

The general shape of the sigmoid function used in a backpropagation network is illustrated in Figure 2.

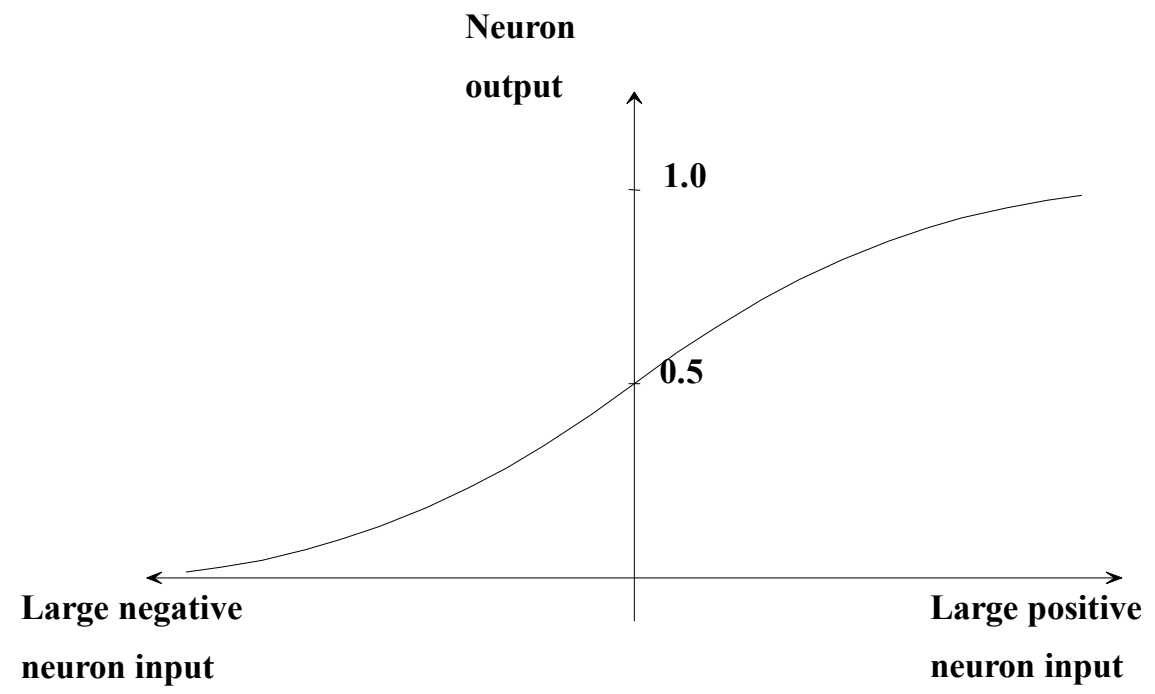

Fig. 2. The sigmoid transfer function used in a backpropagation network.

As can be seen, the output calculated by the sigmoid function is limited to values between 0 and 1 . For an input of zero to the neurone, the output is 0.5 . For large negative input values, the output approaches 0 , and for large positive values, it approaches 1 . 
The non-linear nature of this sigmoid transfer function plays an important role in the performance of the neural network. Other functions such as a hyperbolic tangent can be used, but these have to be continuous and derivative at all points.

The above equations describe the calculation of the output of each hidden layer neurone. The selection of how many neurones should be included in each hidden layer is probably more of an art than a science, and varies largely according to the application. If there are too few hidden neurones, the network probably cannot be trained at all.

Once the outputs of all the hidden layer neurones have been calculated, the input to the output layer neurone and the output from the output layer are calculated in an analogous manner, as described by expressing equations (1) and (2) in the form:

$$
\begin{aligned}
& \mathrm{i}_{1}=\sum_{\mathrm{j}} \mathrm{o}_{\mathrm{j}} \mathrm{w}_{\mathrm{lj}} \text { and } \\
& \mathrm{o}_{1}=\frac{1}{1+\mathrm{e}^{-\mathrm{i}_{1}}} .
\end{aligned}
$$

The calculations resulting in the output state, or activation are carried out in exactly the same way during the training phase as during the testing and running phases.

\section{Backpropagation stage}

During the training phase, the feedforward output state calculation is combined with backward error propagation and weight adjustment calculations representing the network's learning or training. It is essential in the training of the network to define a network error. It is also necessary to identify a measure of how well a network is performing on the training set. According to Rumelhart and McClelland, the error is defined as the difference between the target value of the output neurone $t_{1}$ and the value resulting from the feedforward calculation, $\mathrm{o}_{\mathrm{l}}$. The error for the output unit is calculated as

$$
\mathrm{d}_{1}=\left(\mathrm{t}_{1}-\mathrm{o}_{1}\right) \mathrm{f}^{\prime}\left(\mathrm{i}_{1}\right) \text {, }
$$

where $\mathrm{f}^{\prime}\left(\mathrm{i}_{1}\right)$ is the first derivative of the sigmoid function.

The error term for a hidden neurone is calculated as

$$
d_{h}=f^{\prime}\left(i_{h}\right) \sum_{l=0}^{n_{1}} w_{l h} d_{1},
$$

where the output of a neurone in the hidden layer is a function of its input i.e. $o_{h}=f\left(i_{h}\right)$.

The error calculated by means of the equation (5) is propagated back to perform appropriate weight corrections. This can take place in two manners, by propagating the error back and correcting the weights after each training pattern has been presented to the network (on-line training), or by accumulating the errors for each neurone for the entire 
training set, summing them and propagating them back (batch training). It is the latter that is used in this application.

Using the errors calculated as above, the weight changes for the connections feeding the hidden layer from the input layer can be calculated:

$$
\mathrm{w}_{\mathrm{ji}}(\text { new })=\mathrm{w}_{\mathrm{ji}}(\text { old })+? \mathrm{~d}_{\mathrm{j}} \mathrm{o}_{\mathrm{i}},
$$

where? is the learning rate coefficient, having values between 0 and 1 .

For each hidden neurone, the subscript $i$ has values of 0 to $n_{i}$, the number of input neurones. Correspondingly, the weight changes feeding the output layer from the hidden layer are

$$
\mathrm{w}_{\mathrm{lj}}(\text { new })=\mathrm{w}_{\mathrm{lj}}(\mathrm{old})+? \mathrm{~d}_{1} \mathrm{o}_{\mathrm{j}} \text {. }
$$

The higher the learning rate, the bigger the step. If the learning rate is set too high, the algorithm becomes unstable, while if it is too small, the algorithm will take a long time to converge. The learning rate is usually between 0.25 and 0.75 .

Before it is possible to update the weights, each of them has to be initialized to some value. Neural network researchers recommend a large number of variations on the initial weight range, but it is quite typical to initialize the weights to random numbers between 0.3 and -0.3 for no other reason than that "it works". Most backpropagation networks seem to train faster with these values than with 1 and -1Eventually the initializing weights depend on the application used. 